\title{
La typologie des amphores Günsenin. Une mise au point nouvelle
}

\section{Nergis Günsenin}

\section{Q OpenEdition \\ 1 Journals}

Édition électronique

URL : https://journals.openedition.org/anatoliaantiqua/589

DOI : 10.4000/anatoliaantiqua.589

\section{Éditeur}

IFEA

Édition imprimée

Date de publication : 1 décembre 2018

Pagination : 89-124

ISBN : 9782362450747

ISSN : 1018-1946

\section{Référence électronique}

Nergis Günsenin, « La typologie des amphores Günsenin. Une mise au point nouvelle », Anatolia

Antiqua [En ligne], XXVI | 2018, mis en ligne le 29 juillet 2019, consulté le 03 septembre 2021. URL :

http://journals.openedition.org/anatoliaantiqua/589; DOI : https://doi.org/10.4000/anatoliaantiqua. 589 


\section{ANATOLIA ANTIQUA ESKI ANADOLU}

\section{XXVI}

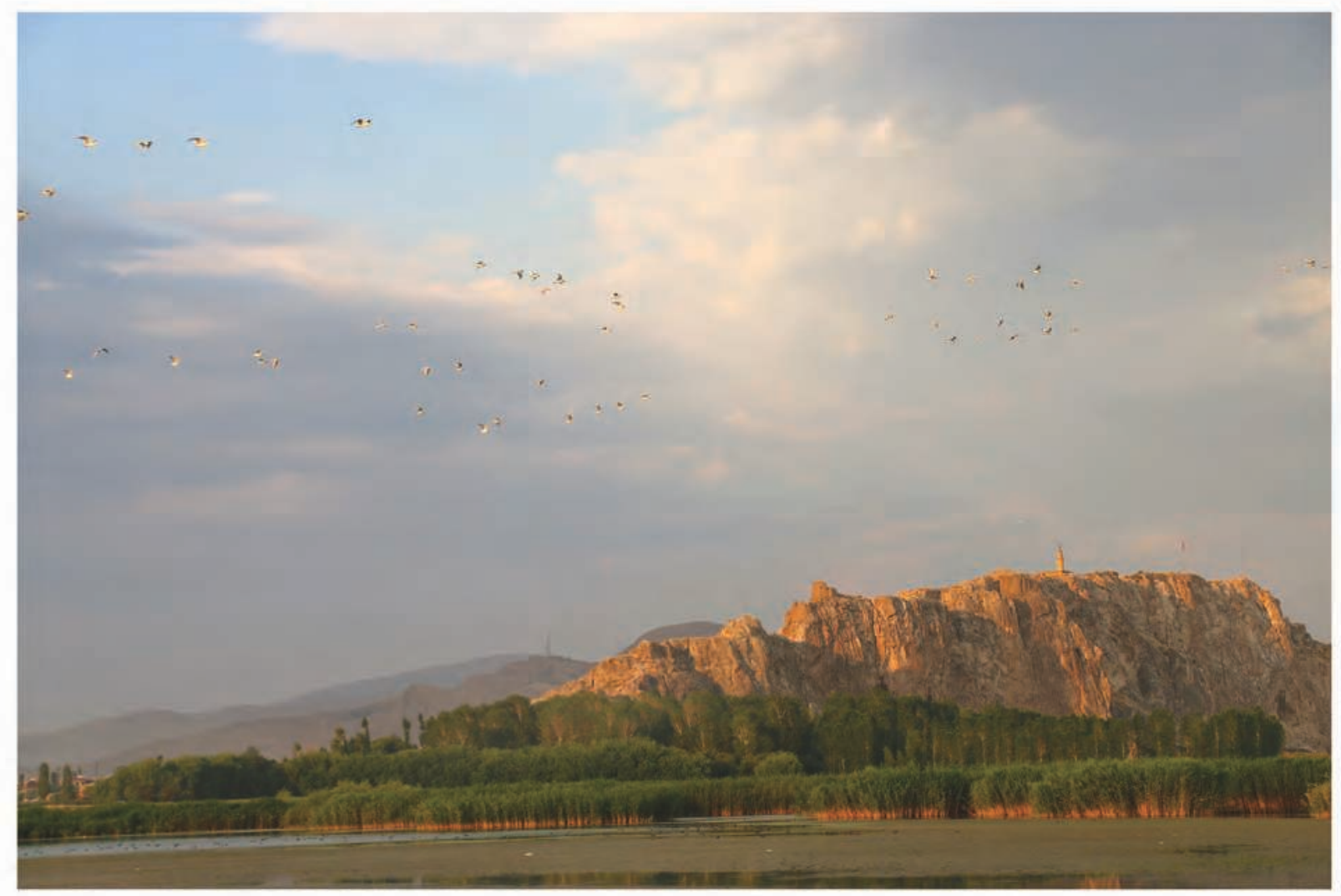

INSTITUT FRANÇAIS D'ETUDES ANATOLIENNES GEORGES-DUMEZIL

CNRS USR 3131

DE BOCCARD 


\section{TABLE DES MATIERES}

Alice VINET et Denis GUILBEAU

A First Glimpse of the Late Neolithic and Early Chalcolithic in Cappadocia through the Lithic

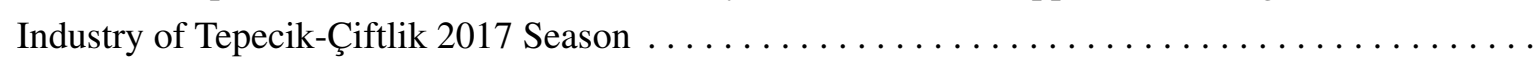

Ergül KODAŞ, Haluk SAĞLAMTIMUR et Yılmaz Selim ERDAL

Three Human Graves of the Hassuna Culture in Türbe Höyük

\section{Kevin PARACHAUD}

Les Galates en Asie Mineure au regard de la culture matérielle. Hellénisation, maintien, acculturation ? 23

H. Asena KIZILARSLANOĞLU et Erkan ALKAÇ

Hellenistic Amphora Stamps from Elaiussa . . . . . . . . . . . . . . . . . . . . .

Aygün EKİN MERİÇ

Late Roman Pottery from the Theatre of Nicaea in Bithynia $\ldots \ldots \ldots \ldots \ldots \ldots \ldots \ldots \ldots$

Nergis GÜNSENIN

La typologie des amphores Günsenin. Une mise au point nouvelle.

Nergis GÜNSENIN et Alessandra RICCI

Les amphores Günsenin IV à Küçükyalı (Istanbul). Un voyage entre monastères ? . . . . . . . . .

\section{CHRONIQUES DES TRAVAUX ARCHEOLOGIQUES EN TURQUIE 2017}

Erkan KONYAR, Bülent GENÇ, H. Banu KONYAR, Armağan TAN et Can AVCI

Excavations at the Old City, Fortress, and Mound of Van: Work in 2017 . . . . . . . . . . . . . .

\section{Çiğdem MANER}

Preliminary Report on the Fifth Season of the Konya Ereğli, Karapınar, Halkapınar and

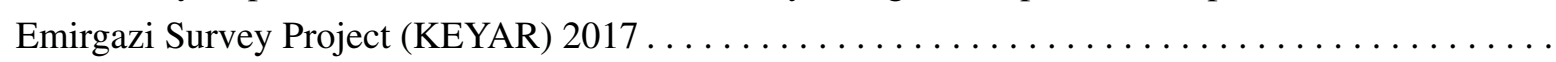

Abuzer KIZIL, Koray KONUK, Taylan DOĞAN, Didier LAROCHE, Enora LE QUERE,

Vasilica LUNGU, Francis PROST et Baptiste VERGNAUD

Eurômos : Rapport préliminaire sur les travaux réalisés en 2017

Olivier HENRY et E. ANDERSSON, J. BLID, Chr. BOST, Ö. ÇAKMAKLI, N. CARLESS-UNWIN, G. ÇİMEN, A. EYİGÖR, A. FRECCERO, A. FREJMAN, Cr. GEORGESCU, E. GOUSSARD, A.-M. GUIMIER-SORBETS, M. HAUCHART, R. HEDLUNG, N. LAMARE, V. LUNGU, Fr. MARCHAND-BEAULIEU, A. SITZ, I. STOJANOVIC, B. VERGNAUD 


\section{LA TYPOLOGIE DES AMPHORES GÜNSENIN UNE MISE AU POINT NOUVELLE}

Je suis reconnaissante à Hélène Ahrweiler qui m'a donné la chance de commencer mes études à l'Université Paris I Panthéon-Sorbonne. Qu'il me soit permis de lui dédier ces pages où je propose une mise au point augmentée de mes travaux antérieurs. Il y a déjà plus de trente ans de cela, en 1984, sous sa direction bienveillante et les conseils avisés de Jean-Pierre Sodini et d'Eric Rieth, mes co-directeurs, j'avais rédigé deux mémoires de D.E.A. (Diplôme d' Etudes Approfondies) qui ont ouvert la voie de mon orientation future ${ }^{1}$. Dans le cadre des études byzantines, j'étais passionnée d'archéologie navale. Quand il a été question de choisir un sujet de thèse M. le professeur Sodini m'a encouragée à poursuivre mes recherches dans le domaine de la céramique. C'est à lui que je dois d'avoir pu mener à bien ma thèse de doctorat intitulée Les amphores byzantines ( $X^{e}$-XIII ${ }^{e}$ siècles): typologie, production, circulation d'après les collections turques ${ }^{2}$.

J'ai donc été amenée à me spécialiser progressivement dans l'étude des amphores byzantines, récipients en céramique destinés au commerce maritime et donc aujourd'hui dispersés sur un très vaste territoire. Mon objectif initial a été de procéder à une enquête minutieuse et systématique dans les musées, des régions côtières, notamment dans leurs dépôts afin de localiser et de répertorier un matériel qui jusque-là restait méconnu de la recherche.

Mais mes attentes allaient au-delà de ce que pouvaient m'apporter les collections des musées, et les renseignements fournis par les inventaires et les discussions avec les conservateurs. Guidée par le désir d'identifier les lieux de trouvaille des amphores, $\mathrm{j}$ 'ai entrepris une enquête plus vaste auprès des habitants, notamment les pêcheurs, des régions où les trouvailles d'amphores étaient importantes. En bref, j'ai suivi toutes les pistes possibles et dans la période allant de 1984 à 1989 j'ai pu étudier plus de cinq cents spécimens (amphores entières ou fragmentaires).

En 1987, mon directeur de thèse le professeur Sodini m'a suggéré de le représenter au colloque intitulé Recherches sur la Céramiques Byzantine, qui était organisé à l'Ecole française d'Athènes et l'Université de Strasbourg II (Centre de Recherches sur l'Europe Central et Sud-Orientale). Il m'a proposé d'y présenter une typologie préliminaire de mes amphores. Ma classification de quatre types d'amphores byzantines a reçu un accueil unanime sur place et suite à sa publication elle a été adoptée dans la bibliographie ${ }^{3}$. Notre prix Nobel de littérature Orhan Pamuk ouvre son roman Yeni Hayat en disant "Un jour j'ai lu un livre et toute ma vie a changé" ("Bir gün bir kitap okudum ve bütün hayatım değişti”) ${ }^{4}$. De mon côté, je peux dire: "j' ai donné une communication et ma vie a changé !".

Dans ma thèse de doctorat, soutenue en 1990, j'ai identifié trente-sept types d'amphores incluant des types intermédiaires pour les quatre premiers types, déjà présentés à Athènes, et des sous-types des types II et IV .

*) Prof. Dr. Nergis GÜNSENIN, İstanbul Üniversitesi-Cerrahpaşa,Teknik Bilimler Meslek Yüksekokulu, Motorlu Araçlar ve Ulaştırma Teknolojileri Bölümü, Sualtı Teknolojisi Program Başkanı, Büyükçekmece Yerleşkesi, 34500-Istanbul, e- mail : gunsenin@istanbul.edu.tr

1) Etude des cargaisons céramiques à l'époque Romaine tardive (entre le IVe siècle et le VIIe siècle) Amphores. Nature du matériel. Nature des marchandises transportées. Agencement de la cargaison dans le bateau, dirigé par H. Ahrweiler et J.-P. Sodini, Université Paris I (Panthéon-Sorbonne), Paris, 1984 ; Le problème du passage du principe de construction "sur borde" (en coquille) au principe "sur couples" (sur squelette) en Méditerrané. L'interprétation des vestiges archéologiques des épaves, problèmes de méthode de restitution des formes des coques des procédés de construction. Bibliographie critique, dirigé par H. Ahrweiler et E. Rieth, Université Paris I (Panthéon-Sorbonne), Paris, 1984.

2) Günsenin 1990.

3) Günsenin 1989.

4) Pamuk, O., Yeni Hayat, Istanbul, İletişim Yayınları,1994.

5) Günsenin 1990 
Ma thèse est devenue l'un des manuels de référence le plus fréquemment cités par les collègues qui s'intéressent aux amphores byzantines. C'est un honneur pour moi que ma proposition de classification des amphores byzantines a été adoptée universellement et que le nom Günsenin se trouve associé à la typologie des amphores. J'ai tout fait pour faire connaître ma thèse à mes collègues dans les bibliothèques tout autour du monde. L'atelier national de reproduction des thèses de Lille III m'a permis de la diffuser en version papier et sous forme de microfiches. Aujourd'hui on peut consulter ma thèse sur ma page web (www.nautarch.org) ainsi que sur mon compte d'academia.edu. Tout en sachant que les matériaux de base de ma thèse puissent contenir des erreurs (dont je me propose de corriger certaines dans le présent article) les générations futures pourront ainsi bénéficier de son libre accès sur internet.

Ma thèse fut la première étape de vingt ans de recherches systématiques sur les amphores byzantines, qui ont donc débutées en 1984 avec la classification des amphores. A cette époque j'avais aussi découvert des ateliers de production et des fours de mon type I. Dans une deuxième étape j'ai entrepris une prospection dans la région des ateliers et j'ai découvert un four à moitié ruiné. La troisième étape fut celle de la fouille du four et d'une prospection magnétique dans le but d'estimer la quantité d'amphores qu'il a pu produire. Constatant que les amphores de type I sont diffusées dans une aire très vaste en Méditerranée et dans la mer Noire, ma quatrième a été d'entreprendre des prospections sous-marines en mer de Marmara. Mon objectif était de trouver les épaves transportant ces amphores. J'ai identifié treize épaves parmi lesquelles huit avaient une cargaison d'amphores de type I. Enfin, ma cinquième étape, la plus longue et la plus enrichissante, a été la fouille de l'une de ces épaves trouvées, datée du $13^{\mathrm{e}}$ siècle, Çamaltı Burnu I, menée de 1998 à $2004^{6}$. C'était un effort pionnier : la première fouille sous-marine turque, qui a servi d'école de terrain aux étudiants qui, depuis, sont devenus des collègues. Je suis actuellement en train de rédiger la publication finale de la fouille, un ouvrage qui va me prendre encore quelques années. Comme vous le savez, la fouille est seulement la partie visible de l'iceberg!

Entre temps, j'observe que les recherches sur les amphores byzantines et les prospections sous-marines se multiplient de jour en jour.

Je vois que les jeunes chercheurs utilisent la typologie Günsenin et qu'ils se limitent, la plupart du temps, aux quatre types principaux que j'avais présentés à Athènes. En effet cette première publication datée de 1989 est toujours le plus fréquemment citée au détriment de la typologie complète que j'ai présenté dans ma thèse. Les types intermédiaires et les sous-types ne sont donc pas pris en considération. Dans plusieurs publications je vois que la plupart des amphores illustrées pourraient être attribuées aux types allant de Günsenin V à Günsenin XXVIII.

C'est pour attirer l'attention sur ce point que j'ai décidé de rédiger le présent article plus de trente ans après ma première communication ${ }^{7}$. Je dois avouer que je n'ai pas eu l'occasion de mettre à jour ma thèse. Les recherches sur la céramique byzantine dans le monde entier ont gagné une telle ampleur qu'il m'est difficile aujourd'hui de suivre chaque trouvaille et chaque identification nouvelle. Une collaboration internationale pourrait amener à une reconsidération des lieux de diffusion et de production de mes types. Néanmoins, malgré les erreurs et défauts éventuels qu'elle peut contenir, ma thèse a servi de référence à un bon nombre de chercheurs et les perspectives multiples dans lesquelles j'ai placé ce travail par la suite m'ont permis d'avoir une vision plus globale de la chaîne opératoire et du processus de distribution des amphores.

Signalons enfin que les photos du présent article sont de l'auteur, à l'exception des Fig. 21, 24, $28,34,35,37$, et que les dessins sont de l'auteur et de Çiğdem Okurer (pour la mise au propre et l'encrage), à l'exception des Fig. 18, 19, 20, 29.

\section{LES AMPHORES BYZANTINES}

Les amphores du monde byzantin, à savoir les "mégarika ou magarika", ont comme leurs prédécesseurs, continué à servir de récipients pour du vin

6) L'épave de Çamaltı Burnu I, datée du $13^{\mathrm{e}}$ siècle, a été choisie pour faire l'objet d'une étude archéologique et historique. La charpente navale de la période était inconnue et la cargaison du bateau était composée des dernières amphores utilisées pour le commerce maritime, non étudiées jusqu'à maintenant. De plus, l'INA n'avait jusqu'alors fouillé que des épaves byzantines datant de la fin du 4" /début 5 ("Yassiada", Bass et van Doorninck 1971 ; van Doorninck 1976) ; du 7e ("Yassiada", Bass et van Doorninck 1982) ;

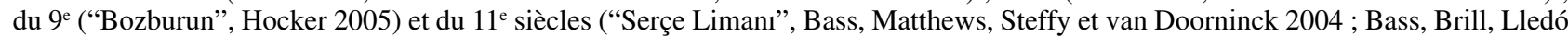
et Matthews 2009). L'épave de Çamaltı Burnu I datée du 13e siècle, pouvait donc élargir notre connaissance maritime au-delà de ces dates, particulièrement dans la région de la mer de Marmara.

7) En tant que répertoire des types afin de les reconnaître plus facilement. Néanmoins, sans la consultation de la thèse l'article resterait incomplet.

8) La typologie proposée dans le présent article est celle de ma thèse. Les appels de note en caractère gras souligné indiquent les remarques qui ont été ajoutées par la suite à partir des travaux récents.

Vous trouverez aussi quelques commentaires récents dans l'Addendum.

9) L'origine du mot venait de la ville de Mégare et désigne à l'époque byzantine toutes les amphores, cf. Bakirtzis 1989. 
et des aliments et ont fait l'objet d'un commerce à distance, surtout par mer. Leur trait caractéristique principal est qu'elles portent toutes des stries sur la panse et ont des fonds bombés.

Dans leur fabrication, les amphores byzantines ont parfois été relativement peu soignées et montrent des irrégularités comme, par exemple, des anses asymétriques. Souvent on n'y voyait que de simples contenants pour le transport. Mais il faudrait souligner que de par leur fonction elles ont des tailles et des capacités précises. Leur apparence est aussi en rapport étroit avec leur fonction et usage.

Les jarres plus petites sont parfois fabriquées seulement d'une masse d'argile, avec des anses qui ont été collées par la suite aux épaules et au col. Plus souvent, le col a été fait d'une masse d'argile séparée qui a été collée à la panse. Parfois le fond de jarres a été aussi fait par une masse d'argile séparée. Du moins c'est ainsi que nous restituons leur fabrication.

Elles offrent des graffiti incisés avec un outil pointu ou une lame avant ou après la cuisson. Les graffiti se présentent comme des lettres, soit grecques ou cyrillique ou runiques, ou bien comme des marques picturales. Les graffiti incisés avant la cuisson peuvent servir à identifier les fabricants ou ceux qui dirigeaient ou contrôlaient la fabrication de la jarre. Les graffiti incisés après la cuisson peuvent, quant à eux, servir à identifier le propriétaire, le contenu ou la capacité de la jarre. Dans ce second cas de figure il est difficile de savoir si les graffiti ont été faits quand l'amphore a été chargée pour la première fois ou lors de sa réutilisation. Quelques timbres appliqués avant cuisson ne semblent pas avoir de signification aussi marquée que ceux de Thasos, Rhodes ou de Cnide par exemple, que l'on peut sans doute interpréter comme des marques d'ateliers. La rareté des timbres peut s'expliquer par le manque d'intérêt des potiers pour leur contenu et leur destination future. Aussi ne possède-t-on, dans l'état actuel des connaissances, qu'un seul exemplaire avec un timbre inscrit qui appartient à une amphore du type $\mathrm{IVe}^{\mathbf{1 0}}$.

L'apparition de trous (trous de fausset, faits normalement après la cuisson) nous indique une probable fermentation du vin dans l'amphore ${ }^{\mathbf{1 1}}$. Cette disposition, que l'on ne rencontre pas souvent sur les amphores antiques, indiquerait un changement dans le moment choisi pour la mise en amphore du vin à l'époque byzantine.

\section{LA TYPOLOGIE PROPOSEE}

\subsection{LES TYPES ( ? ) PRINCIPAUX}

En développant ma typologie, j'ai conservé les quatre types principaux qui avaient déjà été reconnus antérieurement ${ }^{12}$. Ce sont les plus nombreux et les plus diffusés.

Il est bien clair que, les amphores dites Günsenin I, II, III et IV, ont été enrichies chacune, de nombreux "sous-types" qui ont été produits dans des régions de vinification différents. Dans ma thèse j'avais déjà fait un effort pour illustrer cela dans le cas de figure de Günsenin IV. Parvenir à définir avec précision les éléments de différentiation des soustypes de Günsenin I, II et III, -et peut-être modifier le IV, est un objectif essentiel qu'il reste à faire !

Frederick van Doorninck, Jr. suggère définir plusieurs des types comme des "classes". C'est une terminologie que j'approuve aussi et dont je devrai tenir compte dans le futur. Néanmoins, dans le présent article qui se propose comme une synthèse de ma thèse de doctorat il me semble préférable de rester sur ma vieille terminologie. Nous avons le projet d'un article en commun avec van Doorninck où nous tenterons de ranger ma typologie en classes et de déduire ensuite les sous-types. Le projet que nous avons récemment entrepris sur les amphores de l'épave de Çamaltı Burnu I (voir en bas) va nous montrer si cela est possible.

On peut admettre que les amphores de type I ont évolué progressivement (forme et chronologie) et donné naissance aux types III et IV. J'ajoute trois types intermédiaires pour cette transition. Je voudrais les nommer types I-III, I-IV pour souligner leur rattachement aux types I, III et IV. Et II-III pour les mêmes raisons. Les trois types intermédiaires sont très peu attestés, leur présence attestant une période d'essai. Grâce à ces types intermédiaires, nous observons un développement continu des formes. Je propose aussi des sous-types pour les types II et IV (Fig. 1) ${ }^{13}$.

Les types, I, II, III et IV sont les types les plus attestés et plus utilisés parmi les amphores byzantines du $10^{\mathrm{e}}-11^{\mathrm{e}}$ et du $13^{\mathrm{e}}$ siècle. Ils sont assez nombreux pour dominer une époque déterminée et représenter de vrais chargements. Ils ont dû avoir leurs propres ateliers pour une production massive. Et nous avons des indices plus nombreux soit pour leur chronologie soit pour leurs lieux de production.

10) Günsenin 1990 : 32 et 263, pl. LXI/1a, b, c, d, e, cf. infra Fig. 14 (en bas). Nous avons constaté sur les amphores de la cargaison de l'épave de Çamaltı Burnu I, dix monogrammes/timbres différents répétitifs. On pourrait donc se demander s'ils ne sont pas représentatifs d'un système. Nos recherches sont en cours. De même, il ne semble pas que ces timbres puissent faire référence à un quelconque système de taxation comme dans les époques précédentes.

11) Sur ce sujet, cf. Adan-Bayewitz 1986.

12) Günsenin 1989.

13) Günsenin 1990 : Fig. 3. 


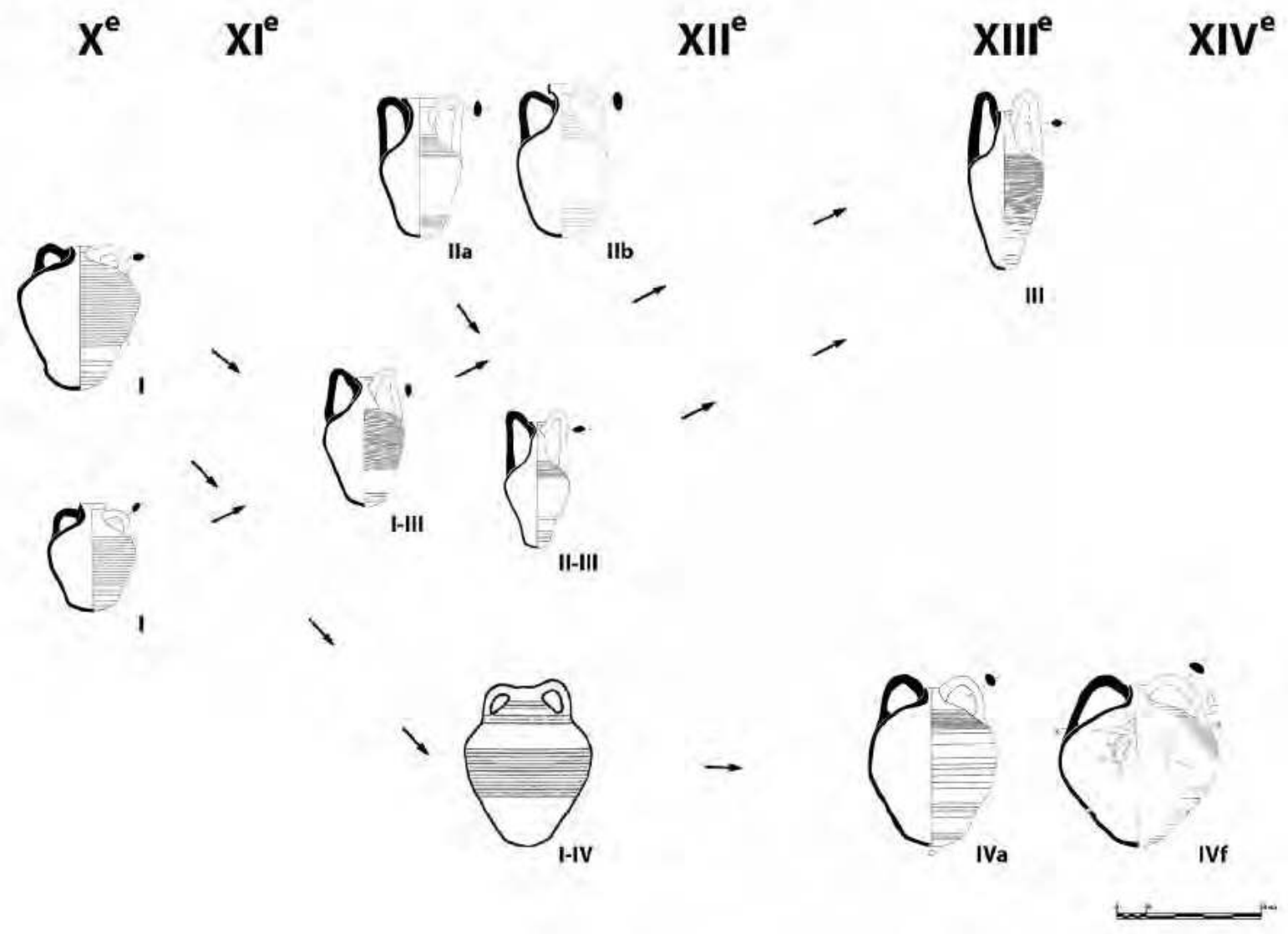

Fig. 1 : L'évolution des principaux types d'amphores (Günsenin 1990 : Fig. 3).

Il faut tenir compte du fait que les quatre types (y compris les types intermédiaires qui sont des produits de transition) sont les amphores byzantines caractéristiques de l'époque que nous traitons (du $10^{\mathrm{e}}-11^{\mathrm{e}}$ et du $13^{\mathrm{e}}$ siècle). Nous allons présenter les caractéristiques de ces amphores en renvoyant pour leurs lieux de découverte en Turquie au catalogue dressé en fin d'étude ${ }^{14}$.

\subsubsection{Type I (Fig. 2)}

Les amphores du type I sont plus abondantes et plus répandues que les autres. Aussi présentent-elles des formes et des dimensions beaucoup plus variées. Ce type et ses "sous-types" sont ceux qui ont connu la production la plus abondante et la circulation la plus étendue de leur ère en com- paraison avec les autres types produits depuis l'âge Bronze $e^{15}$.

Il est très difficile d'en distinguer les variantes car malgré les petites différences elles ont une forme commune. En général, elles sont de petite taille et d'une fabrication robuste. La panse est trapue, avec des stries horizontales tout autour. Un col bas et large, les anses petites et solides dépassent légèrement l'embouchure. On observe bien le rétrécissement au raccord entre la panse et le fond. On peut considérer comme des variantes celles qui ont un col plus haut, des anses au-dessous de l'embouchure et une panse plus régulière (rétrécissement moins visible entre le fond et la panse). Mais ce n'est pas un critère juste pour créer un sous-type car on pourrait trouver toutes ces variables combinées dans une seule amphore ${ }^{\mathbf{1 6}}$. Leur hauteur moyenne mesure autour de $30-40 \mathrm{~cm}$,

14) Pour leurs lieux de découverte en Turquie et pour le catalogue, comme indiqué en haut, il faut que vous alliez aux pages de ma thèse (Günsenin 1990) et m'aider à compléter, avec les données les plus récentes, les lieux de trouvaille et surtout les lieux de production des types Günsenin! Soulignons encore une fois que les références données ici sont contemporaines de la date de soutenance de ma thèse, à l'exception de quelques remarques nécessaires qui ont été ajoutées en note (appels en caractère gras soulignés), à partir des travaux récents.

15) J'ai beaucoup publié sur ce sujet. Voir notamment, Günsenin 1992b et 1995a. Voir aussi infra, dans la Fig. 3, la carte de distribution du type I mise à jour.

16) Je voudrais signaler ici, le travail de V.V. Bulgakov qui a identifié cinq phases chronologiques pour le type Günsenin I plaçant la production de ces amphores entre le premier quart du $10^{\mathrm{e}}$ et la fin du $11^{\mathrm{e}}$ siècle, alors que leur utilisation se poursuit jusqu'au $12^{\mathrm{e}}$. Cf. Bulgakov 2000. 


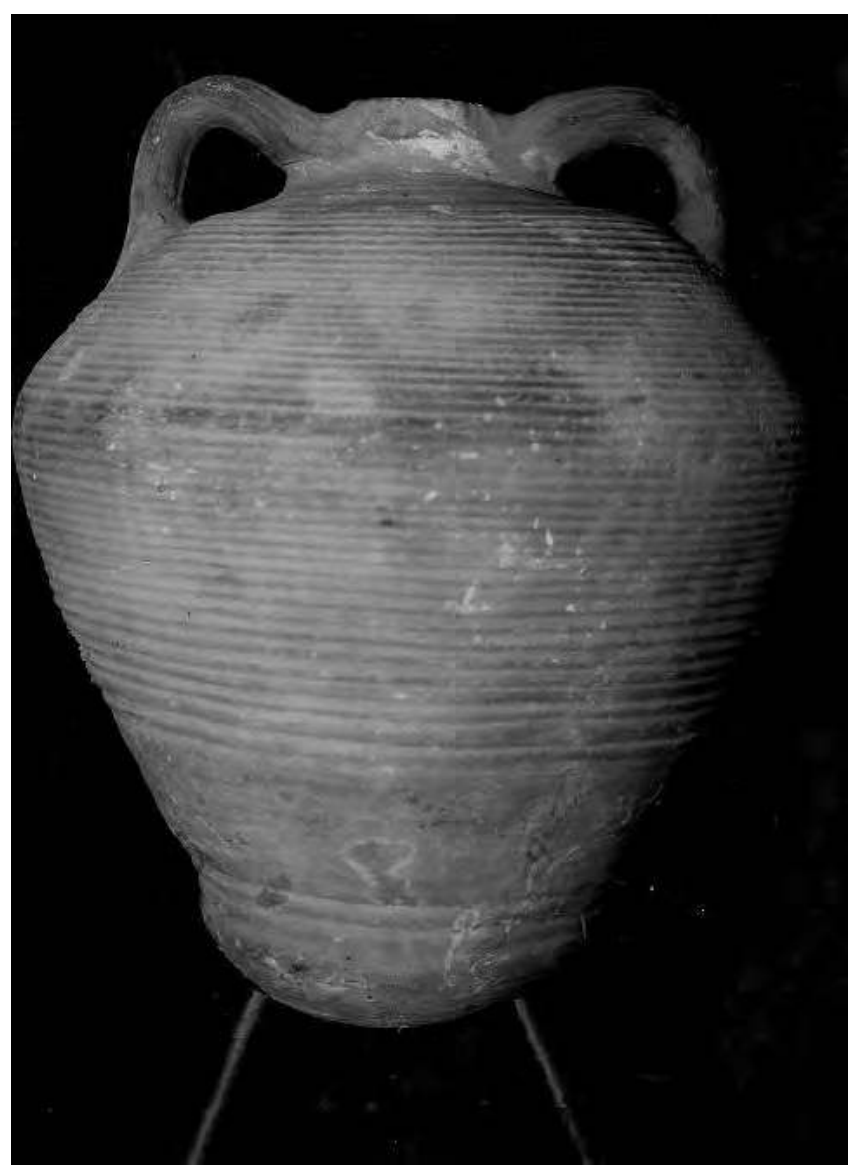

$\mathbf{a}$

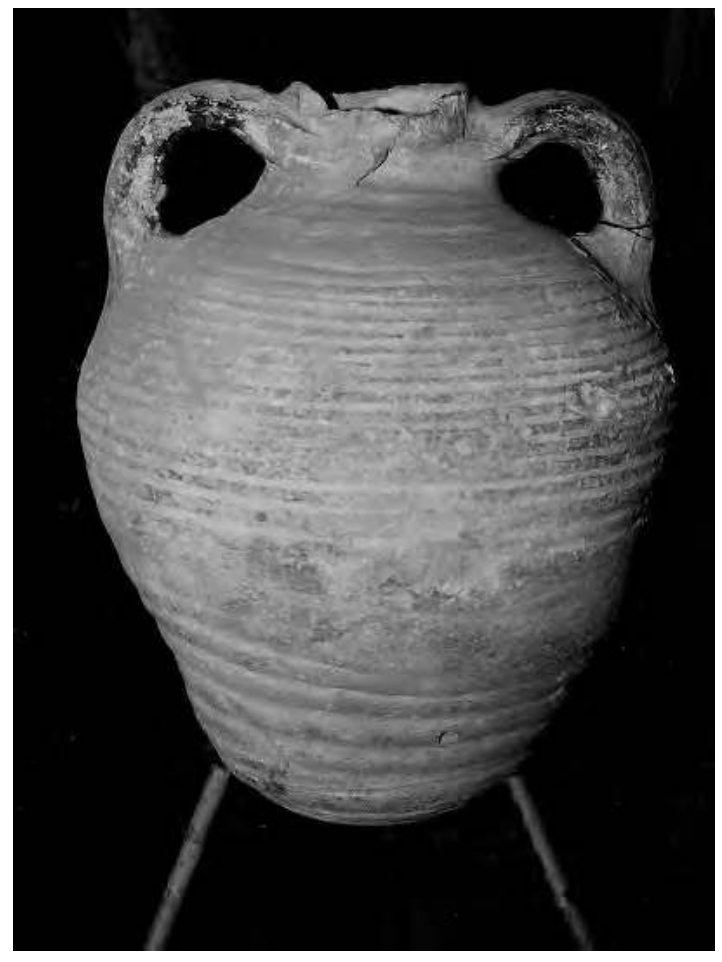

c

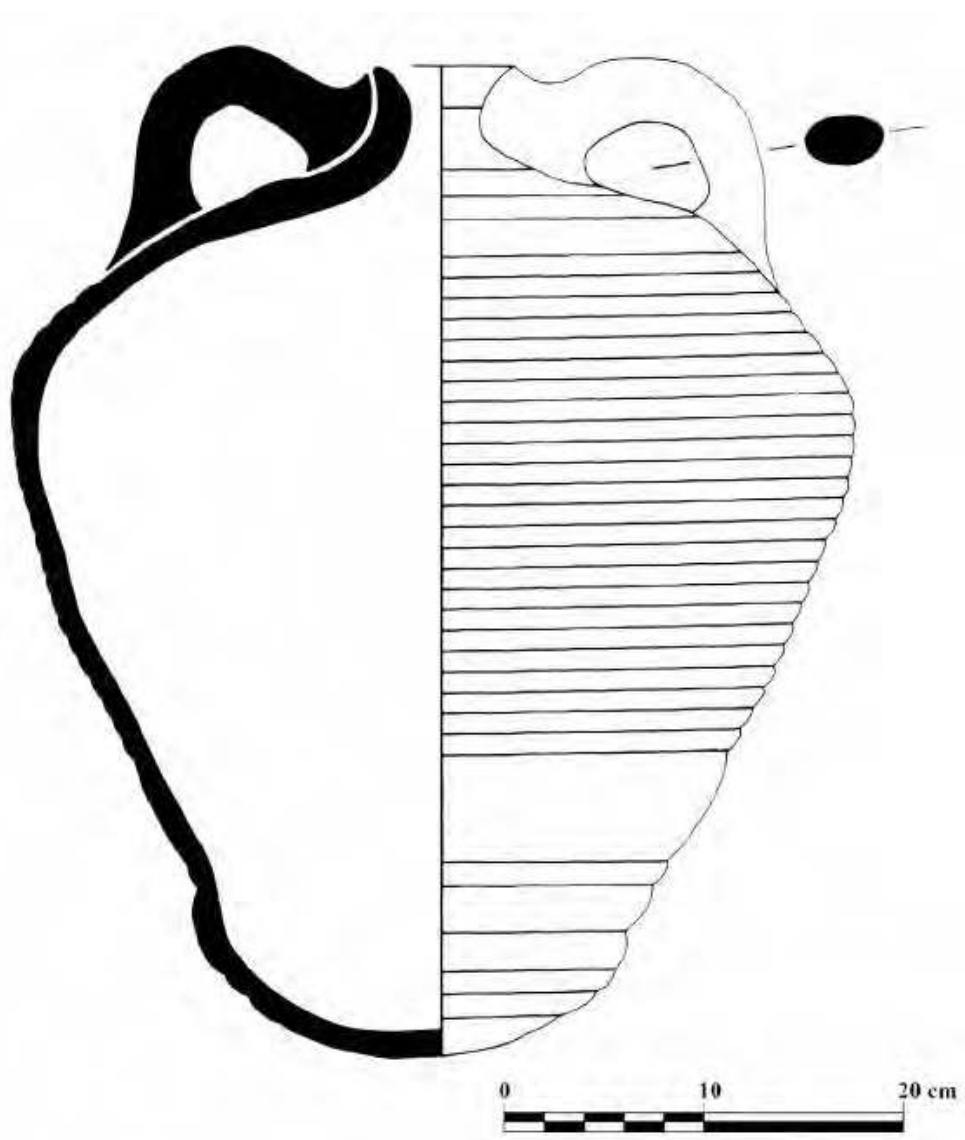

b

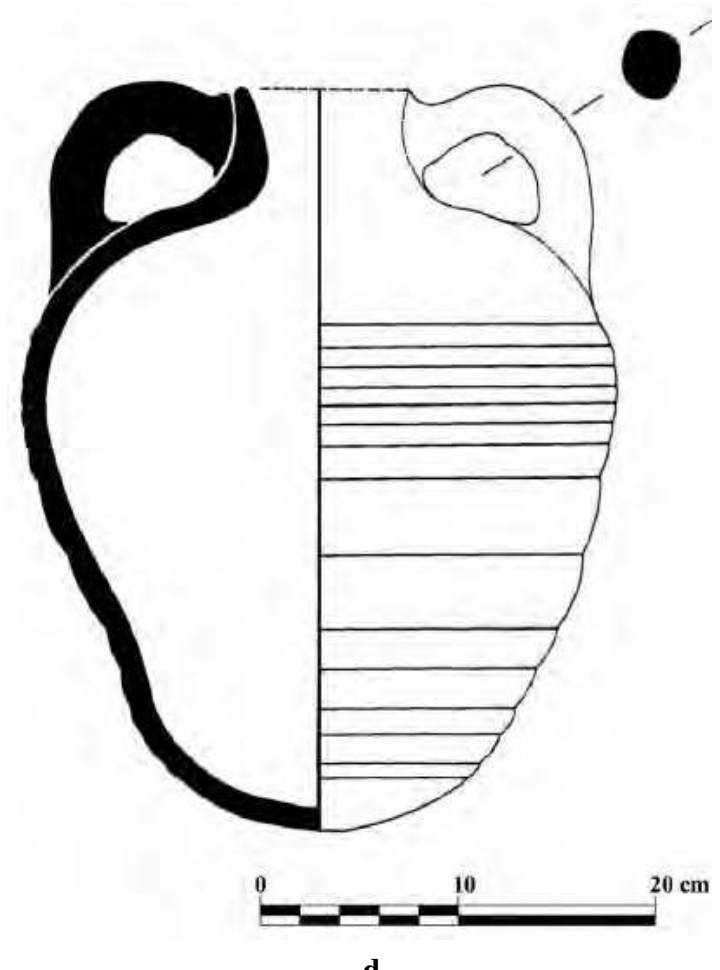

d

Fig. 2 : Amphores Günsenin I : a-b. Musée archéologique d'Izmir, nº inv. 2720 (Günsenin 1990 : 113 , pl. V/1a, b) ; c-d. Musée archéologique d'Izmir, n' inv. 2040 (Günsenin 1990 : 114, pl. V/ 2a, b). 
la plus petite étant de $28 \mathrm{~cm}$, la plus grande $53 \mathrm{~cm}$. Leur diamètre est de peu inférieur à la hauteur. Leur pâte est constituée d'une argile rouge brique, orange soutenu ou beige.

La découverte la plus importante associée avec le type Günsenin I est celle de son lieu de production, qui se trouve à Ganos (actuel Gaziköy) en Thrace. Les différences de forme des sous-types et l'étude des argiles suggèrent qu'il a pu y avoir d'autres lieux de production mais leur étendue semble circonscrite dans la région de la mer de Marmara $\mathbf{1 7}^{17}$.

J'avais découvert les ateliers de Ganos en 1989, un an avant de soutenir ma thèse de doctorat. Cela avait été un "coup d'œil" rapide ! Je me suis empressée d'y retourner en 1991 dans le cadre d'une prospection officielle avec l'autorisation du Ministère de la Culture turc. Pourtant, j'avais fait mon meilleur pour les signaler et les décrire dans ma thèse.

Il faudrait revenir, un jour, aussi à l'analyse des ateliers de Ganos. Nous avons fouillé seulement un four. Dans les prospections magnétiques qui ont été entreprises pour cerner la superficie de la zone de production, les résultats nous donnent un bilan positif avec certainement de nombreux fours et dépotoirs localisés, peut-être une trentaine de structures en tout $\frac{18}{}$.

Les dépotoirs se trouvent normalement à côté des fours. Dans le cas de Ganos, on pourrait se demander si les amphores brisées qui se trouvent dans les alentours représentent des dépotoirs ou si elles ont servi de chamotte ajoutée à l'argile pour réduire son rétrécissement et lui donner plus de corps lors du façonnage. En effet, les amphores Günsenin I de l'épave de Serçe Limanı ont une grande quantité de chamotte dans leur pâte.

J'avais bien constaté la variété des dimensions et des formes des amphores d'après celles qui avaient été jetées pendant le labourage sur les champs cultivés, et sur ce point dans ma thèse $j$ 'avais fait le commentaire suivant: "Ce phénomène pourrait s'expliquer par des différences de travail entre artisans produisant le même type" $\underline{\text { "19}}$. Est-ce que cela est vraiment le cas?

La question qu'on doit introduire ici est celle de la durée de la production des ateliers d'amphores à Ganos. Ce phénomène de dimensions et de formes très variées n'est peut-être pas le résultat de différences de travail entre artisans produisant le même type dans une même époque. Il pourrait s'expliquer aussi par des productions appartenant à des époques différentes. Pourrait-on dire que les formes des amphores de Ganos diffèrent selon les époques? Quelle forme a été produite à quelle époque?

Et je crois que, la réponse à ces questions pourrait être apportée par les amphores de Ganos trouvées ailleurs qu'à Ganos et qui proviennent de couches bien stratigraphiées.

Quand je faisais mes enquêtes dans les musées turcs, au cours desquelles j'ai parcouru presque tout le littoral du pays, j'ai fait de mon mieux pour recueillir autant que possible des échantillons de chacune des amphores (les types principaux). Maurice Picon (Laboratoire de Céramologie, CNRS, Lyon), a très gentiment accepté de rédiger les trois rubriques suivantes pour lesquelles je le remercie infiniment. Ce sont des analyses à l'œil nu, réalisées sous binoculaire. Nous avons utilisé les cartes géologiques de la Direction générale des Recherches et Explorations Minières, "Maden Tetkik ve Arama Genel Müdürlüğ̈̈" (MTA) d'Ankara.

\begin{abstract}
Environnement géologique de l'atelier ${ }^{20}$
"L'atelier se trouve apparemment dans la zone de contact de deux formations géologiques différentes : Le flysch éocène-oligocène qui forme au Nord la montagne du Ganos, les dépôts littoraux du miocène qui bordent vers le Sud-Ouest le détroit des Dardanelles. Il faut signaler encore la présence de formations métamorphiques qui apparaissent sous le miocène et qui sont très probablement à l'origine des micas blancs (muscovite) qui sont relativement abondants dans les pâtes de l'atelier ancien. L'atelier moderne de Hoşköy qui est situé dans les formations miocènes possède également de nombreux micas dans sa pâte. On peut donc supposer que les potiers de l'atelier ancien ont utilisé eux aussi les sédiments miocènes. Cette hypothèse semble d'autant plus vraisemblable que le flysch semble peu métamorphisé, et ne doit donc contenir que des micas résiduels. Ajoutons enfin que les pâtes sont assez fortement calcaires, ce qui s'accorde mieux avec les formations littorales miocène qu'avec le flysch".
\end{abstract}

\section{Caractéristiques visuelles des pâtes}

"Il s'agit de pâtes calcaires dont les éléments détriques sont constitués presque uniquement

17) Voir Günsenin et Hatcher 1997. Voir aussi, infra, les commentaires de Maurice Picon.

18) Günsenin 1995a ;1995b.

19) J'ai étudié des profils différents dans Günsenin 1995a ; Fig. 13.

20) Günsenin $1990: 54-56$. 
de quartz. La granulometrie des quartz est fine, guère supérieure apparemment à 1 ou 2 dixièmes de millimètre. Quelques échantillons, rares, semblent avoir un dégraissant ajouté, constitué de sable de 0,5 à $1 \mathrm{~mm}$ de diamètre, environ. La couleur des pâtes est très variable, depuis l'orange, jusqu' au beige clair. Ces variations semblent dues à des températures de cuisson différentes agissant sur une pâte calcaire. On rappelle que les pâtes calcaires s'éclaircissent à mesure que la température s'élève, passant du rouge orangé, au beige et même au crème. Il ne faut donc pas accorder trop d'importance à ces problèmes de couleur pour l'identification de ces fabrications. Cela est d'autant plus vrai que l'on a sans doute à faire à des amphores fabriquées avec de l'eau de mer, laquelle modifie considérablement les couleurs des pâtes. La modification la plus spectaculaire s'observe sur la face externe des amphores qui est souvent totalement décolorée, formant une sorte de pseudo-engobe blanc. Ce pseudo-engobe est assez fragile, et peut disparaître dans certaines conditions de conservation un peu agressives".

\section{Comparaison des productions de l'atelier et des amphores du type I}

"Il s'agira nécessairement de comparaisons visuelles, faute d'analyses. Ces comparaisons sont par ailleurs rendues difficiles par la finesse des inclusions minéraux ; micas et quartz, et par leur caractère banal. Malgré cela on ne peut manquer d'être frappé par la ressemblance de certains échantillons et des productions de l'atelier de Gaziköy. C'est le cas notamment des exemplaires réutilisés dans la construction du Palais des Manganes à Istanbul, ainsi que de quelques exemplaires provenant de Çanakkale. La plupart des exemplaires examinés proviennent de la côte de la mer Noire (Amasra, Samsun, Sinop) et sont légèrement différents, de couleur moins orangé, plus marron ou beige. Mais on a signalé que ces différences peuvent ne résulter que de la cuisson, l'aspect général de la pâte n'étant pas très différent. Il faut par ailleurs songer que l'atelier de Gaziköy n'est sans doute pas le seul atelier de la région, et que les différences observées peuvent s'expliquer ainsi. Il est possible aussi que des ateliers existent en dehors de la zone des Dardanelles et notamment sur la côte sud de la mer de Marmara. Dans cette hypothèse on devrait avoir des types de pâte très différentes, car les formations géologiques au Sud de la mer de Marmara, et jusqu'à Istanbul, sont très différentes de celles de la région des Dardanelles, et plus généralement de celles de la région allant des Dardanelles à Istanbul, par la côte nord de la mer de Marmara. On signalera ici, le cas de l'amphore de petite taille $\underline{\mathbf{2 1}}$ provenant d'Istanbul qui présente une pâte très différente de toutes celles que l'on a rencontré pour le type I, et qui pourrait peut-être correspondre à ces régions du Sud et de l'Est de la mer de Marmara".

La raison pour laquelle je reprends ces trois rubriques dans cet article est de rappeler que Maurice Picon a eu l'occasion de voir et de comparer de nombreux échantillons de plusieurs types d'amphores : 1) Il a pu constater que la pâte de "certaines" des amphores de type I découvertes dans diverses régions de la Turquie et des fragments d'amphores se trouvant dans les dépotoirs de la région de Gaziköy était identique. Il faut par ailleurs songer que "l'atelier de Gaziköy n'est sans doute pas le seul atelier de la région", et que les différences observées peuvent s'expliquer ainsi. 2) Partant de cette constatation il fait des comparaisons avec les échantillons des autres types principaux, ce qui le mène à faire le commentaire suivant : “... Il est possible d'étendre le raisonnement au type II dont la pâte est similaire à celle du type I et peut-être au type IV, bien que l'on n'ait pas trouvé d'exemplaire de ce type dans la région concernée (Ganos)...."르. Ce commentaire a conduit certains collègues à conclure que Ganos était aussi le lieu de production des amphores de Günsenin IV! Picon a observé les échantillons de chacun de sous-type du type IV. Et le projet que l'on a entrepris avec van Doorninck sur la cargaison d'amphores de l'épave de Çamaltı Burnu I montre déjà qu'il y avait plusieurs lieux de production de ces amphores (voir infra le type IV). Par conséquent, nous ne pouvons pas dire que le type IV a été produit à tel endroit. D'après les cartes géologiques, le type d'argile du littoral de Ganos se répand sur une vaste étendue. Il est donc possible de dire que le type IV n'a pas été produit à Ganos. Eventuellement il a pu avoir été produit dans plusieurs ateliers qui ne sont pas éloignés de la région de Ganos !

Il m'a semblé nécessaire d'éclaircir ce malentendu dans cet article.

Un autre malentendu que je voudrais lever ici concerne l'association erronée, fréquemment attestée dans la bibliographie, de toutes les types de la "classe" Günsenin I à Ganos. Il importe de souligner que Ganos n'était pas le seul lieu de production des amphores Günsenin I.

Et par exemple les amphores découvertes dans l'épave de Yenikapı 12 correspondent à un type différent de la "classe" Günsenin I. Pour ce 
qui est la date de l'épave van Doorninck et moimême considérons une date à l'extrême fin du $9^{\mathrm{e}}$ ou au début du $10^{\mathrm{e}}$ siècle comme la plus probable.

Van Doorninck qui est en cours de publier un chapitre sur les amphores de la cargaison de Serçe Limanı dans le volume III de Serçe Limanı, apportera des renseignements plus détaillés sur ces questions $\underline{\underline{23}}$.

Les références de datation archéologiques que j'ai pu recueillir dans ma thèse montrent essentiellement le début du $11^{\mathrm{e}}$ siècle ${ }^{24}$. John Hayes, de son côté, donne une date, from late $10^{\text {th }}$ to early $12^{\text {th }}$ century contexts, d'après le matériel de Saraçhane $e^{25}$ et nous connaissons aussi une date dans le $12^{\mathrm{e}}$ siècle d'après les matériaux de l'Agora d'Athènes ${ }^{26}$.

En dehors de leur réutilisation comme matériaux de construction dans les voûtes et les coupoles du palais et de l'église des Manganes et le long des murailles maritimes à Constantinople ${ }^{27}$, ces amphores sont attestées dans les fouilles de l'Université de Princeton à Antioche ${ }^{28}$, en Bulgarie ${ }^{29}$, en Roumanie $^{30}$, et au Nord de la mer Noire, à Chersonèse, à Kertsch, à Sarkela-Beloi Vezhi ${ }^{31}$. Un fragment a aussi été trouvé à Otrante ${ }^{32}$. Là, il faut signaler aussi les amphores trouvées dans la galerie ouest de l'église de Sainte-Sophie à Thessalonique ${ }^{\underline{3}}$. J'espère bien que ces amphores seront étudiées et publiées prochainement.

Une proportion de 43,14\% des amphores découvertes lors des fouilles du port théodosien à Yenikapı, Istanbul, correspond au type Günsenin I ${ }^{34}$.

Dernièrement elles sont attestées dans les fouilles de Küçükyall ${ }^{35}$.

J'ai dressé une carte préliminaire, encore incomplète, sur la diffusion géographique de ce type avec l'intention de montrer la vaste étendue de sa distribution dans le bassin Méditerranéen allant de Chypre, le Sud de la France, les Balkans, et la mer Noire jusqu'à l'Ukraine et la Russie. Le type a également voyagé dans le Levant, l'Egypte pour atteindre aussi la Suède $\underline{36}$ (Fig. 3). Van Doorninck a déjà identifié des centaines de localisations dans une vingtaine de pays. Son travail paraîtra dans Serçe Limanı Vol. III.

Les épaves attestées avec une cargaison du type Günsenin I ne sont pas prises en compte dans cette carte $\frac{37}{}$.

\subsubsection{Type intermédiaire I-III (Fig. 4)}

Les amphores intermédiaires du type I-III ont une panse comparable à celle du type I avec des stries plus serrées autour de la panse, mais la forme de leur col et de leur embouchure présente des ressemblances avec le type III. Le col tend à s'allonger et les anses commencent à prendre la forme du type III. Leur hauteur est intermédiaire entre le type I et III (environ $45 \mathrm{~cm})^{38}$. Elles sont de fabrication robuste, l'épaisseur de la paroi est d'environ 1 à $1,5 \mathrm{~cm}$. Leur pâte est constituée d'une argile beige orangé soutenu. Ce type est peu attesté.

Nous observons des traces de dégraissants végétaux sur les anses comme sur les amphores du type III (cf. type III), qui pourraient s'expliquer par un lieu de production commun.

Les amphores de ce type sont attestées à Sarkela, Beloi Vezhi où elles sont datées du $11^{\mathrm{e}}-12^{\mathrm{e}}$ siècle $^{39}$. A l'Agora d'Athènes, elles sont asso-

23) Van Doorninck m'a signalé que, Yona Waksman et Eva Todorova espèrent lancer un projet majeur d'analyse d'argile des amphores de Günsenin I. Elles commenceront par les Günsenin I de l'épave de Serçe Limanı que van Doorninck a déjà classifié en cinq types différents.

24) Günsenin $1990: 21-24$; Bass et van Doorninck 1978 : avec les monnaies de 1025 ; Barnea $1989: 131$, à Aegyssus, avec une monnaie de Romain III Argyre (1028-1034) et à Dinogetia, avec une monnaie de Michel IV le Paphlagonien (1034-1041).

25) Hayes $1992: 73-74$, Type 54, Fig. 24.

26) Günsenin 1990 : 288, pl. LXXVI/1a, b, c, d, e ; 290, pl. LXXVIII/1a, b, c, d ; 294, pl. LXXX/1a, b, c.

27) Demangel et Mamboury 1939 : 148, Fig. 198/4.

28) Waage (éd.) $1948: 103$ et Fig. 96.

29) A Sozopol, Varna, Popina, Svistov, Pliska, Preslav et Silistra, Cangova $1959: 250$, Fig. 5 ; Stancev 1960 : 43, Fig. 10/B et 49, Fig. 16; Chadzidimitrova $1960: 212$, pl. 17, Fig. 2 ; Lazarov : 1975, Fig. 65, 66.

30) A Mangalia, Barnea 1959, Fig. 2/1; à Capidava, Florescu 1959, pl. V, Fig. 7 ; à Aegyssus-Tulcea, Vasiliu et MănucuAdameşteanu 1984 : 544, pl. III/5, 550, pl. IX/5 ; à Pacuiul lui Soare, Diaconu 1960 et 1961 : 603, Fig. 5/1,2 et 497, Fig. 9/1,2 ; à Dinogetia, Barnea 1967: 252, Fig. 154 (voir aussi, Barnea 1989, reprise du travail de 1967).

31) Yakobson $1979: 72$, Fig. 43/5,6 ; Pletneva 1959 : Fig. 29/1.

32) Arthur 1989 : Fig. 11.

33) Ces amphores sont maintenant entreposées dans les réserves du Musée de la Civilisation Byzantine à Thessalonique. Voir notamment, Papanikola-Bakirtzi et Skordali 1999: 59, Fig. 9. Et cf. Papanikola-Bakirtzi 2002 : 144-148, Fig. 158c et 159a.

34) Öncü et Çömlekçi 2018 . Cf. aussi, Günsenin 2016.

35) Cf. Wohmann 2016 ; Ricci et Wohmann 2018.

36) Roslund $1997: 362-366$, fig. 20 et 21.1-2.

37) Pour les épaves, voir Günsenin 1999b et cf. Addendum.

38) Günsenin $1990: 24-25$. Cf. pl. LIII/1a, b, c.

39) Pletneva 1959: 245, Fig. 31/1. Je trouve que la Fig. 4 de Yakobson 1979, découverte à Sarkela et daté au $10^{\mathrm{e}}-11^{\mathrm{e}}$ siècle, correspond à notre type. 


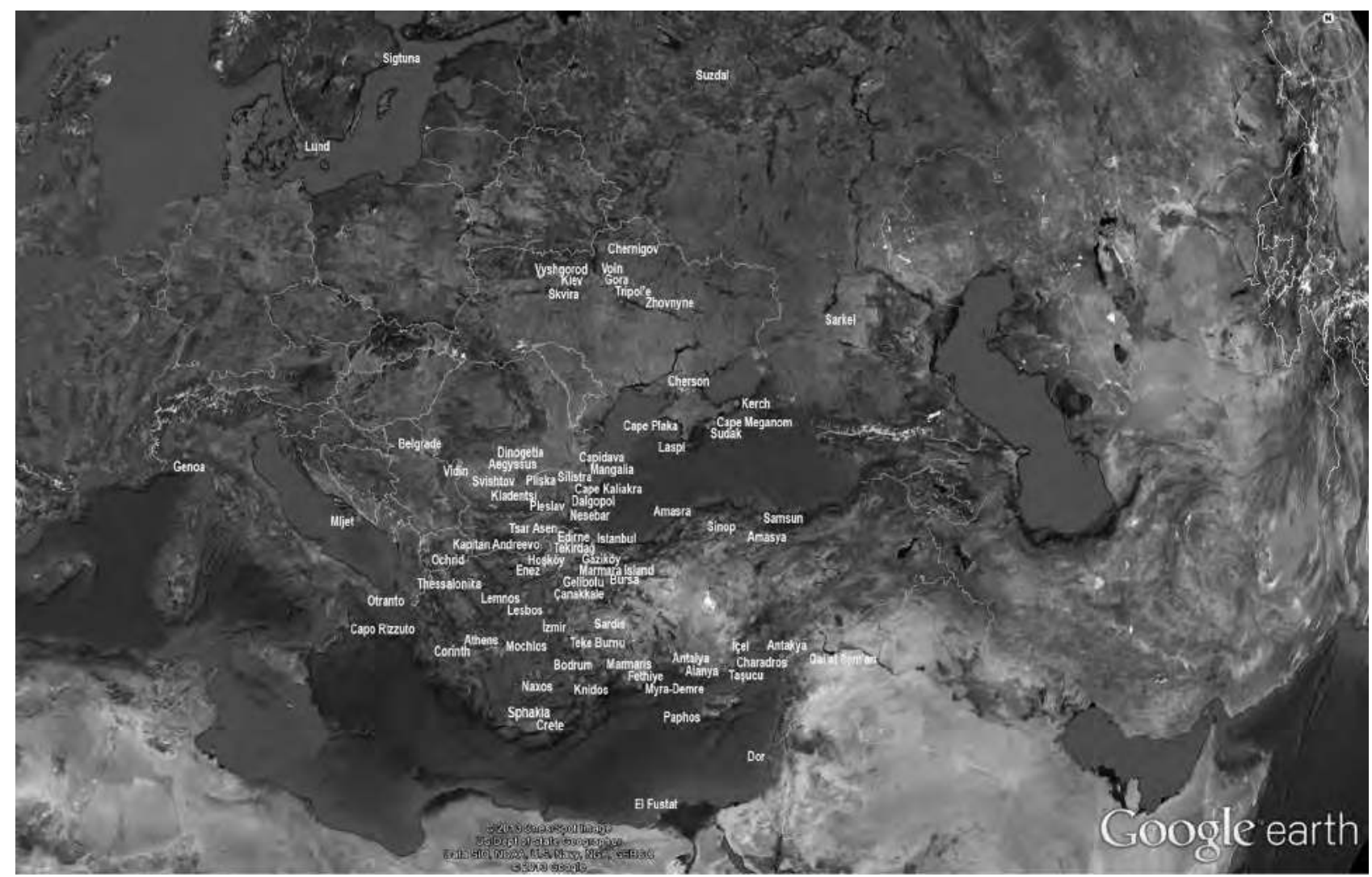

Fig. 3 : Carte de la diffusion géographique du type Günsenin I, à l'état actuel.

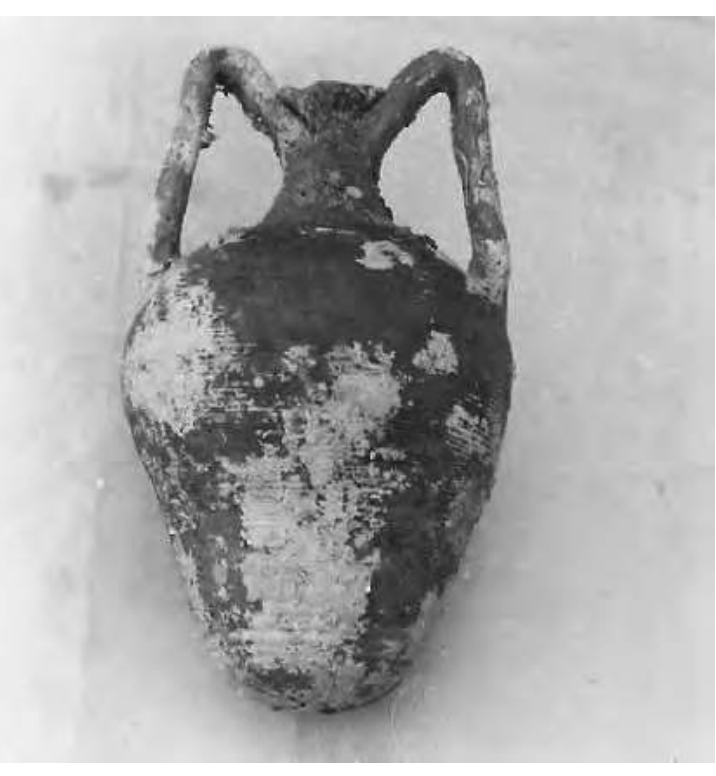

$\mathbf{a}$

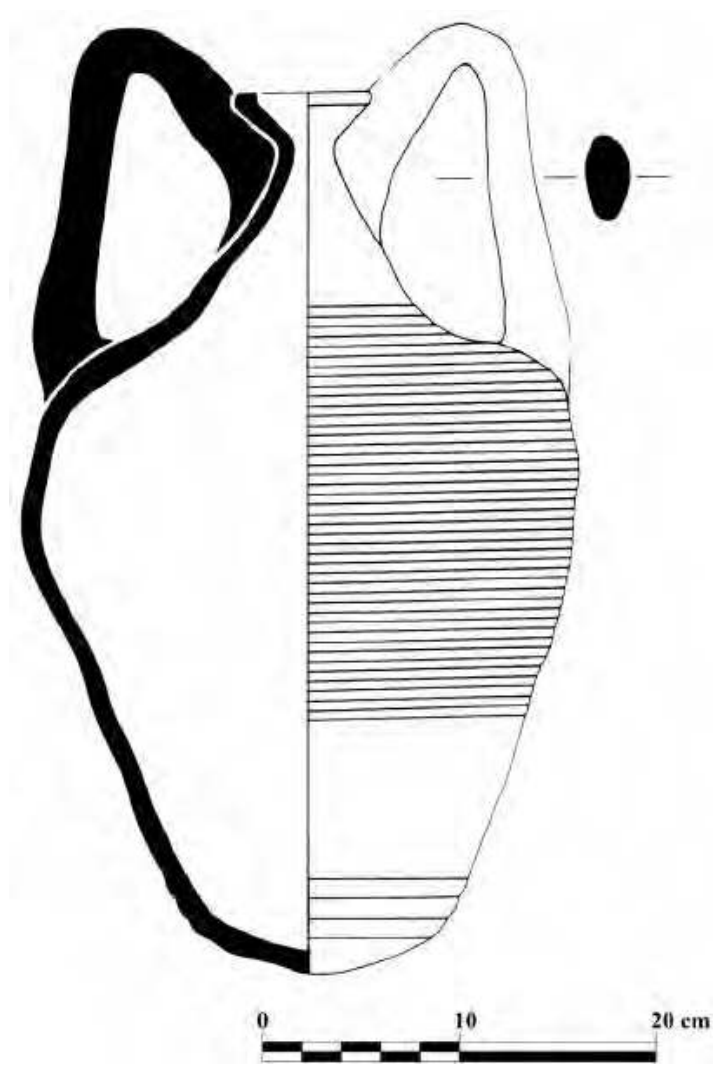

b

Fig. 4 : Amphore Günsenin I-III : a-b. Musée archéologique de Çanakkale, ${ }^{\circ}$ inv. 2981

(Günsenin 1990 : 126, pl. XXXI/1a, b). 


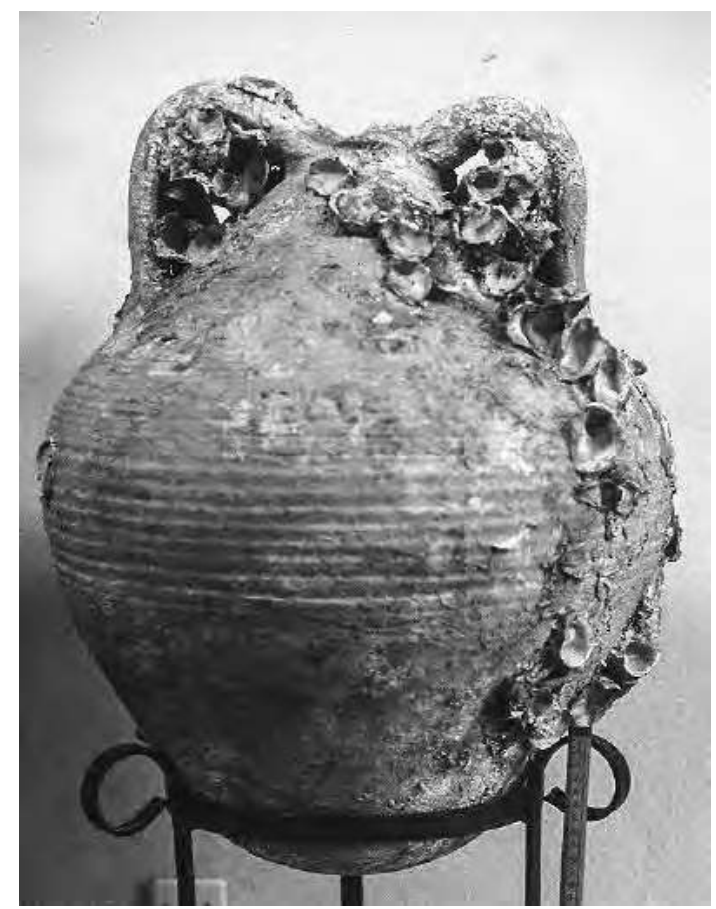

Fig. 5 : Amphore Günsenin I-IV : Musée archéologique de Tekirdağ, $\mathrm{n}^{\circ}$ inv. 1519

(Günsenin 1990 : 152, pl. LIV/1).

ciées à des monnaies anonymes datées des années 1059-106740.

Il m'est agréable de constater que les recherches sur les origines des amphores byzantines augmentent de jour en jour. Il m'importe de signaler la dernière publication de Yona Waksman en collaboration avec Skartsis, Kontogiannis, Todorova et Vaxevanis à propos des lieux de production des types Günsenin I-III, IIa et III $\underline{41}$.

\subsubsection{Type intermédiaire I-IV}

Dans les musées côtiers de Turquie je n'ai rencontré qu'un seul exemplaire de cette amphore, localisé au Musée de Tekirdağ ${ }^{42}$ (Fig. 5). C'est un type qui m'a paru assez étrange. La panse globulaire avec des stries sur son pourtour me rappelait le type I, mais ses dimensions (h. $58,5 \mathrm{~cm}$, d. 50 $\mathrm{cm}$ ) et les anses qui dépassent l'embouchure et s'y raccordent directement ressemblent au type IVa. La pâte est constituée d'une argile orange. Je préfère mettre cette amphore dans un type à part au lieu de la ranger comme un sous-type du type I ou IV. Les potiers voulaient peut-être garder la panse globulaire de type I, tout en faisant évoluer la forme des anses pour arriver au type IV. Une amphore de ce type datée du $11^{\mathrm{e}}-12^{\mathrm{e}}$ siècle à Dinogetia ${ }^{43}$ et un fragment conservé à partir du haut de la panse dans les trouvailles du Grand Palais de Constantinople en association avec des monnaies de Manuel I ${ }^{\text {er }}$ Comnène (1143-1180) et d'Alexis III Comnène (1195-1203) $)^{44}$ confortent son insertion chronologique entre les types I et IV.

\subsubsection{Type II}

Les amphores de type II se caractérisent par leur lèvre en ourlet. Elles ont une panse piriforme, les anses partent de l'épaule, montent plus haut que l'embouchure et se raccordent au col, sous la lèvre. Cette définition représente le type dominant parmi les amphores qui ont des panses piriformes et la lèvre en ourlet ${ }^{45}$. Nous l'appelons IIa (Fig. 6) ${ }^{46}$. Toutefois, j'ai remarqué une autre forme qu'on pourrait classer comme le sous-type IIb (Fig. 7). Le type IIa, représente une fabrication plus soignée et des dimensions plus homogènes. Les hauteurs moyennes sont de $43,5-45,5 \mathrm{~cm}$ et le diamètre de la panse de $25-27 \mathrm{~cm}$. Le type IIb est moins piriforme et l'embouchure est plus étroite. Les anses sont au niveau de l'embouchure ou au-dessous de celle-ci. Leur hauteur est plus grande (supérieure à $50 \mathrm{~cm}$ ), le diamètre des panses est plus important (environ $31 \mathrm{~cm}$ ). Ce sous-type est moins diffusé que le IIa. Toutes les deux formes présentent des stries espacées décorant la panse au niveau de l'attachement de l'anse et du fond. L'épaisseur de la paroi est plus fine que dans le type I. Elles sont faites d'argile beige orangé.

On leur attribue une date entre le $10^{\mathrm{e}}$ et le $12^{\mathrm{e}}$ siècle, le plus souvent le $11^{\mathrm{e}}$ siècle. Le type IIa est le mieux représenté parmi les amphores qui ont été trouvées au palais des Manganes ${ }^{47}$. Elles sont également attestées à Chersonèse ${ }^{48}$, à Sarkela-Beloi

40) Günsenin $1990:$ 301, pl. LXXXIII/1.

41) Waksman et al. 2018.

42) Günsenin $1990: 25$ et 152, pl. LIV/1.

43) Barnea 1967 : Fig. 159/6.

44) Rice 1958 : Fig. 24-E.

45) Günsenin $1989: 271 ; 1990: 26-27$.

46) Voir supra note 40.

47) Cf. Demangel et Mamboury 1939 : 148, Fig. 198/1.

48) Yakobson 1979 : Fig. 68/1 (10 $-11^{\mathrm{e}}$ siècles), Fig. 3 découverte à Anara, (type IIb) ; Romanchuk 1981 : Fig. 6/6 et Antonova et al. 1971 : Fig. 23 (découverte dans la couche du $10^{\mathrm{e}}-11^{\mathrm{e}}$ siècles). 


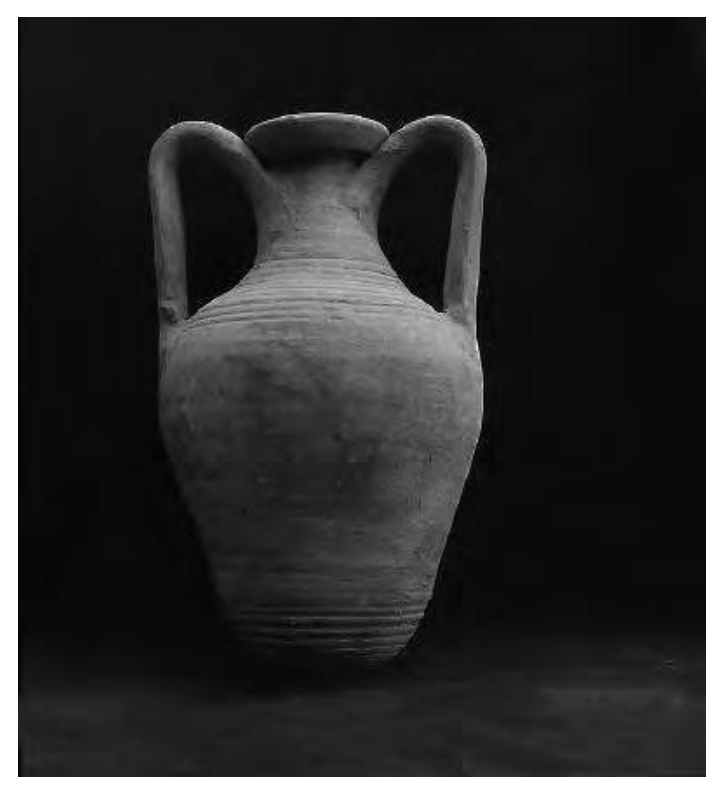

$\mathbf{a}$

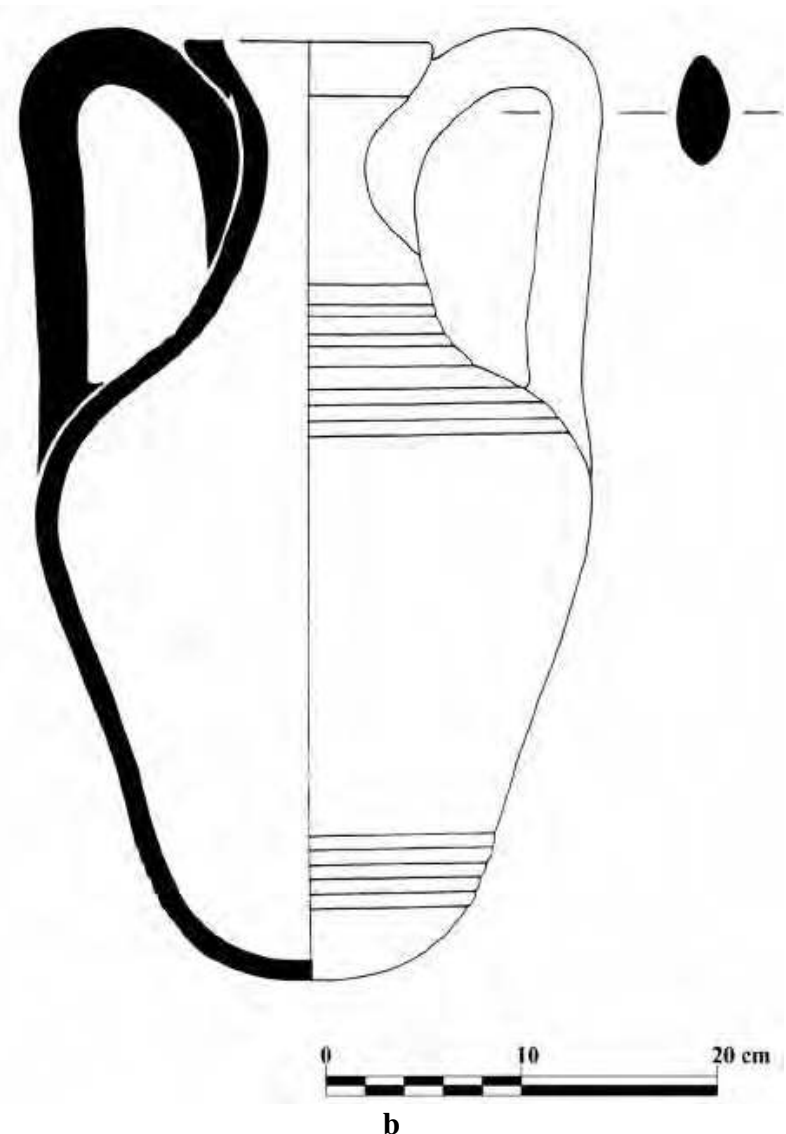

b

Fig. 6 : Amphore Günsenin IIa : a-b. Les Musées archéologiques d'Istanbul, $n^{\circ}$ inv. ? (Günsenin 1990 : 176, pl. XXXIV/1a, b).

Vezhi $^{49}$, en Bulgarie ${ }^{50}$, en Roumanie ${ }^{51}$, à l'Agora d'Athènes ${ }^{52}$. Comme le type I les amphores du type IIa, ont été trouvées dans la galerie ouest de l'église de Sainte-Sophie à Thessalonique ${ }^{\underline{53}}$.

\subsubsection{Type intermédiaire II-III (Fig. 8)}

Ce type aussi m'a paru comme une production de transition. Les amphores ont une panse comparable à celle du type II (encore plus piriforme), tandis que leur col long et leurs anses surhaussées évoquent celles du type III. La lèvre au niveau de l'embouchure est identique à celle du type intermé- diaire I-III. Des stries espacées décorent la panse comme dans les amphores du type II au niveau de l'attachement des anses et du fond. Elles sont aussi moins attestées comme c'est le cas des autres amphores de type intermédiaire.

L'épaisseur de la paroi est assez fine, 0,5-1 cm. La pâte est faite d'une argile orange chamois.

Ce type est attesté à Mangalia, Ada Marinescu et Noviodunum dans des contextes du $11^{\mathrm{e}}$ siècle $^{54}$, ainsi qu'à Chersonèse ${ }^{55}$ où il a été livré par une couche du $10^{\mathrm{e}}-11^{\mathrm{e}}$ siècle $^{56}$. A l'Agora d'Athènes, il est associé à des monnaies byzantines anonymes des années 1078-108157.

49) Pletneva 1959 : 245, Fig. 31/1, 3, 4 (type IIb).

50) A Pliska, Cangova 1959 : 256, Fig. 10 (type IIb, daté au 11 1 e $^{-12}$ siècles) ; Lazarov 1975 : 201, Fig. 67 (IIb), 68

51) A Dinogetia, Barnea 1967 : Fig. 159/1, à Mangalia, Barnea 1959 : Fig. 3/1, à Capidava, (voir aussi, Barnea 1989, reprise du travail de 1967), Florescu 1959 : 620, pl. V, Fig. 8 (daté de la 1ère moitié du 11 ${ }^{\mathrm{e}}$ siècle), à Aegyssus-Tulcea, Vasiliu $1980: 445$ pl. VI et 446, pl. VII et réimpression, Vasiliu et Mănucu-Adameșteanu 1984 : 544, pl. III/6, 546, pl. V/1, 550, pl. IX/4, 554, pl. XIII/3 (date donnée, 1036-1064 et mentionnée comme des amphores d'importation).

52) Günsenin 1990 : 302, pl. LXXXIII/2 (IIa) ; 303, pl. LXXXIII/3 (IIb) ; 304, pl. LXXXIII/4 (IIb).

53) Voir supra note 28 et cf. Papanikola-Bakirtzi $2002: 144-148$, Fig. 157a.

54) Barnea 1959 : Fig. $2 / 2$ et Fig. 3/2 ; Barnea et Barnea $1984: 518$ pl. XVI.

55) Romanchuk $1981: 331$, Fig. 6/7 et Yakobson $1979:$ Fig. 68/2.

56) Antonova et al. 1971 : Fig. 22.

57) Günsenin $1990: 27-28$ et 305, pl. LXXXIV/1. 


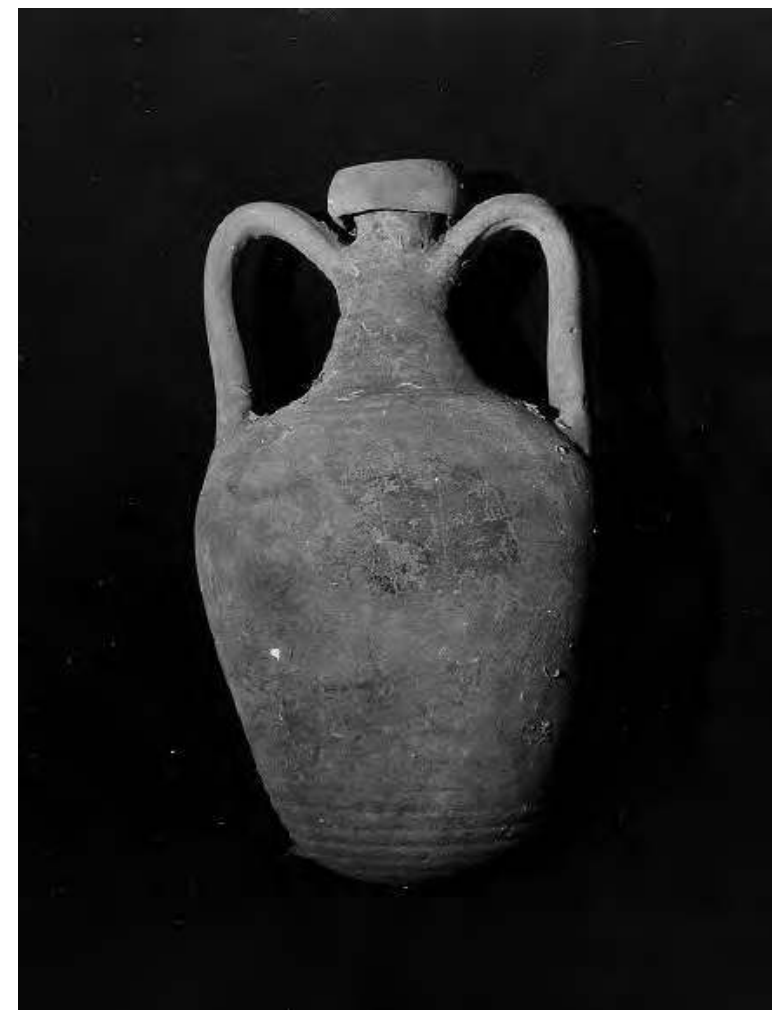

$\mathbf{a}$

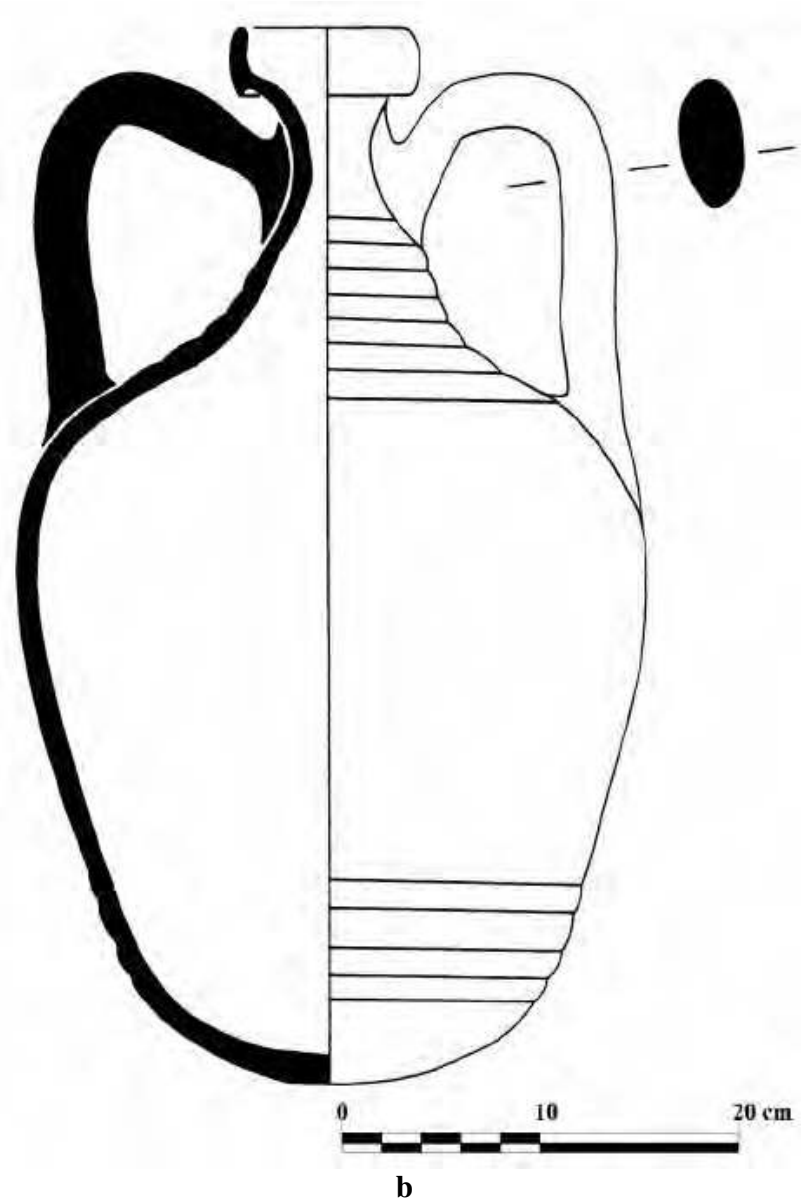

b

Fig. 7 : Amphore Günsenin IIb : a-b. Musée archéologique de Sinop, ${ }^{\circ}{ }^{\text {inv. } 36.1 .77}$ (Günsenin 1990 : 234, pl. XXXVII/1a, b).

\subsubsection{Type III (Fig. 9)}

Les amphores du type III montrent la même particularité que le type I. Aussi présentent-elles des formes et des dimensions très variées. Pour les mêmes raisons que celles invoquées pour le type I, je préfère les réunir sous un seul type ${ }^{\underline{58}}$. Malgré de petites différences, elles ont une forme commune. Elles ont une panse piriforme allongée (on dirait que les types I et I-III ont été comprimés des deux côtés) qui présente des stries très serrées de l'épaule jusqu'au milieu de la panse et espacées jusqu'au fond. Le col est long et conique. Les anses surhaussées font saillie bien au-dessus de l'embouchure étroite et elles ont une section assez épaisse. Les hauteurs mesurent entre 53 et $63 \mathrm{~cm}$; le diamètre de la panse varie de 24 à $30 \mathrm{~cm}$. Ce type d'amphore, avec une panse allongée et des anses surhaussées, présente des similarités avec le K 113 de l'Agora d'Athènes (dit Kapitan II ; première moitié du $3^{e}$ première moitié du $4^{\mathrm{e}}$ siècle) -à première vue bien évidemment. Il a la même panse allongée et les mêmes anses surhaussées ${ }^{59}$. Quand on observe les lieux de découverte du K 113, nous constatons que ses zones d'apparition sont à peu près pareilles à celles de notre type III : le littoral de la mer Noire, le bassin égéen et la Méditerranée ${ }^{60}$. Y a-t-il eu une influence du type Agora K 113 sur notre type III, malgré un intervalle d'environ 900 années ?

Ces amphores présentent des traces particulières sur les anses ${ }^{61}$. J'avais déjà attiré l'attention sur ce fait en parlant "d'abondantes alvéoles dont l'origine, pour l'instant nous est inconnue (traces de dégraissant végétal ?)"62. Je suis maintenant en

58) Pour l'instant, comme indiqué supra dans "les types (?) principaux". Günsenin 1990 : 28-30.

59) Günsenin 1990 : cf. pl. XCI/3.

60) Voir la carte de diffusion des amphores d'Agora K 113 dans Panella 1986.

61) Günsenin 1990 : cf. pl. XL/1c et pl. L/1c.

62) Günsenin $1989: 274$. 


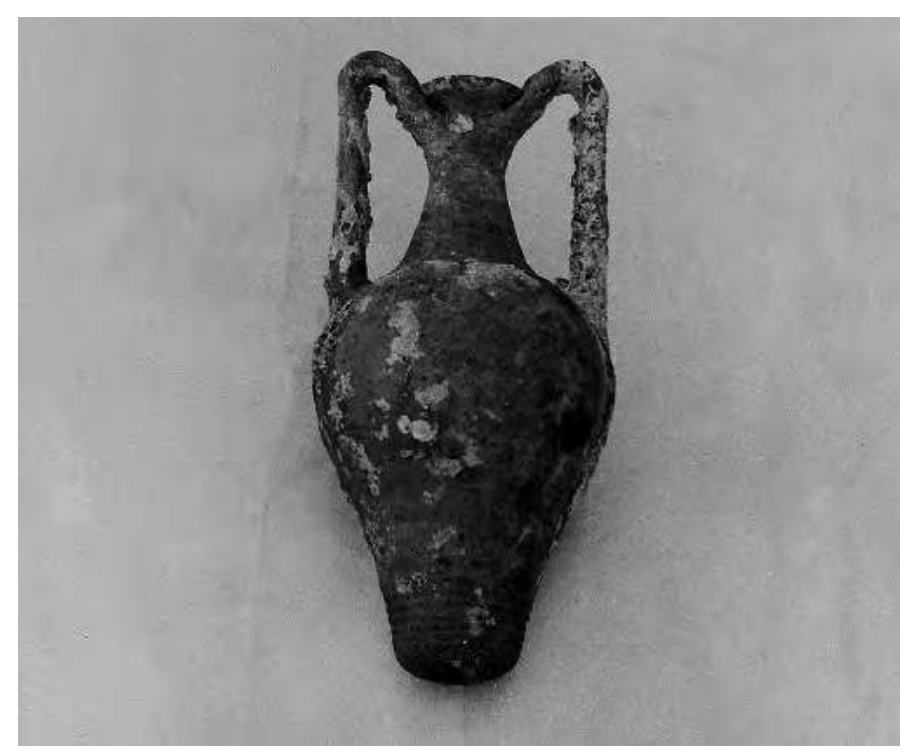

a

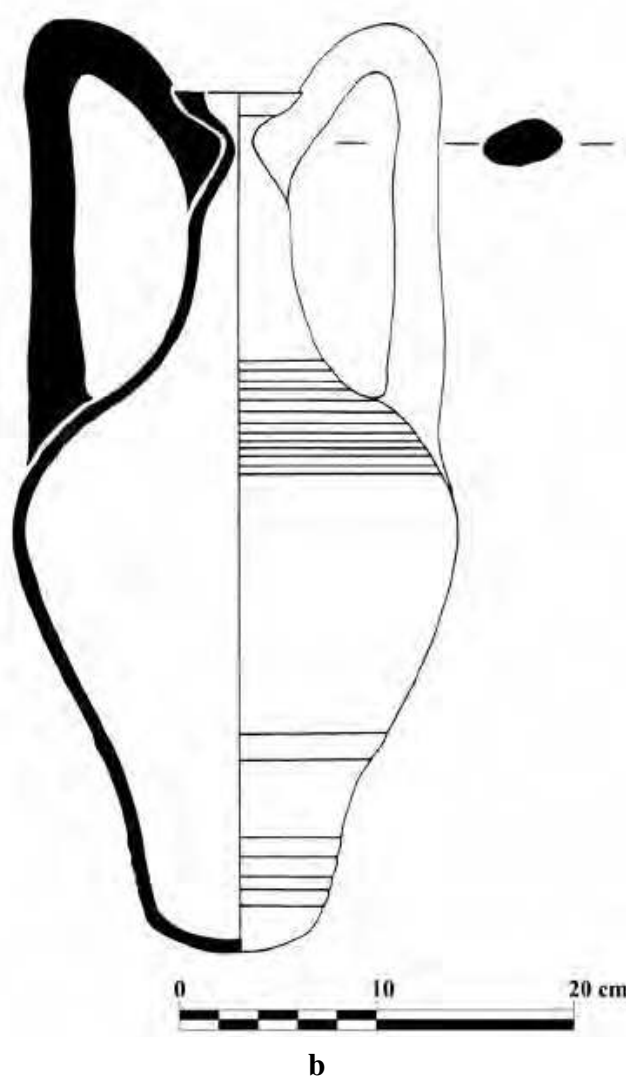

b

Fig. 8 : Amphore Günsenin II-III : a-b. Musée archéologique de Çanakkale, $n^{\circ}$ inv. 2027 (Günsenin 1990 : 128, pl. XXXVIII/1a, b).

mesure d'avancer une explication de ce phénomène qui s'observe sur les amphores de ce type, qui est le seul à porter des anses plus épaisses que les autres. Afin d'éviter que l'argile pure se casse, on a vraisemblablement ajouté des dégraissants qui introduisent une certaine flexibilité. Il pourrait s'agir de son que les potiers modernes utilisent comme dégraissant en Turquie ${ }^{63}$. Ces traces, abondantes sur chacune des amphores, indiquent une provenance commune $\underline{64}$.

Ces amphores présentent des variantes selon la forme de la panse, ainsi que des anses plus ou moins allongées. Elles sont faites d'une argile beige orangé.
Les fouilles de Paphos suggèrent pour ce type une date au début du $13^{\mathrm{e}}$ siècle ${ }^{65}$. A la lumière des trouvailles de l'Agora d'Athènes, Virginia Grace l'a également daté du $13^{\mathrm{e}}$ siècle ${ }^{66}$. John Hayes le place $\mathrm{du} 12^{\mathrm{e}}$ au $13^{\mathrm{e}}$ siècle d'après le matériel de Saraçhane ${ }^{67}$. Des exemplaires de ce type ont également été découverts dans une église située à Mstislav (St. Petersburg) datée de $1160^{68}$, ainsi que pendant la restauration du toit de Zeyrek Camii à Istanbul $\underline{69}$. Ce type est aussi attesté à Chersonèse, Odessa, et Kertsch en Crimée, alors qu'en Ukraine, on le trouve à Kiev, Tmutarakan ${ }^{70}$, Sarkela, Beloi-Vezhi ${ }^{71}$. Romanchuk indique qu'on le retrouve même au $14^{\mathrm{e}}$ siècle à Chersonèse ${ }^{72}$. Il est aussi répandu en Bulga-

63) Güner 1988.

64) Voir supra note 40.

65) Megaw 1972 : Fig. 27 et Rosser $1985: 86$, Fig. C.

66) Günsenin $1990: 306$, pl. LXXXIV/2.

67) Cf. dans Hayes 1992: 76, Type 61, Fig. 26/10, 11.

68) Yakobson 1951: Fig. 35 ; Yakobson 1979 : Fig. 68/8.

69) Le Monastère du Christ Pantokrator, édifié par Jean II Comnène et Irène en $c a$. 1118-1136. Cf. Özügül 2000.

70) Yakobson 1979 : Fig. 68/5, 6, 7 et Antonova et al. 1971 : Fig. 24 ; découverte avec des monnaies des $12^{\mathrm{e}}-14^{\mathrm{e}}$ siècles.

71) Pletneva 1959 : Fig. $31 / 5$.

72) Je la remercie pour cette information. 


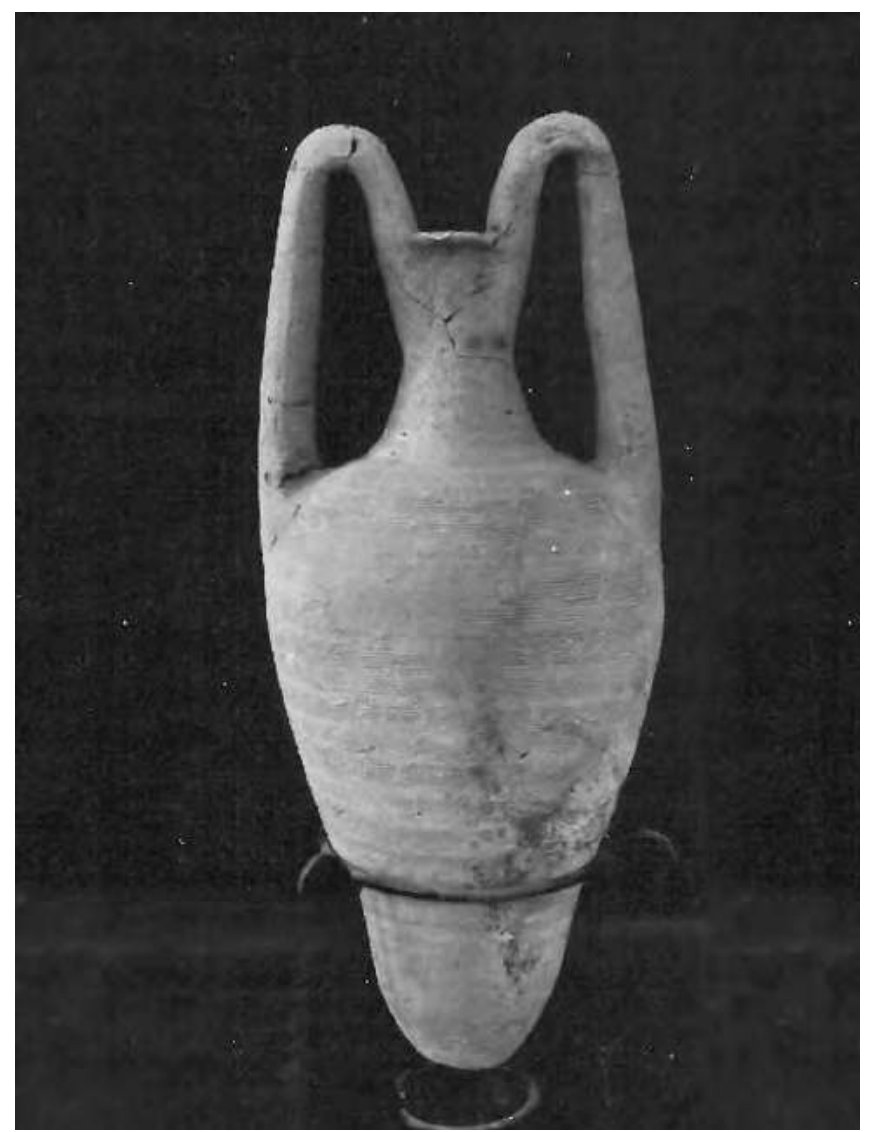

a

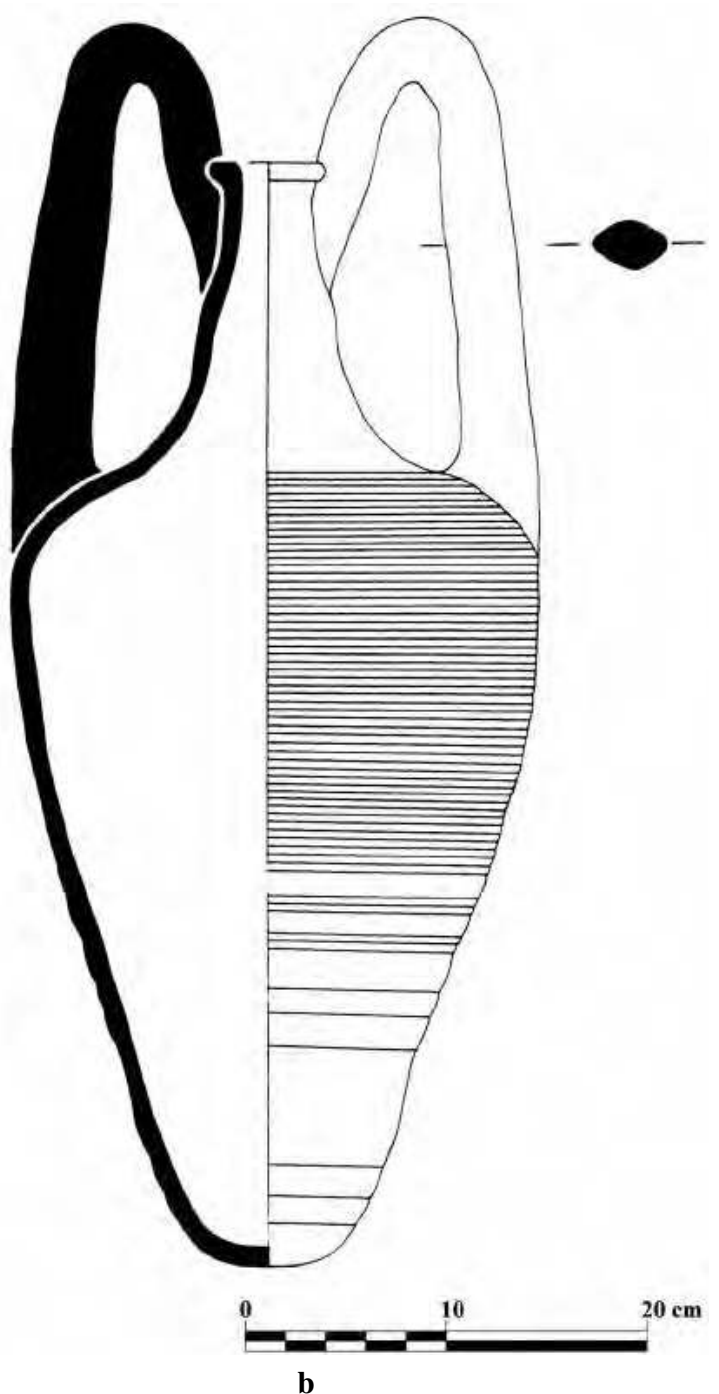

b

Fig. 9 : Amphore Günsenin III : a-b. Musée archéologique d'Amasra, ${ }^{\circ}$ inv. A/70 3.8 (Günsenin $1990:$ 214, pl. XLVII/1a, b).

rie $^{73}$ et en Roumanie ${ }^{74}$, dans la mer d'Atlit ${ }^{75}$, à Tartus en Syrie $^{76}$ et a circulé jusqu'à Otrante en Italie ${ }^{77}$. Et, il va atteindre aussi Lund et Sigtuna en Suède ${ }^{78}$.

Une dizaine d'exemplaires proviennent de l'épave de Çamaltı Burnu Iำ.

Dernièrement elles sont attestées dans les fouilles

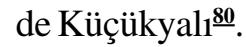

\subsubsection{Type IV}

Dans mon article issu du colloque d'Athènes, j'avais réuni les amphores de type IV dans un seul groupe tout en notant 'qu'on observe des variantes selon la forme de la panse qui peut être plus ou moins allongée ou élargie" ${ }^{81}$. A présent, j'essaierai

73) A Sozopol, Cangova 1959 : 257, Fig. 11 ; au musée de Sozopol avec un graffiti (K Y) sur la panse sous la jointure du col. Je remercie P. Gianfrotta pour ce renseignement. Lazarov 1975 : 202, Fig. 70.

74) Barnea 1967 : Fig. 159/4 (voir aussi, Barnea 1989, reprise du travail de 1967).

75) Zemer $1977:$ pl. $25, \mathrm{n}^{\circ} 74$.

76) Une épave a été découverte avec les amphores du type III à Tartus. Malgré mes efforts pour entrer en contact avec M. Ayogi, Prof. de l'Université de Tokyo, chargé de la fouille, je n'ai obtenu aucun renseignement jusqu'à maintenant. M. Al-Maqdussi m'a signalé que G. Falsone de l'Université de Palerme (à qui j'ai alors écrit) est en train de publier un article sur les amphores de l'épave. Dans une brève notice de catalogue, le professeur S. Tanabe fait état d'un nombre d'environ 1000 amphores correspondant à notre type III : The Exhibition of Great Civilization of Syria, Tokyo, 1988 : 144-147.

77) Arthur 1989 : Fig. 12.

78) Roslund $1997: 239-297,273-275$, Fig. 21.3.

79) Günsenin 2001b : 125, Fig. 9.

80) Cf. Wohmann 2016 ; Ricci et Wohmann 2018 ; Günsenin et Ricci 2018 : dans ce volume pp. 125-139.

81) Günsenin $1989: 276$, note 28 ; Günsenin $1990: 31-34$. 


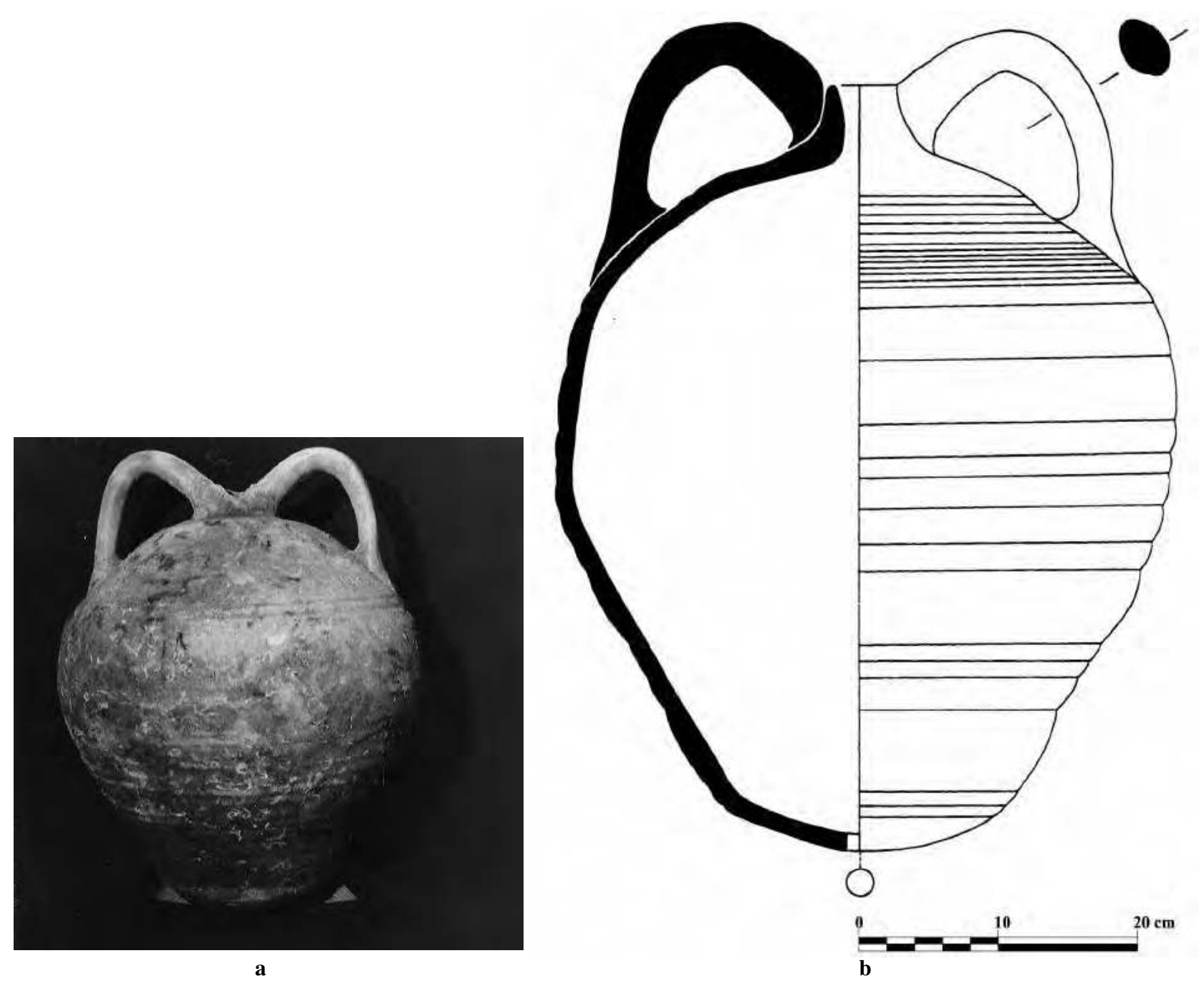

Fig. 10 : Amphore Günsenin IVa : a-b. Musée archéologique de Sinop, $\mathbf{n}^{\circ}$ inv. 34.2.80

(Günsenin 1990 : 239, pl. LVIII/1a, b).

de classifier les sous-types à partir de l'évolution des formes.

Les amphores du type $\mathbf{I V a}^{82}$ (Fig. 10) ont une panse piriforme, large à mi-hauteur, rétrécie vers le fond. Elles constituent une sorte de continuation des types I et I-IV. Les hauteurs varient entre 31 et 60 $\mathrm{cm}$ avec un diamètre de la panse de 31 à $49 \mathrm{~cm}$. La pâte est constituée d'une argile orange.

Les amphores du type IVb sont de petite taille et leur panse piriforme devient progressivement globulaire. Un exemplaire est attesté au Musée archéologique de $\operatorname{Samsun}^{83}$ (Fig. 11). Sa hauteur est de $32 \mathrm{~cm}$; le diamètre de la panse est de $27,2 \mathrm{~cm}$.
Leur pâte est constituée d'une argile orange soutenu. Un second exemplaire, quasiment identique, est conservé à Nesebar en Bulgarie ${ }^{84}$.

Les amphores du type IVc ont une taille très réduite et une anse plutôt globulaire. J'ai un seul exemplaire de ce type au Musée archéologique de Samsun $^{85}$ (Fig. 12). Son hauteur est de $29 \mathrm{~cm}$ et le diamètre de la panse $24 \mathrm{~cm}$. Leur pâte est constituée d'une argile beige orangé.

Les amphores du type IVd (Fig. 13) ont une taille plus importante que les types IVb et IVc et leur panse commence à prendre un aspect conique. Les hauteurs varient entre 41 et $45 \mathrm{~cm}$ et le diamètre de la panse

82) Günsenin $1990: 31$.

83) Günsenin $1990: 31$ et 261, pl. LIX/1a, b.

84) Cf. infra note 96.

85) Günsenin $1990: 32$ et 262, pl. LIX/2. 


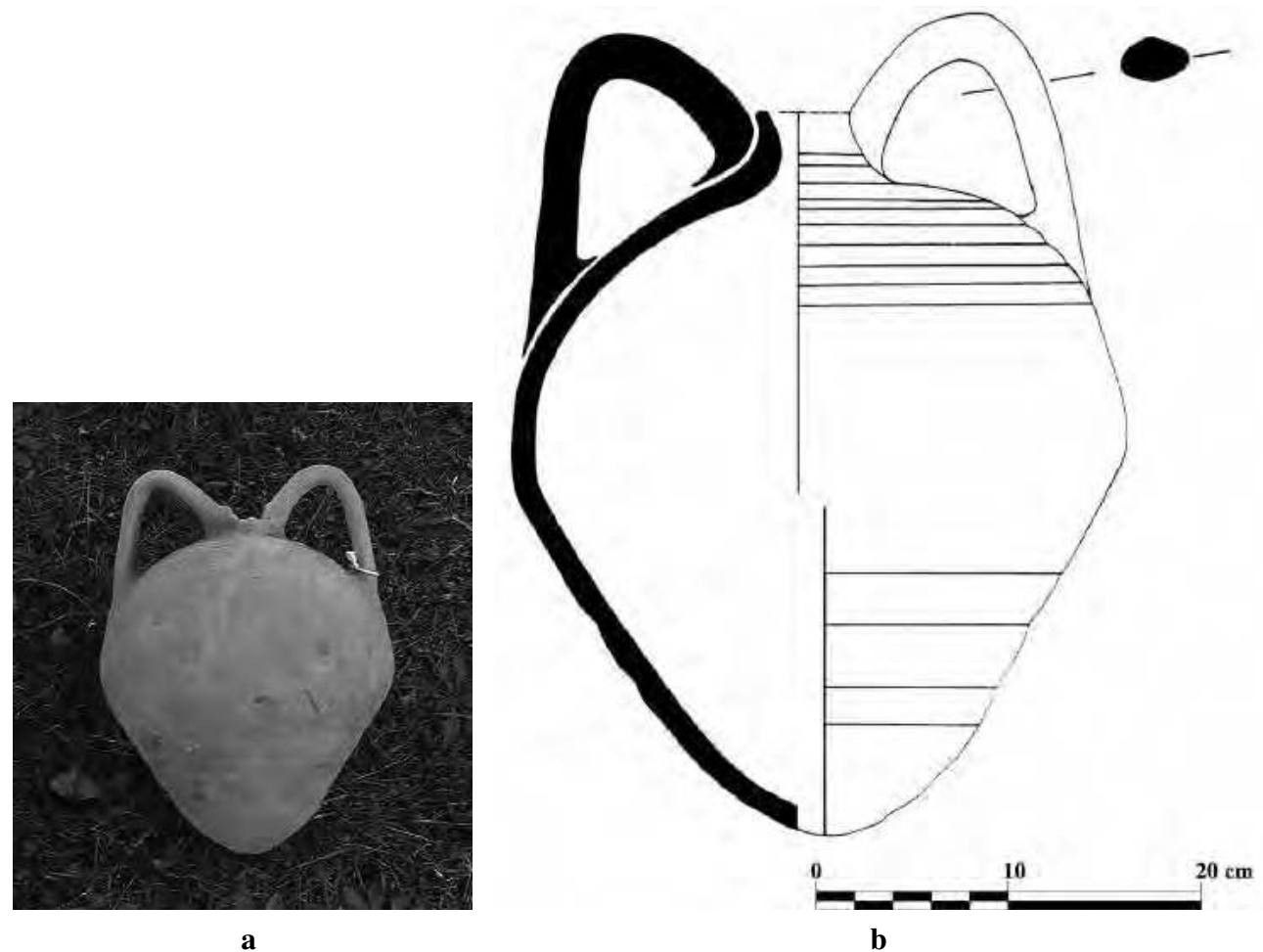

Fig. 11 : Amphores Günsenin IVb : a-b. Musée archéologique de Samsun, ${ }^{\circ}{ }^{\text {inv. 8.7.1981 }}$ (Günsenin 1990 : 261, pl. LIX/1a, b).

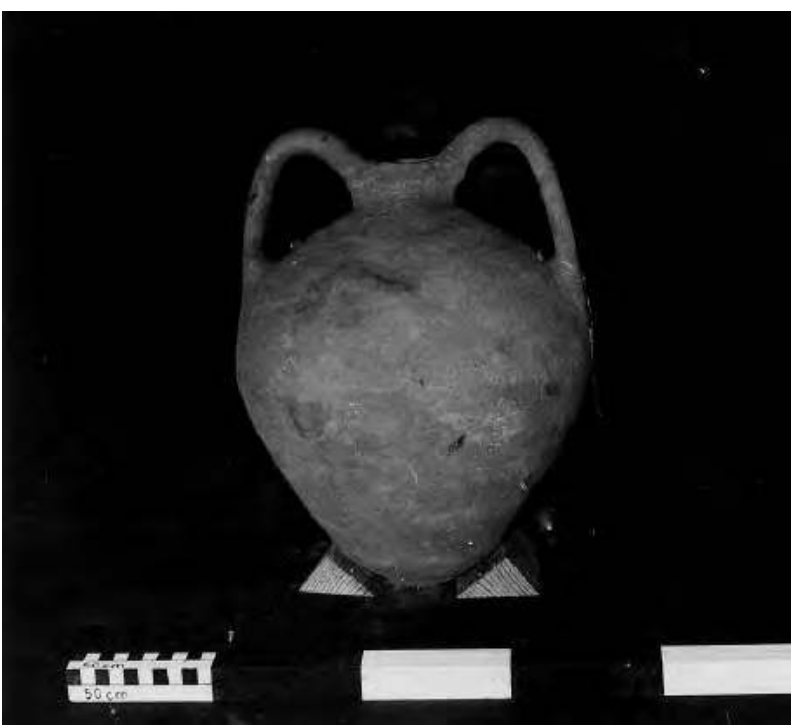

Fig. 12 : Amphore Günsenin IVc : Musée archéologique de Samsun, $n^{\circ}$ inv. 2.5.1983 (Günsenin $1990: 262$, pl. LIX/2). entre 32 et $38 \mathrm{~cm}$. Elles sont aussi très peu attestées ${ }^{86}$. Je connais un autre exemplaire au Musée de Sinop ${ }^{87}$. Leur pâte est constituée d'une argile beige orangé.

Les amphores du type IVe ont une panse allongée à partir d'épaules larges. Leur hauteur moyenne est de $61-63 \mathrm{~cm}$; le diamètre des panses de 48,5-50 cm. Deux exemplaires de ce type au Musée archéologique de Samsun qui portent des timbres au bas de l'anse, dont l'un est inscrit (Fig. 14) ${ }^{88}$. Et un autre exemplaire avec une taille réduite au Musée de Sinop ${ }^{89}$. Leur pâte est constituée d'une argile beige orangé.

Les amphores du type $\mathbf{I V f}^{90}$ (Fig. 15) ont une panse conique, très large à mi-hauteur avec une haute épaule convexe, un col court et des anses qui dépassent l'embouchure et s'y raccordent directement. Des stries décorent toute la panse. Elles sont assez serrées au niveau du col jusqu' à mi-panse. Les hauteurs sont autour de $50 \mathrm{~cm}(+5-6 \mathrm{~cm})$ et les diamètres des panses sont en homogénéité avec les hauteurs, ce qui explique la forme conique. Leur pâte est constituée d'une argile beige orangé.

86) Günsenin $1990: 32$ et 153, pl. LX/1a, b (Günsenin 1989 : Fig. 12).

87) Günsenin 1990 : 240, pl. LX/2a, b.

88) Günsenin 1990 : 263, pl. LXI/1a, b, c, d, e et 264, pl. LXII/2a, b, c, d.

89) Günsenin $1990: 241$, pl. LXII/1.

90) Günsenin $1990: 32$ et 242, pl. LXIV/1a, b. Voir les détails des dessins dans, ibid., pl. LXV/1a, b, c, d, e, f, g, h, i ; pl. LXVIa/1a, b, c et LXVIb. 


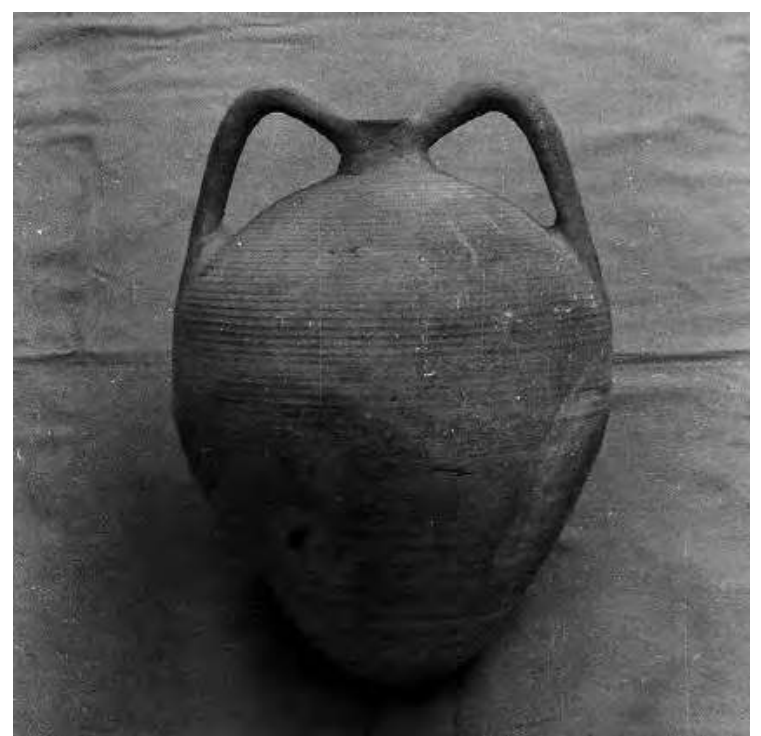

$\mathbf{a}$

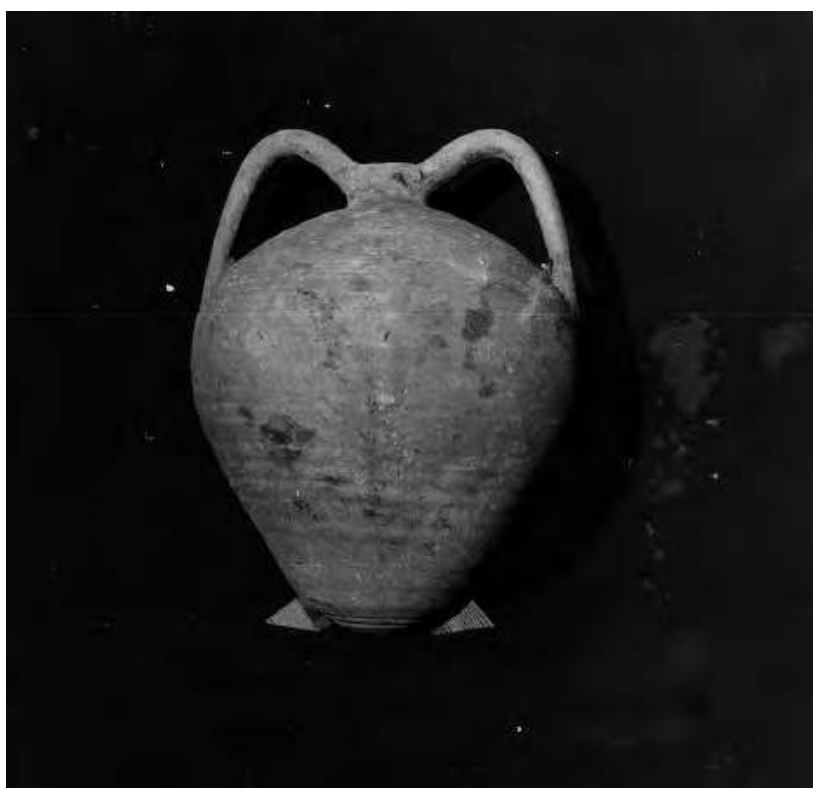

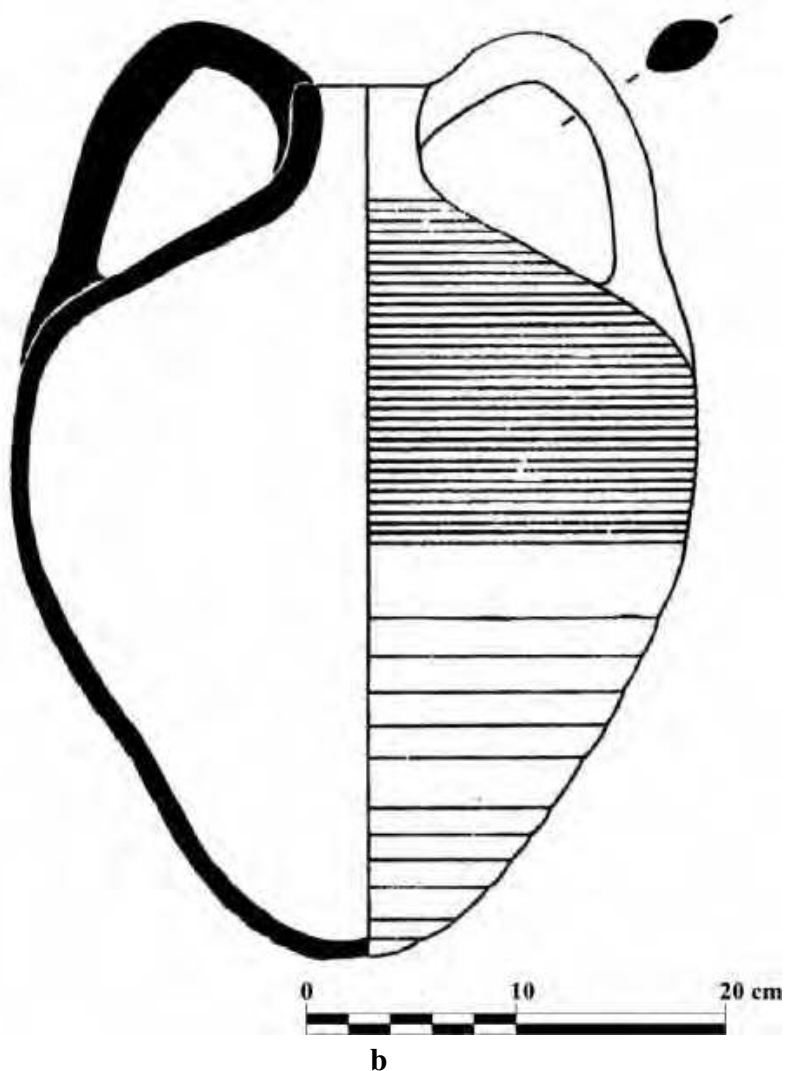

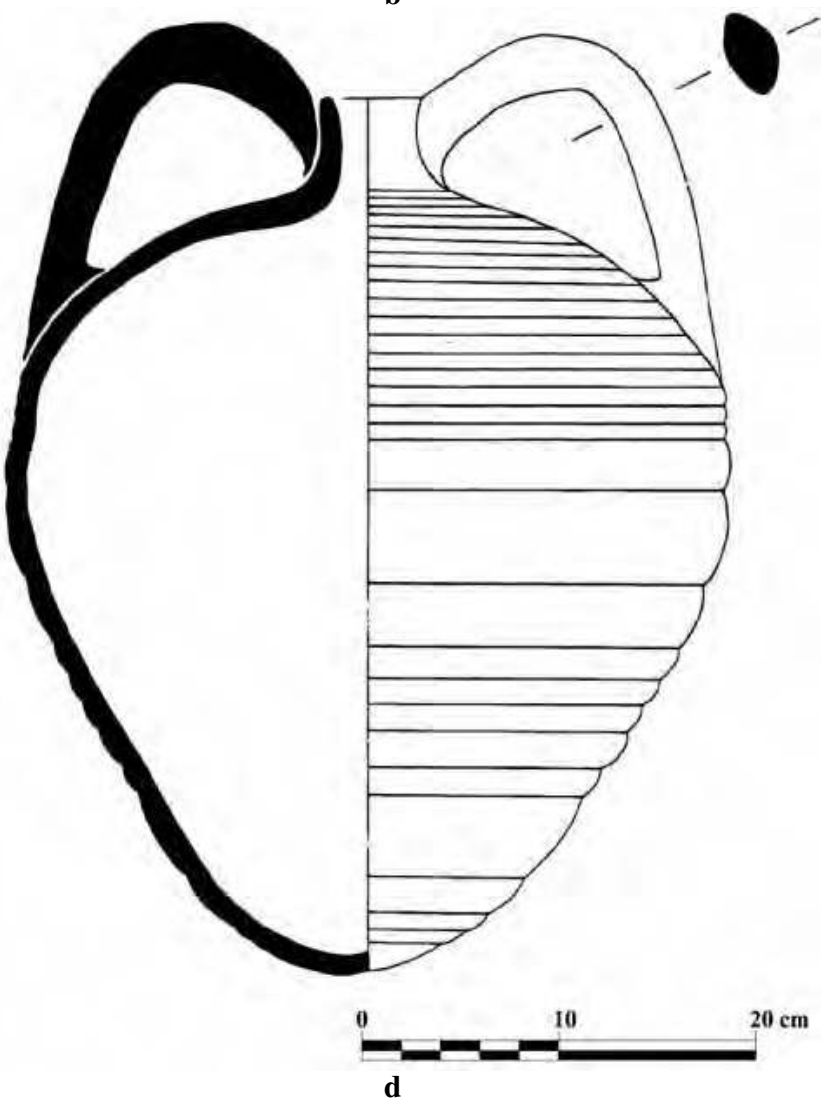

Fig. 13 : Amphores Günsenin IVd : a-b. Musée archéologique de Tekirdağ, ${ }^{\circ}$ inv. 349 (Günsenin 1989 : 275, Fig. 12 et Günsenin 1990 : 153, pl. LX/1a, b) ; c-d. Musée archéologique de Sinop, $\mathbf{n}^{\circ}$ inv. 22.1.82 (Günsenin 1990 : 240, pl. LX/2a, b). 


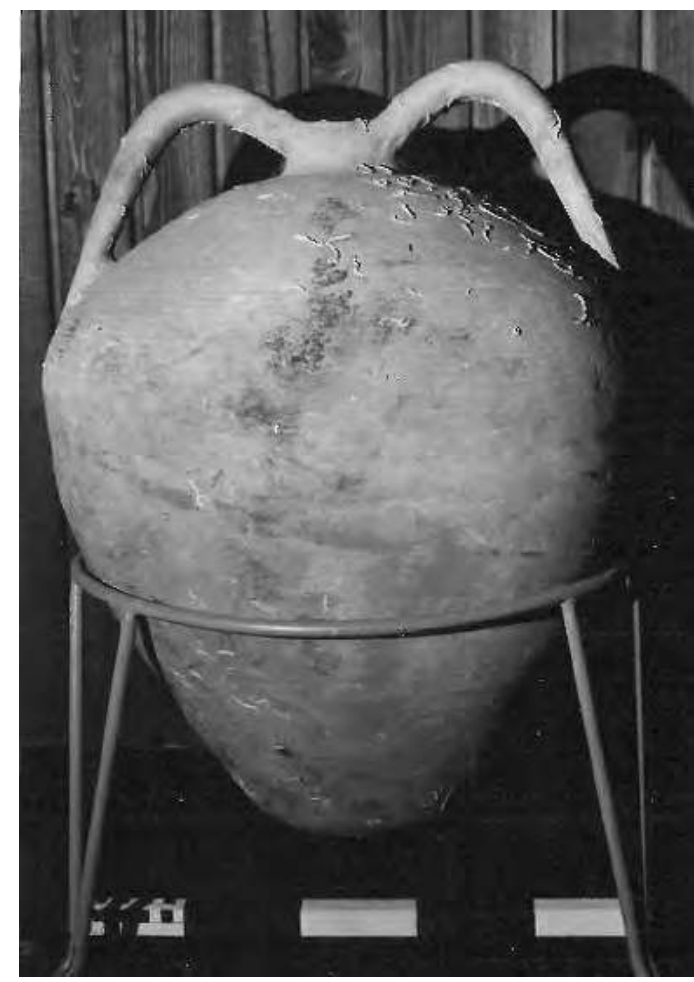

a
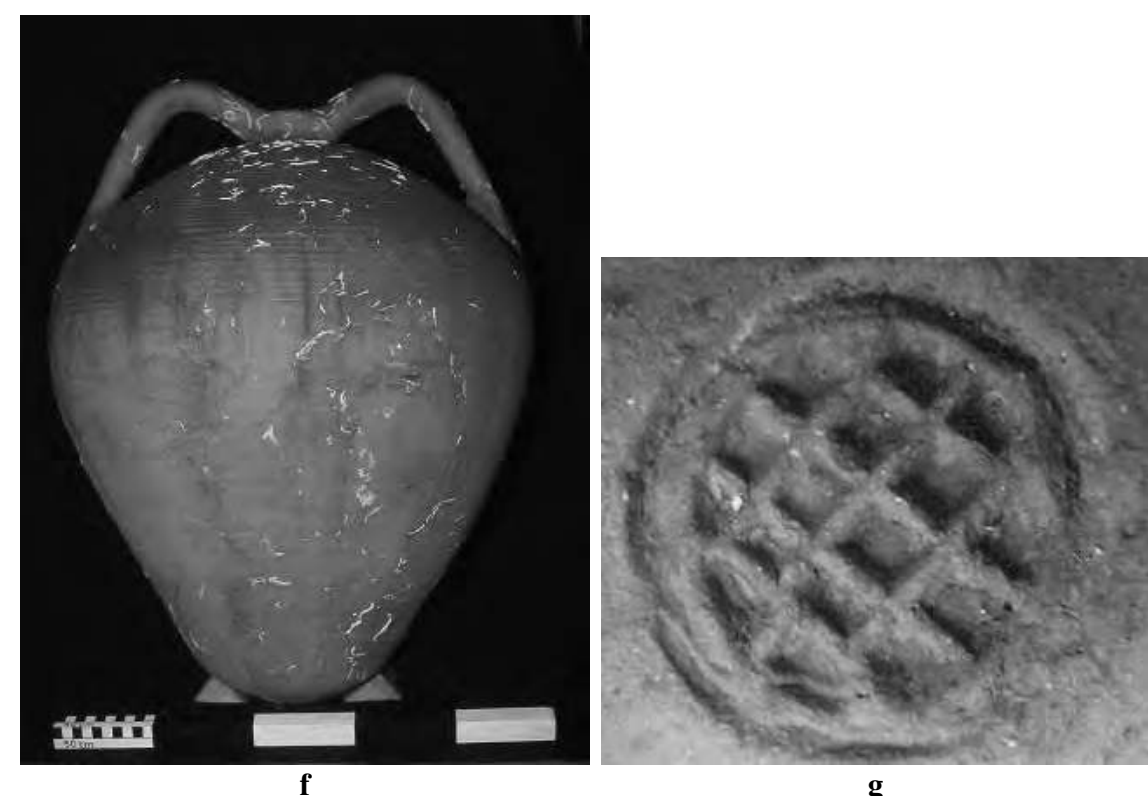

g
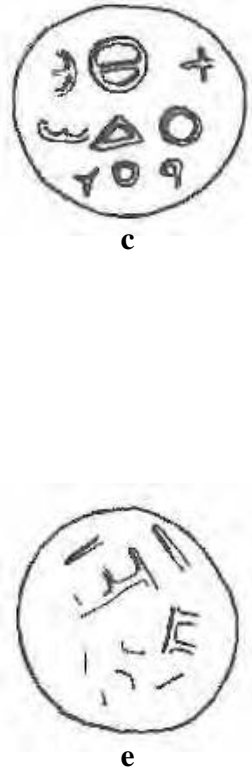

Fig. 14 : Amphores Günsenin IVe : a-b-c-d-e. Musée archéologique de Samsun, ${ }^{\circ}$ inv. 3.2.1983 (Günsenin $1990: 263$, pl. LXI/1a, b, c, d, e) ; f-g-h. Musée archéologique de Sinop, $\mathbf{n}^{\circ}$ inv. 13.5.1982 (Günsenin 1990 : 264, pl. LXII/2a, c, d). 


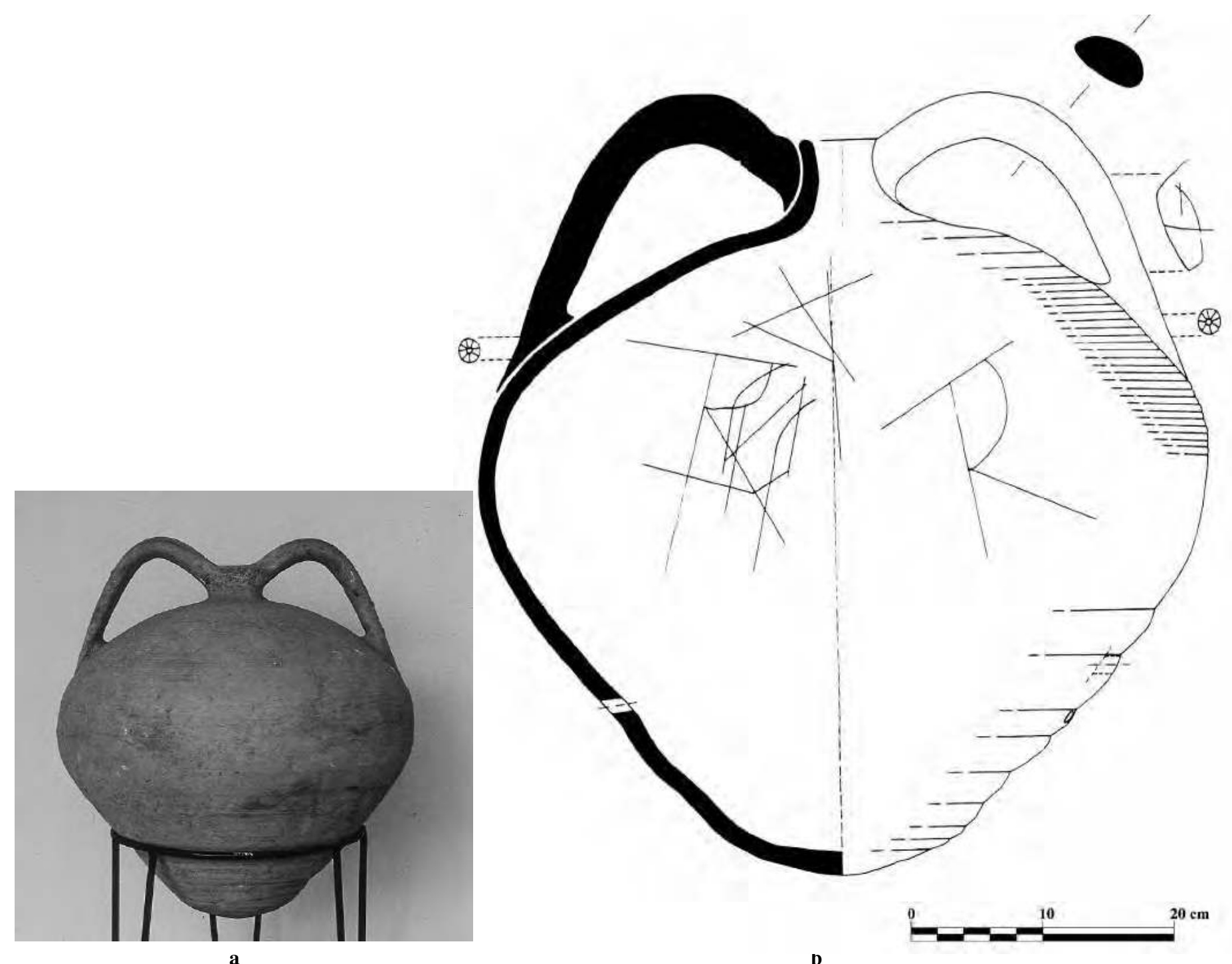

Fig. 15 : Amphore Günsenin IVf : a-b. Musée archéologique de Sinop, ${ }^{\circ}$ inv. 3.24.73/1665 (Günsenin 1990 : 242, pl. LXIV/1a, b).

Dernièrement le type IVf est attesté dans les fouilles de Küçükyalı comme indiqué en bas.

Les types IVa et IVf sont les formes les plus répétitives et les plus répandues parmi les variantes. En l'absence d'une fouille d'atelier ou d'une épave로 on se pose la question de savoir si ces productions sont contemporaines ou étalées dans le temps. On pourrait admettre peut-être que le type IVa est plus ancien que les autres.

En l'état actuel de nos connaissances, toutes ces variantes ont à peu près la même date. Leur pâte varie du marron au rouge orangé et la texture de la pâte est homogène, ce qui pourrait indiquer une production commune.

Nous constatons que ces amphores sont apparues à partir du $12^{\mathrm{e}}$ siècle et ont circulé jusqu'au $15^{\text {e }}$ siècle $^{92}$. Dans les fouilles effectuées à Paphos, on les a datées du début du $13^{\mathrm{e}}$ siècle. D'après les renseignements fournis par Romanchuk, une grande quantité de ces amphores se trouve au musée d'Asaka-Tana en Crimée orientale et appartiennent au $14^{\mathrm{e}}-15^{\mathrm{e}}$ siècle $^{93}$. L'auteure ne donne guère d'information pour leur production.

91) La fouille de l'épave de Çamaltı Burnu I n'a débuté qu'en 1998, huit ans après la rédaction de ma thèse de doctorat !

92) Megaw 1972 : Fig. 23 (IVa).

93) Je la remercie pour cette information. On ne peut pas dire de quelles variantes elle parle car elle fait ses commentaires d'après mon article de 1989 où je n'avais pas encore mentionné les sous-types. 
Des amphores de ce type ont été découvertes à Chersonèse, Balaklava, Eski-Kermen, Sarkel et Kertsch $^{94}$, dans le Sud-Ouest de la Crimée ${ }^{95}$, à Novogrod $^{96}$, en Bulgarie ${ }^{97}$, en Roumanie ${ }^{98}$, en Yougoslavie dans la région du Danube ${ }^{99}$. Hayes a décrit Günsenin IV comme Type 62 d'après le matériel de Saraçhane $\frac{100}{}$.

La seule épave fouillée avec une cargaison contenant des amphores du type IV est celle de Çamaltı Burnu I. Reprenons mes observations dans ma publication de 2001: "la cargaison principale est constituée par des amphores du type Günsenin IV qui sont les dernières céramiques utilisées pour le transport maritime de marchandises avant leur remplacement par les tonneaux (malgré leur grande taille, la paroi d'argile est très fine, ce phénomène pouvant s'expliquer comme une transition vers le tonneau). Ces amphores présentent une grande variété de dimensions et de capacités. Il est possible que les différentes capacités des amphores représentent les multiples d'une unité standard de capacité, comme il a été démontré pour les capacités des amphores de l'épave de Serçe Limanı; des mesures plus précises sont nécessaires pour s'en assurer $101 . . . . "$

En effet, les mesures plus précises qu'on a commencé à prendre avec van Doorninck sur un échantillon de neuf amphores parmi les centaines montrent déjà l'existence de huit tailles/volumes. Je voudrais vous informer avec grand plaisir que nous avons lancé un projet en collaboration sur les amphores de la cargaison de l'épave de Çamaltı Burnu I. Van Doorninck a déjà une immense expérience qui lui vient notamment de sa bonne connaissance des amphores des épaves de Yassiada, Bozburun, et Serçe Limanı. Notre premier séjour au musée de Bandirma en décembre 2016 pour une semaine, où sont conservées les trouvailles de la fouille, a été très productif. Il a été très passionné par le fait qu'il pouvait observer une continuité dans tous les sens (de la métrologie) dans le monde byzantin. En attendant la publication de notre travail en collaboration, sa propre bibliographie pourra donner une idée sur l'approche que nous proposons d'entreprendre $\frac{\mathbf{1 0 2}}{}$.

Deux amphores trouvées dans la fouille de l'inhumation d'un prince turcique à Q1pčaq/Cuman/ Polovtsian dans la prairie du Sud de l'Ukraine apportent les parallèles formels les plus proches à celles de notre épave $\frac{103}{}$.

La trouvaille la plus intéressante au sujet du type IV est issue de la fouille de Küçükyalı ArkeoPark menée par les Musées archéologiques d'Istanbul sous la direction scientifique d'Alessandra Ricci depuis $2008 \underline{104}$.

Pour celles qui ont été trouvées en mer Noire, on peut consulter les recherches de Centre d'archéologie sous-marine de l'Université nationale Taras Shevchenko de Kiev노․

Rappelons que Günsenin IV a donné naissance à des "amphores de petite taille", je suppose donc qu'elles servaient de récipients de stockage ainsi que de consommation pendant le transport. Elles, aussi, présentent une grande variété de dimensions et de capacités (voir infra les types XXI et XXII).

Il me semble qu'avec les recherches en cours, on pourrait élargir les sous-types du type IV, comme en témoigne la forme des amphores de l'épave Çamaltı Burnu I.

\subsection{LES TYPES SECONDAIRES}

En dehors de ces quatre types principaux, il y a certaines amphores qui représentent presque des "types isolés", voire des formes uniques. Chronologiquement elles se rapprochent des quatre types pilotes, mais leur faible nombre interdit toute précision. Elles ont pu avoir été produites par l'un des ateliers de ces quatre types ou bien, mais cette hypothèse est moins vraisemblable, par des ateliers spécifiques.

\subsubsection{Type V}

Cette amphore qui a été trouvée à Istanbul avec un groupe de type III $^{106}$ constitue une forme unique (Fig. 16). La panse est allongée ; les anses surhaussées avec deux cannelures montent directement de

94) Yakobson 1964 : Fig. 29 ; Yakobson 1979 : Fig. 69 /1-2 (IVa), 4 (IVf), 5 (IVc) ; Antonova et al. 1971 : Fig. 25 (IVd), 26 (IVa).

95) Rudakov 1975 : pl. 4, Fig. 1 (IVa).

96) Malevskaya 1962: 238-41 (IVa).

97) A Nessebar, Cangova 1959 : 257, Fig. 12 (IVb), Lazarov 1975 : 201, Fig. 69 (IVa) ; au musée de Sozopol et Varna, renseignement aimablement fourni par P. Gianfrotta (avant ma distinction de sous-types).

98) A Dinogetia, Barnea 1967 : Fig. 159 /2 (IVa).

99) Bjelajac 1989 : Fig. 3 /3 (IVa).

100) Cf. dans Hayes $1992: 76$, Type 62, Fig. 24/12, 13.

101) Günsenin 2001b : 117-118.

102) Un article pionnier de lui, voir, van Doorninck 1994 et dans le Vol. III de Serçe Limanı qui est à paraitre.

103) Holoda et Yuriy Rassamakinb 2012.

104) Voir Günsenin et Ricci 2018 : dans ce volume pp. 125-139 et Günsenin (sous presse).

105) Zelenko 2008.

106) Günsenin $1990: 177$. 


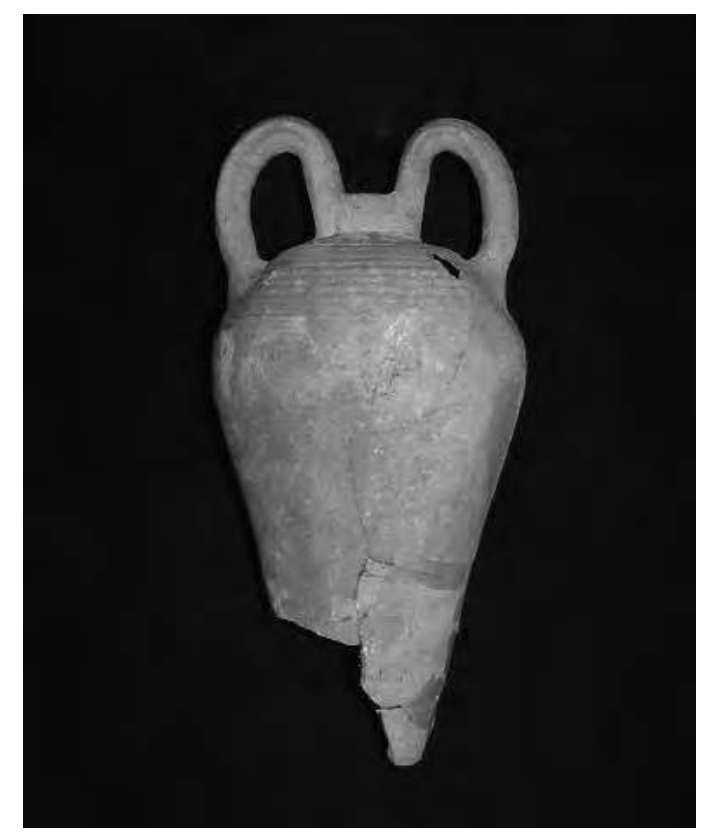

$\mathbf{a}$

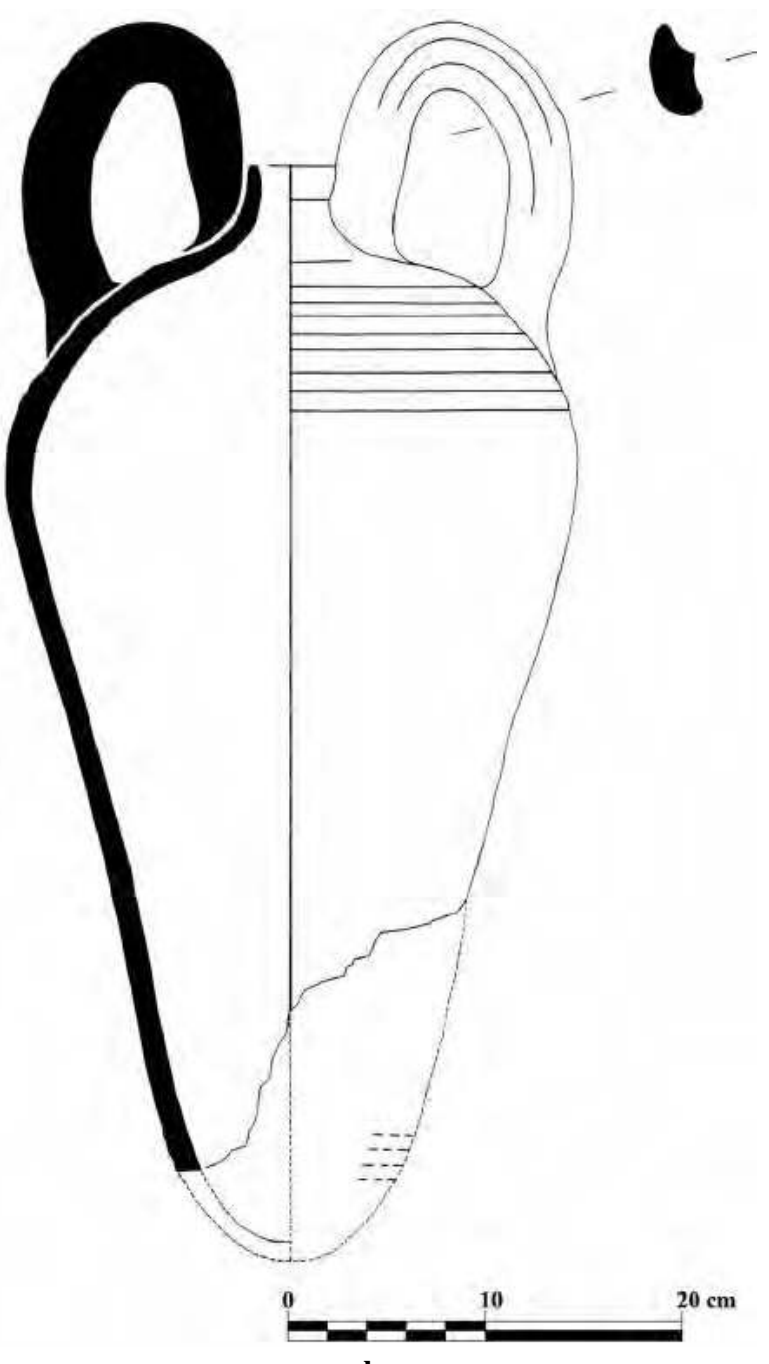

b

Fig. 16 : Amphore Günsenin V : a-b. Musées archéologiques d'Istanbul, ${ }^{\circ}{ }^{\text {inv. }}$ 86.21

(Günsenin $1990:$ 190, pl. LXIX/1a, b).

l'embouchure très étroite et se raccordent sur les épaules. Le col est très court. Les stries décorent l'épaule et le fond de la panse. La pâte est faite d'une argile orange. Elle a une hauteur d'environ $60 \mathrm{~cm}$. En plus de sa forme, la seconde particularité de ce type réside dans l'aspect de la pâte. Elle est complètement différente de celle des autres productions (nous l'avons comparée avec des échantillons représentatifs de chaque type) car elle contient du micaschiste ${ }^{107}$.

Je pense qu'il vaut mieux créer un nouveau type pour cette amphore. Son association avec des amphores de type III dans des contextes archéologiques suggère une date dans le $13^{\mathrm{e}}$ siècle.

\subsubsection{Type VI}

Ce type d'amphore a une panse ronde et renflée, décorée totalement de stries. Le col bas se termine par une lèvre. Les petites anses se raccordent entre les épaules arrondies et sous la lèvre. Les hauteurs avoisinent $40 \mathrm{~cm}$.

Je n'ai trouvé qu'un seul exemplaire de ce type au Musée archéologique de Çanakkale (Fig. 17) ${ }^{108}$. La pâte est faite d'une argile orange soutenu. Deux amphores similaires ont été découvertes à l'Agora d'Athènes ${ }^{109}$ avec des monnaies byzantines anonymes du $10^{\mathrm{e}}-11^{\mathrm{e}}$ siècle et une troisième, datée début du $12^{\mathrm{e}}$ siècle $^{110}$.

107) Günsenin $1990: 34-35$ et 190, pl. LXIX/1a, b.

108) Günsenin $1990: 35-36$ et 130, pl. LXIX/2a, b.

109) Günsenin $1990: 308$, pl. LXXXIV/3.

110) Shear $1984: 56$ et pl. 16/d. 


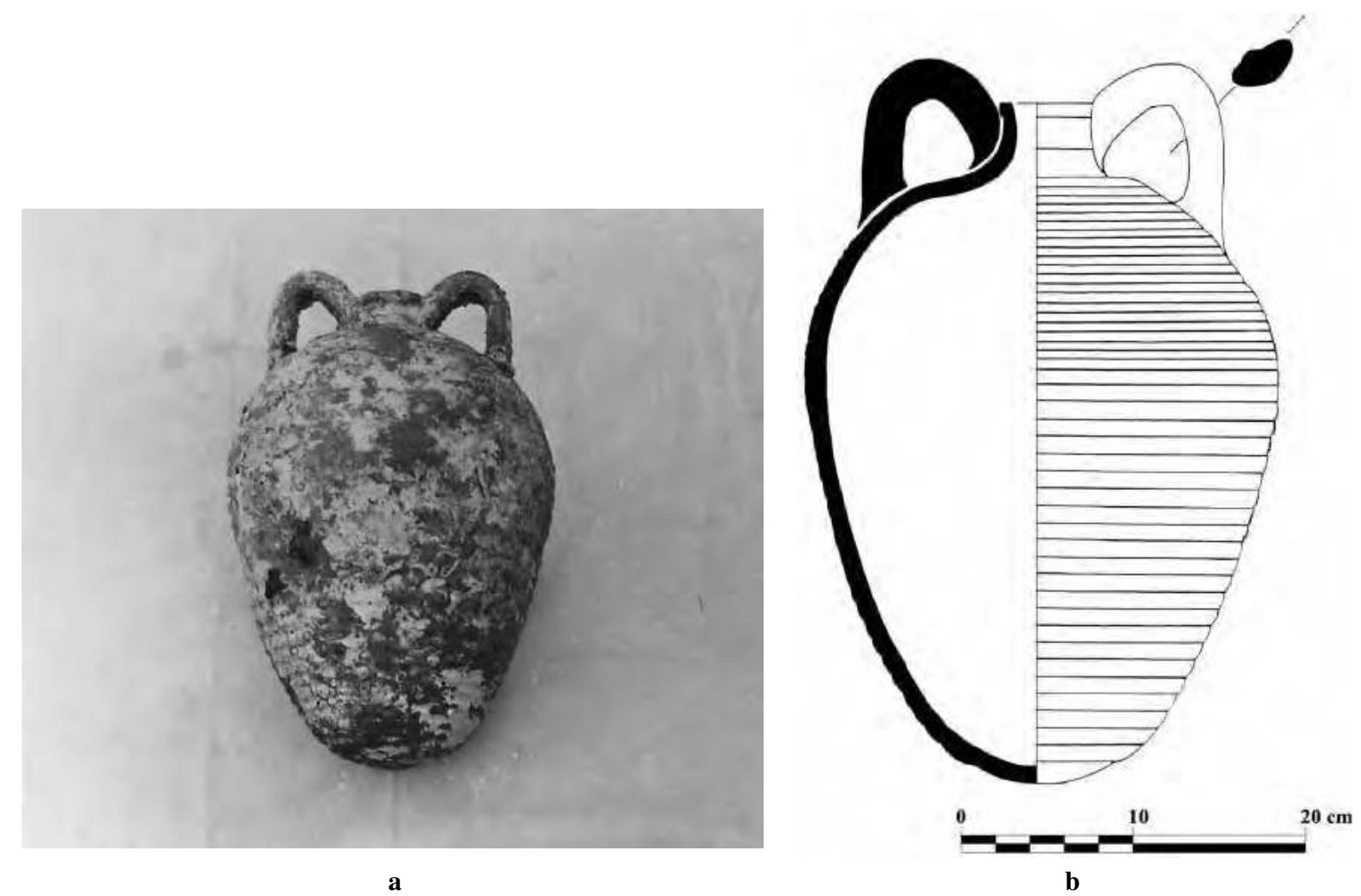

Fig. 17 : Amphore Günsenin VI : a-b. Musée archéologique de Çanakkale, $n^{\circ}$ inv. 2979

(Günsenin 1990 : 130, pl. LXIX/2a, b).

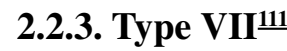

L'amphore que nous rangeons dans ce type a été découverte dans les couches médiévales de la citadelle de Ras (Fig. 18). Comme nous l'avons déjà noté, elle est de "(...) petite taille, en forme de fuseau, aux parois arrondies et au fond resserré ; l'embouchure est verticale et elle passe directement en col cylindrique. Sous l'embouchure se trouvent deux anses en forme de rubans qui se joignent à l'épaule. Sur le ventre se trouvent de larges rainures en relief qui se perdent vers le fond ; d'après les fragments retrouvés, leurs dimensions ne dépassaient pas $40 \mathrm{~cm}$. Elles sont faites de pâte résonnante et bien épurée de cuisson brun jaune, les autres fragments d'amphores correspondent ordinairement aux couches $\mathrm{du} 12^{\mathrm{e}}$ siècle et qu'on ne les retrouve pas dans les couches plus récentes qui précèdent la destruction de la citadelle de Ras (...)"112.
Elles sont aussi attestées dans la fouille de Saraçhane et sont désignées comme "twelfth to early thirteenth century types"

\subsubsection{Type VIII}

Ce type est aussi attesté dans les couches médiévales de la citadelle de Ras. Il a "(... ) les anses plantées verticalement, partant de l'embouchure qu'elles dépassent plus ou moins. Sur le ventre se trouvent de petites rainures en relief (Fig. 19). Par rapport au groupe précédent (type VII), ces amphores ont été faites de pâte moins épurée, de cuisson allant du brun au rouge et certains exemplaires portent un enduit d'engobe blanchâtre sur la surface extérieure. Les fragments de ce groupe appartiennent à quatre ou cinq amphores dont une a été trouvée sur le sol d'une maison, précisément daté du troisième quart

111) Les amphores de type VII ne sont guère attestées dans les cotes anatoliennes dans mes recherches jusqu' à présent. Il vaut mieux chercher une origine dans les sites qui sont sur le littoral de la mer Adriatique. Cf. aussi Günsenin 1990: 77, note 150. Voir Addendum.

112) Popovic $1989: 128-129$, Fig. 6/1, 2. Cf. aussi Günsenin $1990: 36-37$, pl. LXX/1a.

113) Cf. dans Hayes $1992: 76$, Type 65, Fig. 26/6 


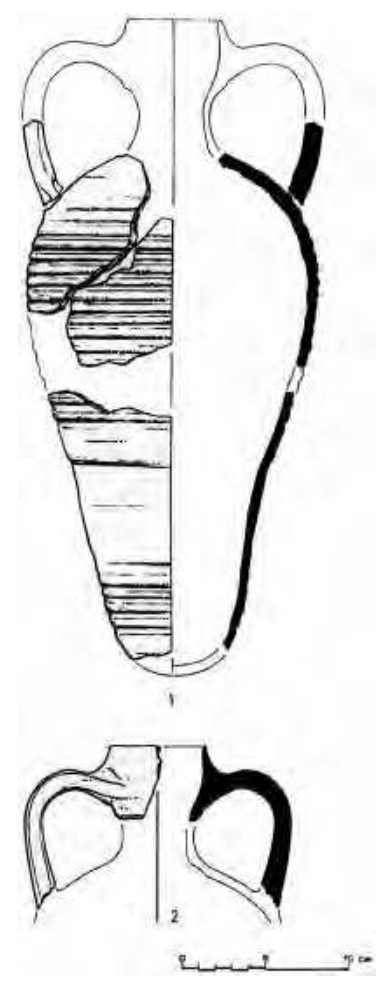

Fig. 18 : Amphore Günsenin VII : L'amphore de Ras, Serbie (Popovic 1989 : Fig. 6/1,2; Günsenin 1990 : pl. LXX1a).

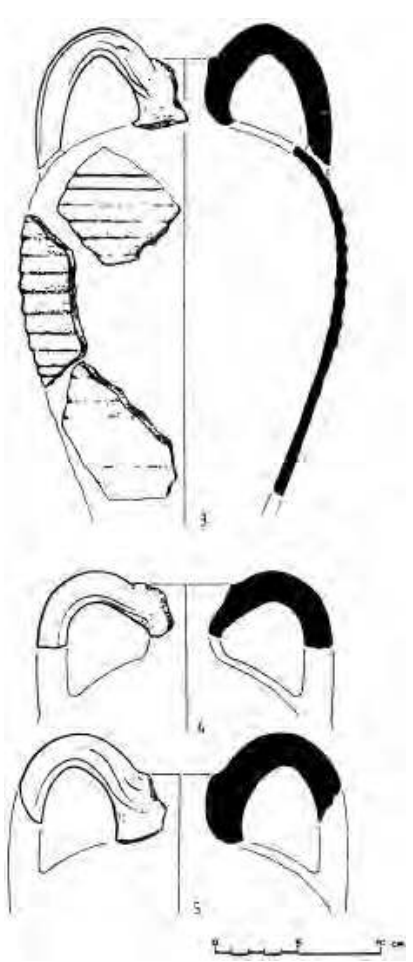

Fig. 19 : Amphore Günsenin VIII : L'amphore de Ras, Serbie (Popovic 1989 : Fig. 6/3, 4, 5 ; Günsenin 1990 : pl. LXX, 1b).

du $12^{\mathrm{e}}$ siècle (...)"114. Il vaut peut-être mieux classer le fragment d'amphore découvert dans la région du Serbo-Danube ${ }^{115}$ avec le type VIII.

\subsubsection{Type IX (Fig. 20) ${ }^{116}$}

Ces amphores de petite taille ont une panse cylindrique rétrécie vers le fond décoré par des stries.

Les petites anses à deux cannelures sortent directement de l'embouchure qu'elles dépassent en hauteur et se raccordent sur l'épaule. Leur hauteur est inférieure à $40 \mathrm{~cm}$.

Elles sont attestées dans la plupart des cas à l'Est de l'Adriatique ${ }^{117}$ et dans le cours serbe du Danube. Elles sont datées aux $12^{\mathrm{e}}-13^{\mathrm{e}}$ siècles d'après les monnaies trouvées dans la forteresse de Belgrade ${ }^{118}$.

Il me semble que deux amphores découvertes dans la rade de Marseille et en Corse du Sud appartiennent aussi à ce type ${ }^{119}$.

Enfin, je corrige mon attribution (en haut) de deux amphores découvertes dans la rade de Marseille et en Corse du Sud au type Günsenin IX. Celles-ci devraient entrainer l'identification d'un autre type $\frac{\mathbf{1 2 0}}{\mathbf{0}}$.

\subsubsection{Type $X$}

Cette amphore présente une panse oblongue, décorée de stries ; les anses partent directement de l'embouchure et se raccordent sur le haut de la panse. Les épaules sont peu marquées. Elle est attestée dans l'église d'Aphendiko à Mistra (1310) comme matériau de remplissage du mur (Fig. 21) ${ }^{121}$.

\subsubsection{Type $\mathrm{XI}$}

Ce type présente une forme conique, arrondie au niveau de l'épaule et resserrée vers le fond. Un col court, des anses petites dont la hauteur ne dépasse pas l'embouchure. Des stries espacées décorent la panse. La hauteur moyenne est de $30 \mathrm{~cm}$.

Des amphores de ce type ont été trouvées dans les fouilles d'Antioche, dans deux puits, sous des maisons datées du $11^{\mathrm{e}}$ siècle par les monnaies byzantines et croisées ${ }^{123}$. Le fouilleur J. Lassus a indiqué une date dans le $10^{\mathrm{e}}$ siècle pour le matériel des puits $^{124}$. Un autre exemplaire est attesté au Musée de Silifke (Fig. 22) ${ }^{125}$. En Croatie, il a été découvert

114) Popovic 1989 : 128-129, Fig. 6/3-5. Pour l'origine de ces deux types (type VII et type VIII), cf. les commentaires d'auteur dans ibid. : 129-130 ; Günsenin 1990 : 37, pl. LXX/1b.

115) Bjelajac 1989 : 113-115, Fig. 3/1. Voir Addendum.

116) Bjelajac 1989: 113-115, Fig. 3/2 ; Günsenin $1990: 37-38$, pl. LXXI/1. Voir Addendum.

117) Brusic 1976 : pl. IV, Fig. 5.

118) Blejac $1989:$ 114-115, Fig. 3/2.

119) Bonifay et Villedieu 1989: 43 Fig. 18 ; Bonifay et Villedieu $1985: 106-107$, Fig. 462.

120) Ici, j’exclue les amphores dans Günsenin 1990 : pl. LXXI/2, 3 !

121) Bakirtzis 1989 : pl. 39a. Günsenin $1990: 38$. Voir Addendum.

122) Les amphores du type XI à XX sont une catégorie de "petite taille". Elles ne représentaient pas, à mon avis, une vraie cargaison dans les bateaux et servaient plutôt d'ustensiles à bord. On les retrouve aussi dans des sarcophages, peut-être comme offrande funéraire. Cf. les types XI, XII, XIII et XV trouvés dans l'épave de Serçe Limanı vol. 3.

123) Günsenin $1990: 39$ et pl. LXXII/2a.

124) Waage $1948: 103$ et Fig. 96.

125) Günsenin 1990 : 90, pl. LXXII/1a. 


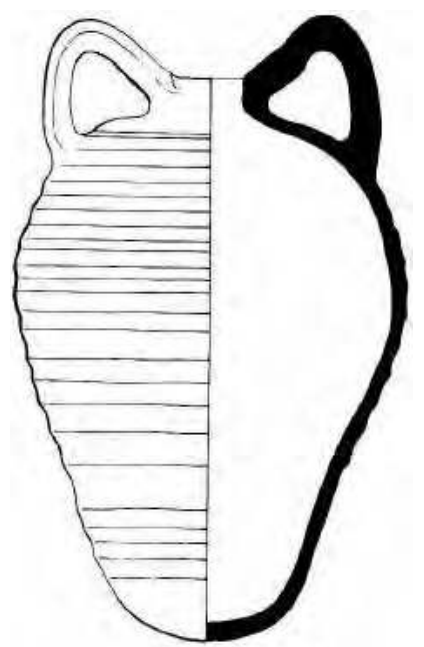

Fig. 20 : Amphore Günsenin IX : L'amphore de Serbo-Danube (?) (Bjelajac 1989 : 113-115, Fig. 3/2 ; Günsenin 1990 : pl. LXXI/1).

dans une épave à côté de l'île de Mljet ${ }^{126}$. On le trouve aussi à Tripoli au Liban ${ }^{127}$ ainsi qu'à l'Agora d'Athènes où l'amphore est associée à des monnaies byzantines anonymes du $10^{\mathrm{e}}-11^{\mathrm{e}}$ siècles ${ }^{128}$.

Finalement ; “(...) A complete and a partial example of the type were found on the Serçe Limanı Wreck. The complete jar has a capacity of 5 Byzantine silver pounds of wine, the silver pound being used to weigh silver but also in commerce with Syria. (Thus, here again, a jar especially made for commerce with Syria) (...)" 129

\subsubsection{Type XII}

Ces toutes petites amphores qui ressemblent à des miniatures du type I présentent une hauteur d'environ $25 \mathrm{~cm}$. La pâte est faite d'une argile orange. Elles sont également attestées dans les fouilles d'Antioche (comme les types I, VI et XI) où elles sont datées au $11^{\mathrm{e}}$ siècle $\mathrm{e}^{130}$. Un exemplaire est conservé au Musée de Silifke (Fig. 23) ${ }^{131}$. Et je suggère ; ainsi que, dans la galerie ouest de l'église de Sainte-Sophie à Thessalonique $\stackrel{132}{ }$.

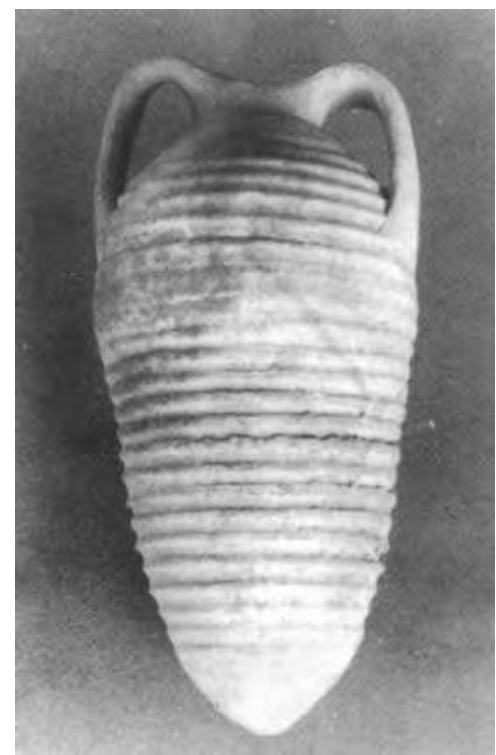

Fig. 21 : Amphore Günsenin X : L'amphore de Mistra, Grèce (Bakirtzis 1989 : pl. 39a).

Ici, je voudrais partager avec vous la contribution généreuse de van Doorninck :
“(...) I would be more than happy that you in- clude any unpublished results from my own work that would be an improvement to your work. I have just finished the text of my chapter on the Glass Wreck amphoras, a study begun over 30 years ago. I do not wish to wait until volume 3 is published for colleagues to learn about all that I have discovered... where we have learned almost all there is to know about these jars: the Glass Wreck...Known Günsenin XII jars range in size from the Silifke example that probably would contain 3 pounds of wine and is $25 \mathrm{~cm}$ high to the largest of the Serçe Limanı jars that contains 21 pounds of wine and is $35 \mathrm{~cm}$ high... The Serçe Limanı jars are of unusual importance since a majority were made to carry Byzantine pounds of wine, but some were made to carry Arab pounds of wine and thus had been made es- pecially for commerce with Muslim Syria...The Günsenin XII jars were made to carry sparkling wine.... How do we know they were made for sparkling wine? Because the juncture between shoulder and neck occurs at mid shoulder level

126) Brusic 1976, pl. IV, Fig. 3.

127) Amadouny 1973.

128) Günsenin $1990: 312$, pl. LXXXV/3. Une amphore similaire mais avec un col plus long.

129) Je remercie Frederick van Doorninck, Jr. pour le renseignement inédit. Il ajoute : "an example in a private collection in Split (Vrsalović, D. 1974: Istraživanja i zaštita podmorskih arheoloških spomenika u SR Hrvatskoj : 142 and pl. 236, near bottom-right corner of photograph)".

130) Günsenin $1990: 39-40$, pl. LXXII/2b.

131) Günsenin $1990: 39-40$ et 91 , pl. LXXII/1b. Voir Addendum.

132) Voir supra note 33, et cf. Papanikola-Bakirtzi $2002: 145$; l'amphore du milieu au premier plan de la photo d'ensemble. 


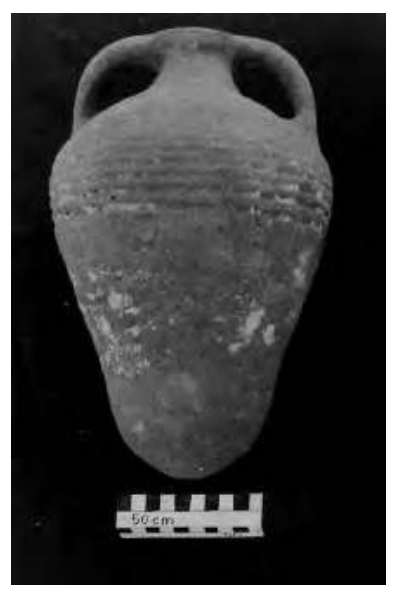

Fig. 22 : Amphore Günsenin

XI : Musée archéologique de Silifke, $\mathbf{n}^{\circ}$ inv. 2483

(Günsenin 1990 : 90, pl. LXXII/1a).

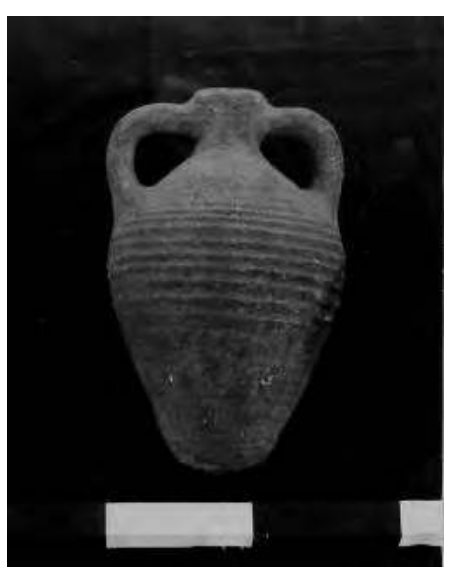

Fig. 23 : Amphore Günsenin

XII : Musée archéologique de Silifke, $n^{\circ}$ inv. 744

(Günsenin 1990 : 91, pl. LXXII/1b).

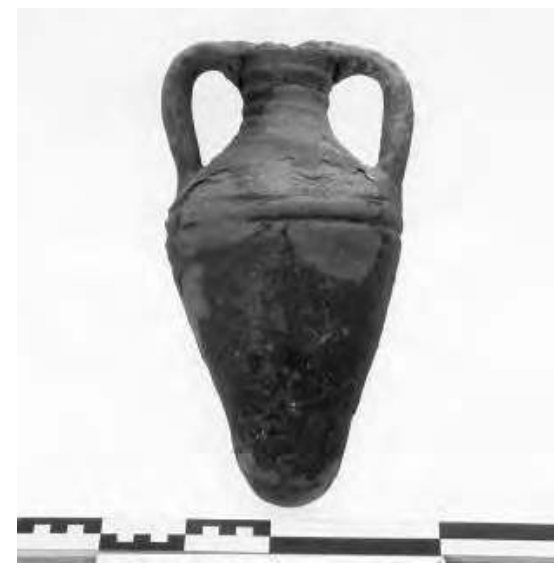

Fig. 24 : Amphore Günsenin XIII : L'amphore de l'épave de Serçe Limanı. Courtoisie F.H. van Doorninck, Jr. (van Doorninck

1988 : Fig. 1, au milieu ; Günsenin 1990 : pl. LXXII/3b). rather than at the base of the vertical neck. Such a juncture was not easily made and must have been made for an important reason. We now know that in the case of Byzantine amphoras, the jar was filled right to the neck/shoulder juncture. The extra space left in the upper shoulder in this case was to make it possible for the jar to accommodate the build up of $\mathrm{CO}_{2}$ pressure from the wine. All of the Serçe Limanı Günsenin XII jars have the neck/shoulder juncture at mid shoulder... All were possibly made in the Ganos region (...)".

“(...) They are present with Günsenin I amphoras on a shipwreck at Kötü Burun near Fethiye off the south coast of Turkey $\underline{\mathbf{1 3 3}}$, and several partial jars have been found at Ramla in Israel 134 . A complete example has been found at Caesarea $\frac{135}{}$, while a second partial jar preserved at and below the maximum diameter may be another example" $\underline{136}$.

\begin{abstract}
"Of particular interest is the presence of 'miniatures of Günsenin I jars' at sites within the region of medieval Bulgaria: in the northeast at Aegyssus [Tulcea] $\stackrel{137}{ }$, Nufăru [near Tulcea] ${ }^{138}$, possibly Pliska ${ }^{139}$; in the southeast at Stara Zagora [Beroe] and several fairly close settlements to the east $\frac{140}{}$, and Kapitan Andreevo [on border with both Greece and Turkey] (...)"
\end{abstract}

\subsubsection{Type XIII}

Le type se caractérise par une petite panse qui se termine en pointe et striée dans sa partie haute. Les anses partent du niveau de l'embouchure et se raccordent sur l'épaule. La hauteur n'atteint pas $25 \mathrm{~cm}$.

Quatre exemplaires de ce type sont attestés dans l'épave de Serçe Limanı et peuvent donc être datés du $11^{\mathrm{e}}$ siècle (Fig. 24) ${ }^{\mathbf{1 4 2}}$. La pâte est faite d'une argile brun foncé. Le type est également présent à

133) Pulak $1985: 35$ - 45, 44, Fig. 2.

134) Arnon $2007: 64-65$; Tal et Taxel $2008: 147$ et 151 , Fig. 6.95.

135) Arnon $2008: 47, \mathrm{n}^{\circ} 853: 54$, type $853: 309$, type $853 \mathrm{c}$.

136) Brosh $1986: 87$ et 86 , pl. 5.6. Unfortunately, the jar is described only briefly without dimensions, but its somewhat pronounced piriform shape similar to that of Am 89, the same kind of decorative grooving on its body, and the brief description 'brick ware; white grits; buff slip' in combination inclines me to think that it probably is a Günsenin XII amphora.

137) Complete jar from hut: Vasiliu et Mănucu-Adameşteanu 1984 : 148, 544, pl. III.5, et 550, pl. IX.5.

138) Damian et al. $2007: 118$ et 146, Fig. 23, bottom.

139) Lower part of two jars with maximum diameters of about 0.245 : Antonova et Demjanov $1969: 32$ et 36, Fig. 6.13-14.

140) Complete jar excavated in Beroe : Borisov $2002: 24,27$, Fig. 7, and 237, catalog $n^{\circ} 1$; fragmentary remains from excavations in settlements of Djadovo, Karanovo, Znamenos, Iskrica, and P. Gradec: ibid. : 27. "Maritsa-Iztok". Archaeological Research, Vol 6. Radnevo.

141) Partial jar from settlement: Grozdanova $2009: 248$, Fig. 2/3, et 249.

142) Je remercie Frederick van Doorninck, Jr. pour cette photo. 
Antioche (cf. types I, VI, XI, XII), où on retrouve la même datation.

\section{Retournons à la contribution généreuse de van Doorninck :}

“ (...) This jar type is turning out to be of great interest. It is presently known, as you state, from 2 sites: the Glass Wreck and Antioch. We believe, partly because of the hull construction and the wood used, that one of the most likely places where the Glass Wreck ship might have been built is the Antioch region. Thus, it is of considerable interest that the fabric of the Günsenin XIII jars on the ship has the same visual appearance as does that of the ship's own cooking pots and a majority of the ship's storage jars. The fabric core color is light brown (7.5 YR 6/4); the surface where least discolored is brown to light brown (7.5 YR 4/4 to 6/4) (...) This type of jar does not attain a height of 25 $\mathrm{cm}$, yet the 3 complete jars of this type from the Glass Wreck have a height of 29.9, 30.8 and 32.2 $\mathrm{cm}$ (...) There are 4 examples of this jar type from the Glass Wreck. 3 of the jars have complete bodies. One of them carried 5 regular Byzantine pounds (logarikai litrai) of wine, but the other 2 carried 5 silver Byzantine pounds (argyrikai litrai) of wine and thus had been made especially for commerce in Syria (...)".

\subsubsection{Type XIV}

Cette amphore qui ressemble au type XIII, sauf pour les anses qui sont plus rondes et le col plus mince, a été trouvée à Istanbul (Fig. 25) ${ }^{143}$ dans un puits avec le type III ${ }^{144}$. La pâte est faite d'une argile rouge brique. Cette trouvaille indiquerait une date dans le $13^{\mathrm{e}}$ siècle d'après les amphores du type III, mais sa ressemblance avec les amphores du type XIII milite pour une date plus récente.

\subsubsection{Type XV}

Une petite panse ronde, décorée de stries et un col bas se terminant par une lèvre. Les anses arron- dies partent du col, dépassent légèrement le niveau de l'embouchure et se raccordent à l'épaule. La hauteur est d'environ $30 \mathrm{~cm}$. Ce type est présent aux Musées archéologiques d'Istanbul (Fig. 26) ${ }^{145}$. La pâte est faite d'une argile orange. Deux exemplaires semblables ont été trouvés à l'Agora d'Athènes ${ }^{146}$. Le premier est associé à des monnaies d'Alexis $\mathrm{I}^{\mathrm{er}}$ (1081-1118) et Manuel I ${ }^{\text {er }}(1143-1180)^{147}$.

Un seul exemplaire de ce type est aussi attesté dans l'épave de Serçe Limanı $\frac{148}{}$.

\subsubsection{Type XVI}

Une panse plutôt cylindrique, décorée de stries au niveau de l'anse et du fond. Petites anses rondes dépassant légèrement la lèvre. Environ $38 \mathrm{~cm}$ de hauteur. Type isolé aux Musées archéologiques d' Istanbul (Fig. 27) ${ }^{149}$. La pâte est faite d'une argile beige orangé. On peut la rapprocher du type XV et, peut-être, d'une amphore trouvée à l'Agora d'Argos datée de la fin du $11^{\mathrm{e}}$-début du $12^{\mathrm{e}}$ siècle $^{150}$.

\subsubsection{Type XVII}

Petite panse conique, anses rondes se raccordant à l'épaule et sous l'embouchure. Le haut de la panse est décoré de stries. La hauteur ne dépasse pas 30 $\mathrm{cm}$.

Un exemplaire provient de l'Agora d'Athènes (Fig. 28) ${ }^{151}$. La pâte est faite d'une argile beige chamois. Une amphore similaire a été découverte dans une tombe nomade datée du $11^{\mathrm{e}}-13^{\mathrm{e}}$ siècle à Skadovsk sur la côte nord de la mer Noire ${ }^{152}$. J'ai aussi identifié ce type au Musée archéologique d'Antalya. L'amphore en question de provenance inconnue est exposée dans les salles du musée ${ }^{153}$.

\subsubsection{Type XVIII}

Petite panse conique décorée de stries. Col et embouchure larges, petites anses coniques se raccordant à l'épaule et sous l'embouchure. La hauteur moyenne est de $30 \mathrm{~cm}$. Cette amphore figure parmi

143) Günsenin $1990: 40$ et 191, pl. LXXIII/1.

144) Günsenin $1990: 187,194$, cf. les amphores n ${ }^{\circ}$ inv. 9821-5 et 9821-7.

145) Günsenin $1990: 41$ et 192, pl. LXXIII/2. Le n ${ }^{\circ}$ d'inventaire de cette amphore n'est pas connu.

146) Günsenin $1990: 313$ et 314, pl. LXXXVI/1 et pl. LXXXVI/2.

147) Cf. aussi, Brusic 1976 : p. XI/2, l'amphore découverte à Mljet et l'amphore qui se trouve au Musée de Durrësit en Albanie ; Tartari 1982 : 263, Fig. 24b. Ces amphores adriatiques pourraient être mises dans la même famille du type XV. Voir Addendum.

148) Pour les trouvailles récentes en mer Adriatique voir infra la note 183.

149) Günsenin $1990: 41$ et 193, pl. LXXIII/3. Le nº d'inventaire de cette amphore n'est pas connu.

150) Piérart et Thalmann $1980: 477$, pl. V, Fig. B1.

151) Günsenin $1990: 42$ et 315, pl. LXXXVI/3a, b.

152) Arkeologija Ukrainskoj 1986 : Fig. 120/1, Vol. 3, Kiev.

153) Günsenin $1990:$ pl. LXXIII/4. 


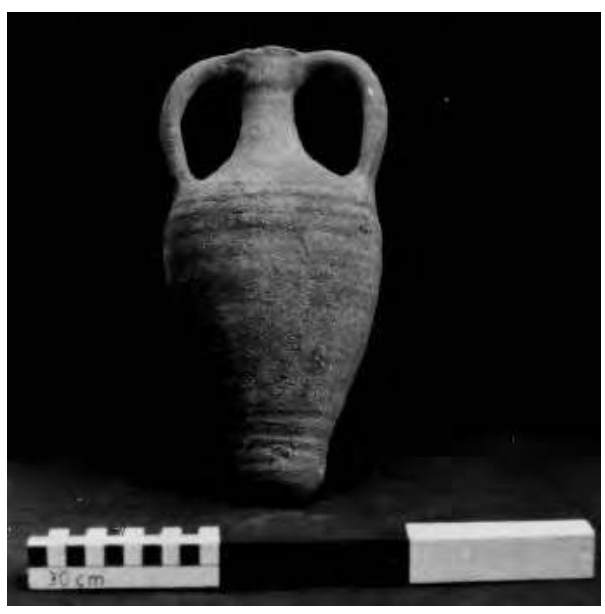

Fig. 25 : Amphore Günsenin XIV : Musées archéologiques d'Istanbul, $\mathbf{n}^{\circ}$ inv. 9821-2

(Günsenin 1990 : 191, pl. LXXIII/1).

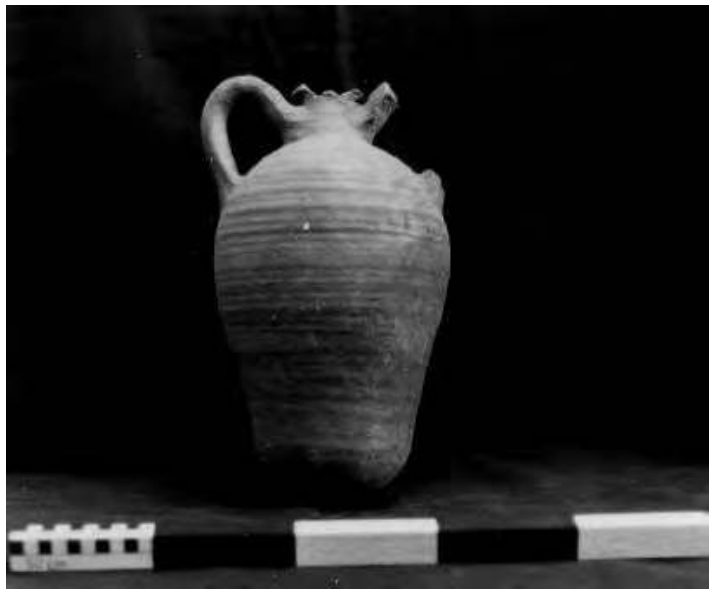

Fig. 26 : Amphore Günsenin XV : Musées archéologiques d'Istanbul, $\mathbf{n}^{\circ}$ inv. inconnu (Günsenin 1990 :192, pl. LXXIII/2).

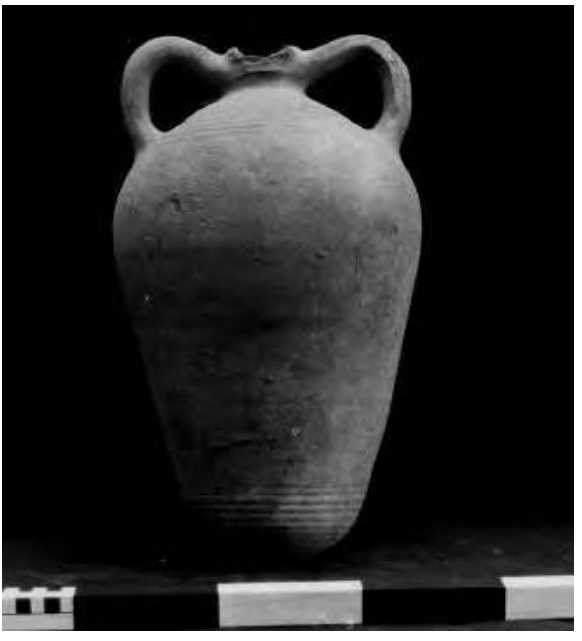

Fig. 27 : Amphore Günsenin XVI : Musées archéologiques d'Istanbul, $\mathbf{n}^{\circ}$ inv. inconnu

(Günsenin 1990 : 193, pl. LXXIII/3).

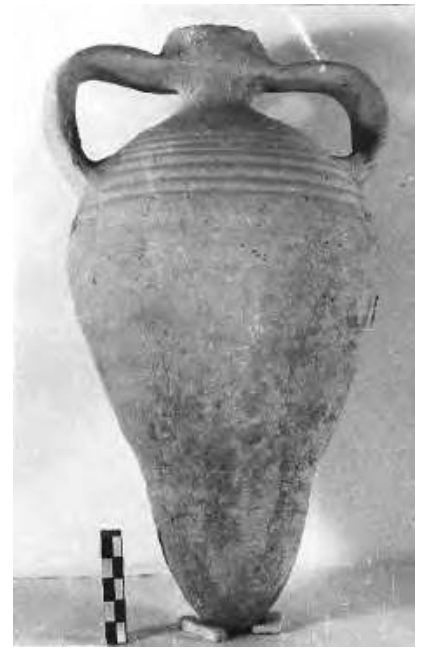

Fig. 28 : Amphore Günsenin XVII : L'amphore de l'Agora d'Athènes $P$ 10732. Courtoisie

V. Grace et H. Thompson

(Günsenin 1990 : 315, pl. LXXXVI/3a).

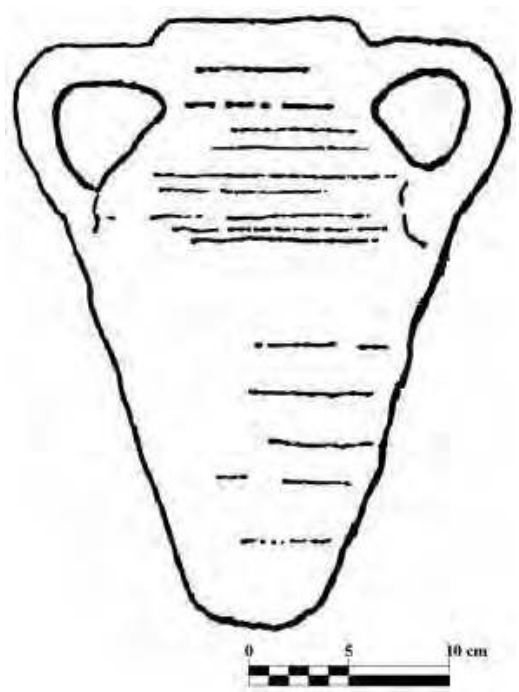

Fig. 29 : Amphore Günsenin XVIII : L'amphore des Manganes, Constantinople

(Demangel et Mamboury 1939: 148, Fig. 198/5 ; Günsenin 1990 : pl. LXXIII/5). les types attestés dans la construction des voûtes et des coupoles au palais et à l'église des Manganes et le long des murailles maritimes à Constantinople (Fig. 29) ${ }^{154}$, et je suggère ; ainsi que, dans la galerie ouest de l'église de Sainte-Sophie à Thessalonique $\underline{155}$.

\subsubsection{Type XIX}

Petite panse allongée décorée de stries, petites anses rondes dépassant l'embouchure. La hauteur moyenne atteint $30 \mathrm{~cm}$. L'amphore représentative de ce type a été découverte dans un sarcophage byzantin à Edirne (Fig. 30 ${ }^{156}$. La pâte est faite d'une argile rouge brique. 


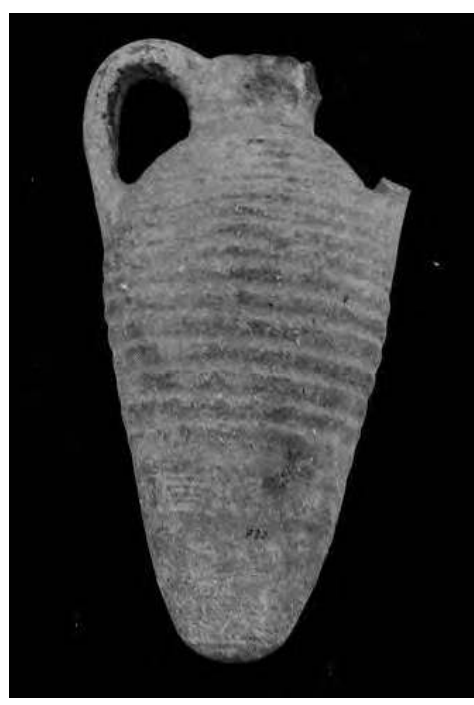

$\mathbf{a}$

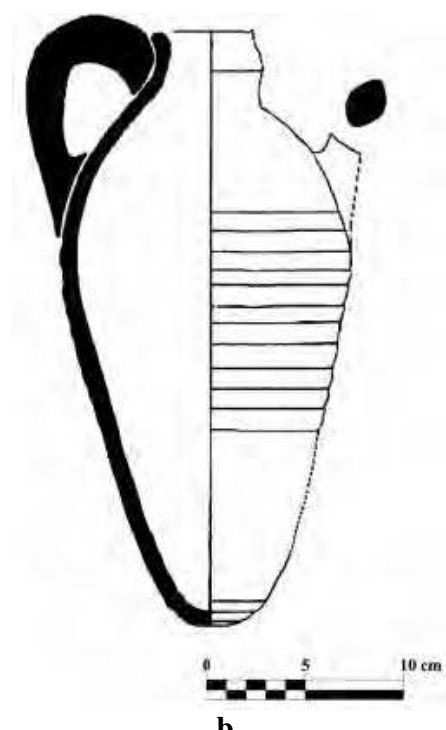

b

Fig. 30 : Amphore Günsenin XIX : a-b. Musée archéologique d'Edirne, $n^{\circ}$ inv. 732

(Günsenin 1990 : 162, pl. LXXIII/6a, 6b).

\subsubsection{Type $X X$}

Petite panse étroite, les anses droites dépassent l'embouchure et se raccordent à l'épaule et sous l'embouchure. La hauteur constatée est de $27 \mathrm{~cm}$. Cette amphore a été découverte dans une tombe dans la région de Trébizonde (Fig. 31) ${ }^{157}$.

\subsubsection{Type XXI ${ }^{158}$}

Fond plat du sous-type IVc. Attesté au Musée archéologique de Samsun (Fig. 32) ${ }^{159}$ et à Eski-Kermen, où il est daté du $12^{\mathrm{e}}-13^{\mathrm{e}}$ siècle $^{160}$.

Si lors de la rédaction de ma thèse il m'avait paru utile de classifier ces jarres dans un type à part, il est clair aujourd'hui, et cela est confirmé par la cargaison de l'épave de Çamaltı Burnu I, que le type Günsenin XXI correspond tout simplement à une version de petites capacités de Günsenin IV, destinée au transport maritime tout en servant probablement à la consommation, catégorie que l'on désigne habituellement comme des "table amphoras"161.

Pour des commentaires nouveaux sur ce type, voir l'article conjoint de Metodi Daskalov et Evelina Todorova. Les auteurs indiquent un lieu de production pour ce type à Urdoviza ${ }^{\mathbf{1 6 2}}$. Il faut peut-être approfondir les recherches aux alentours de cette région dans le but de trouver les ateliers de type Günsenin IV ?

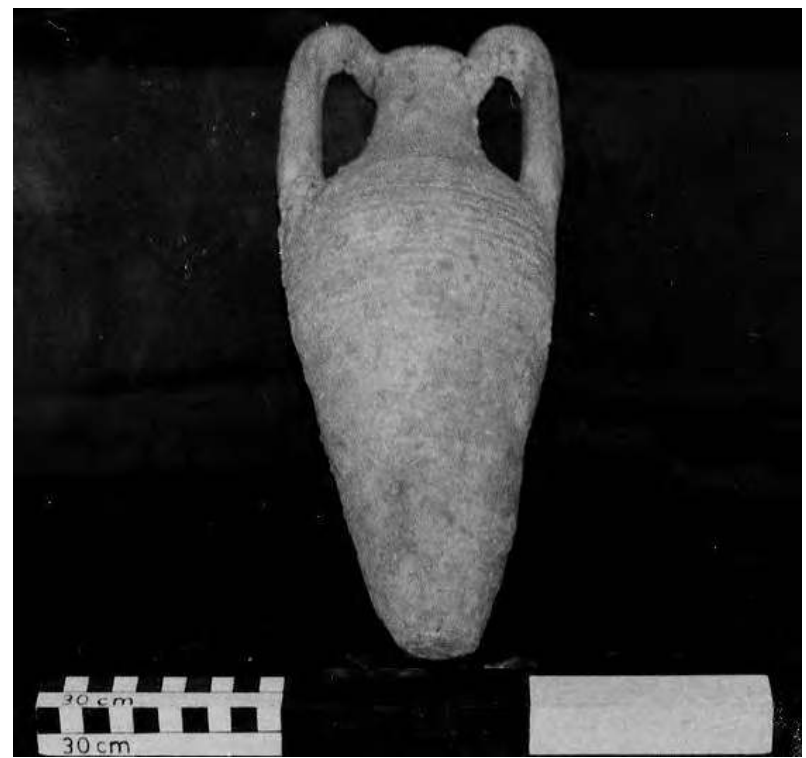

Fig. 31 : Amphore Günsenin XX :

Musée archéologique de Trabzon, $\mathrm{n}^{\circ}$ inv. inconnu (Günsenin 1990 : 278, pl. LXXIII/7).

\subsubsection{Type XXII}

Version à fond plat du sous-type IVa, attestee au Musée de Sinop (Fig. 33) ${ }^{163}$. La pâte est faite d'une argile beige orangé.

157) Günsenin $1990: 43$ et 278, pl. LXXIII/7. Le $n^{\circ}$ d'inventaire de cette amphore n'est pas connu.

158) Les types XXI à XXVIII ont dû servir plutôt à la consommation. En effet les fonds plats et les décors sur la panse ne sont pas fréquents pour les amphores destinées au transport maritime.

159) Günsenin $1990: 43$ et 268, pl. LIX/3a, b.

160) Yakobson $1979:$ Fig. 69/3.

161) Cf. dans Günsenin 2003 : Fig. 19.

162) Daskalov et Todorova 2018.

163) Günsenin $1990: 43$ et 245-246, pl. LVIII/3a, b, et voir supra, note 161. 


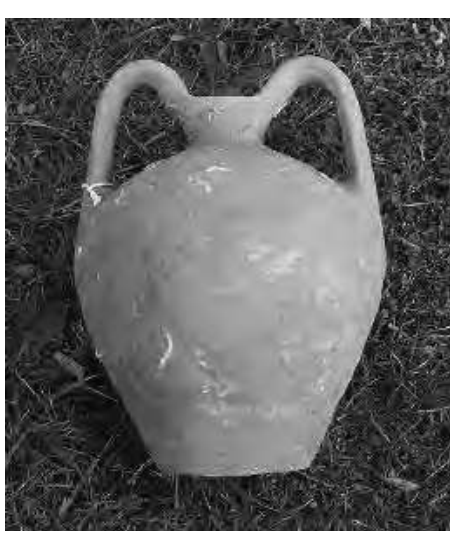

$\mathbf{a}$

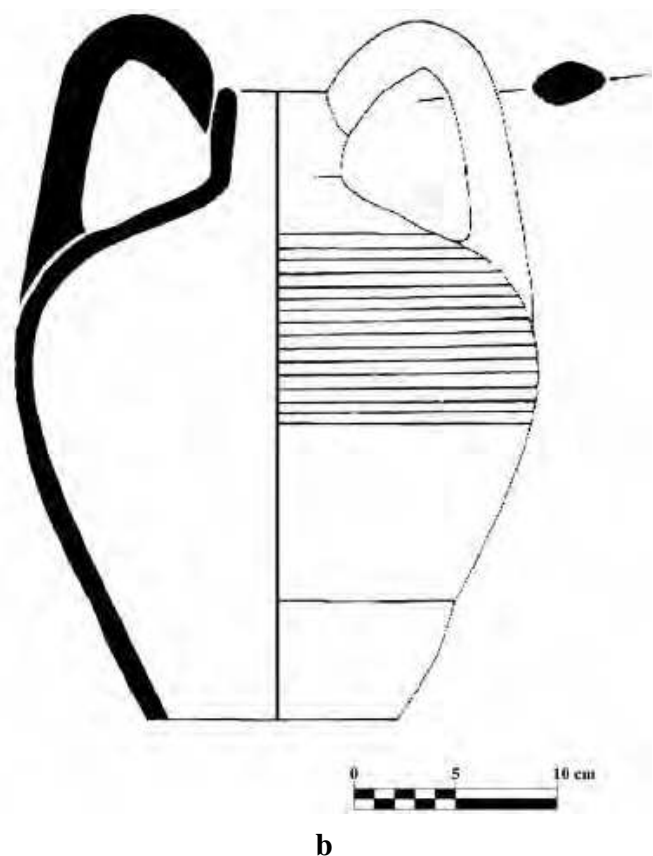

Fig. 32 : Amphore Günsenin XXI : a-b. Musée archéologique de Samsun, $n^{\circ}$ inv. 9.5.1980 (Günsenin 1990 : 268, pl. LIX/3a, b).

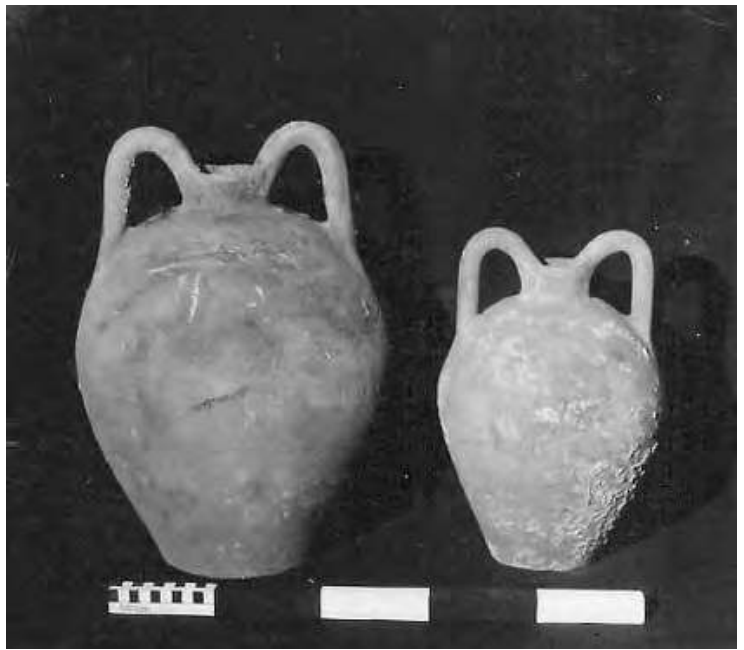

Fig. 33 : Amphores Günsenin XXII : a-b. Musée archéologique de Sinop, $n^{\circ}$ inv. 5.1.83 (Günsenin $1990: 245$, pl. LVIII/3a) ; $\mathbf{n}^{\circ}$ inv. 4.13.83 (Günsenin $1990: 246$, pl. LVIII/3b).

\subsubsection{Type XXIII}

Ce type illustré par une amphore des Manganes $^{164}$ a un fond plat (concave). Six exemplaires ont été découverts dans l'épave de Serçe Limanı (Fig. 34) ${ }^{\mathbf{1 6 5}}$, belong to a class of tenth and eleventh century amphoras $\frac{\mathbf{1 6 6}}{}$. Un autre exemplaire provient de l'Agora d'Athènes ${ }^{167}$.

\subsubsection{Type XXI}

Le type est illustré par un exemplaire de l'Agora d'Athènes (Fig. 35) ${ }^{168}$. Le type est doté d'une panse renflée et arrondie avec un col étroit et la lèvre marquée par un épaississement conique aplati sur la tranche. Des anses larges, dépassant l'embouchure, fortement infléchies, sont attachées au col et à l'épaule. Sur celle-ci, on trouve une alternance de stries obliques excisées (à la gouge ?) et des segments concaves incisés. La pâte est faite d'une argile rosâtre. L'amphore de ce type est datée du $11^{\mathrm{e}}-12^{\mathrm{e}}$ siècle.

164) Demangel et Mamboury $1939:$ 148, Fig. 198/3.

165) Je remercie Frederick H. van Doorninck, Jr. pour cette photo. Cf. aussi van Doorninck 1988 : Fig. 1 (à droite) ; cf. dans Günsenin $1990:$ 44, pl. LXXII/3c. Voir Addendum.

166) D'après lui : (...)"Let me just point out that Günsenin XXIII is very definitely a class rather than just an amphora type. There are 2 major groups within the class. The Glass Wreck examples all belong to just one of the groups but belong to 4 different types among the 6 jars. The five complete examples from the Glass Wreck range in height from 36 to $41 \mathrm{~cm}$...". Je le remercie pour le renseignement.

167) Günsenin $1990: 316$, pl. LXXXVII/1a,b.

168) Günsenin $1990: 44$ et 317, pl. LXXXVII/2. Voir Addendum. 


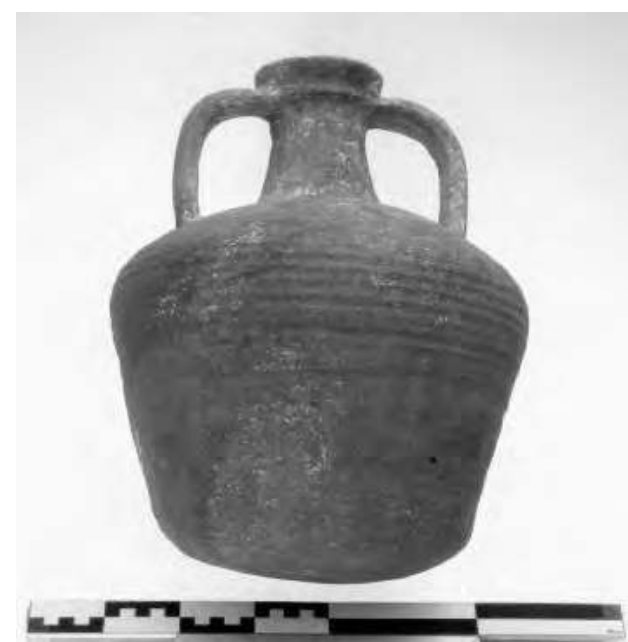

Fig. 34: Amphore Günsenin XXIII : L'amphore de l'épave de Serçe Limanı. Courtoisie F.H. van Doorninck, Jr.

\subsubsection{Type XXV}

Une panse globulaire de fabrication robuste et un fond plat. Le type est attesté à Istanbul (Fig. 36) ${ }^{169}$ dans un puits avec le type III (cf. aussi type XIV).

\subsubsection{Type XXVI ${ }^{170}$}

Type illustré par un exemplaire de l'Agora d'Athènes (Fig. 37) ${ }^{171}$. La pâte est faite d'une argile rouge brun.

\subsubsection{Type XXVII}

Type doté d'un fond plat, attesté à Sinop, à l'Hôtel Melisa-Kasım (Fig. 38) ${ }^{172}$. La pâte est faite d'une argile marron.

\subsubsection{Type XXVIII}

Type doté d'un fond plat, attesté au Musée archéologique de Samsun (Fig. 39) ${ }^{173}$. La pâte est faite d'une argile orange foncé.

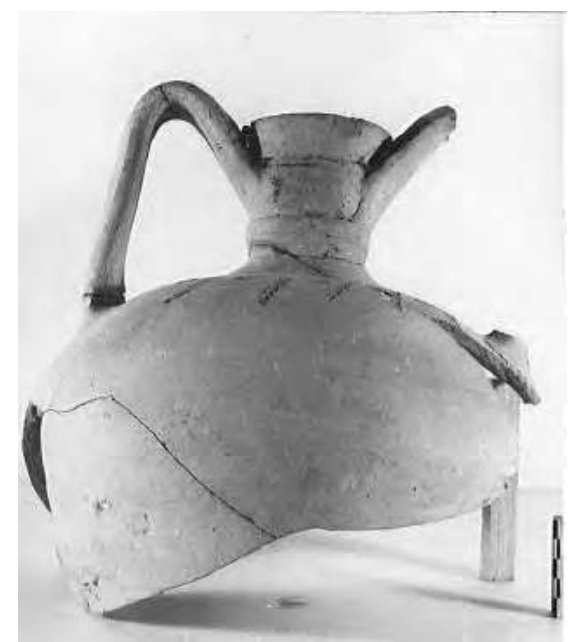

Fig. 35 : Amphore Günsenin XXIV : L'amphore de l'Agora d'Athènes $P$ 17,496. Courtoisie

V. Grace et H. Thompson (Günsenin 1990: 317, pl. LXXXVII/2).

\section{CONCLUSION}

Il est très difficile de conclure sur la typologie des amphores et leur mode de fabrication si l'on ne fait pas des analyses plus poussées $\frac{174}{}$. J'ai déjà souligné l'importance des recherches sur les origines des amphores byzantines. Une autre question vitale est de réussir à comprendre comment et pourquoi les sites de production se sont développés à travers l'histoire. C'est-à-dire, pourquoi les ateliers se trouvent dans telle région, quelle a été leur expansion, la durée de leur fonctionnement, d'où venait l'argile, quels étaient les fabricants/potiers, peut-on parler de continuité ou d'héritage entre les potiers, comment se faisait l'embarquement des amphores sur les bateaux... L'objectif majeur est d'insérer la production de ces amphores non seulement dans leur contexte historique mais aussi socio-économique. J'ai essayé d'illustrer le cas de Ganos dans le symposium d'Oxford qui avait été organisé par Marlia Mango, -j'ai peut-être réussi à réunir suffisamment de donnes nécessaires! $\mathbf{1 7 5}$.

Vous allez mettre à jour votre information à propos des découvertes terrestres ainsi que sous-marines, les lieux de production et la circulation des types Günsenin.

169) Günsenin $1990: 44$ et 194, pl. LXXIV/1a, b.

170) Les types XXVI, XXVII et XXVIII ont le même décor de motifs incisés faits d'ondulations et de zigzags.

171) Günsenin $1990: 45$ et 318, pl. LXXXVIII/1a, b. Voir Addendum.

172) Günsenin $1990: 45$ et 250, pl. LXXIV/2a, b, c.

173) Günsenin $1990: 45$ et 269, pl. LXXV/1a, b.

174) Dernièrement les amphores venant des fouilles de l'INA ont été emmenées à un hôpital de Bodrum pour être soumises aux rayons $\mathrm{X}$ en vue de l'identification de leur mode de fabrication.

175) Günsenin 2009a 


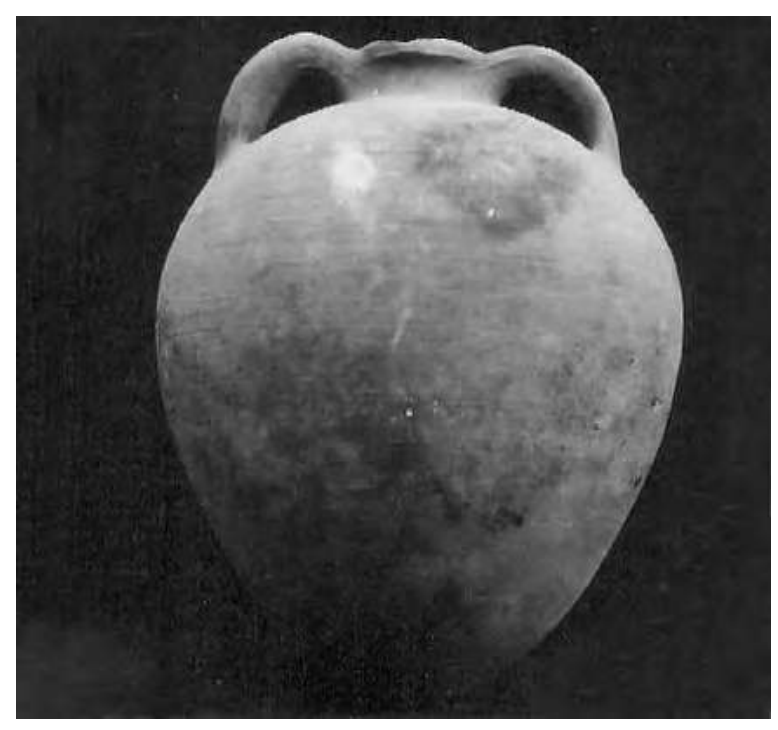

a

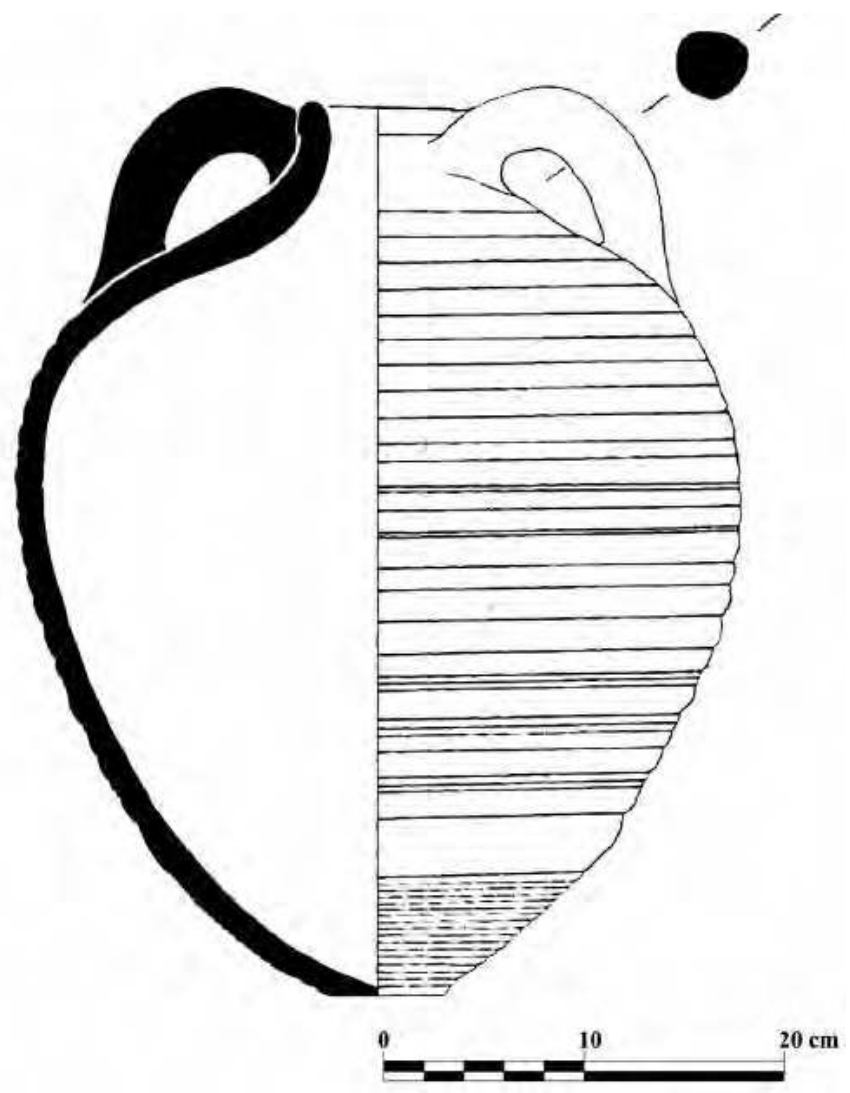

b

Fig. 36 : Amphore Günsenin XXV : a-b. Musées archéologiques d'Istanbul (Günsenin 1990 : 194, pl. LXXIV/1a, b).

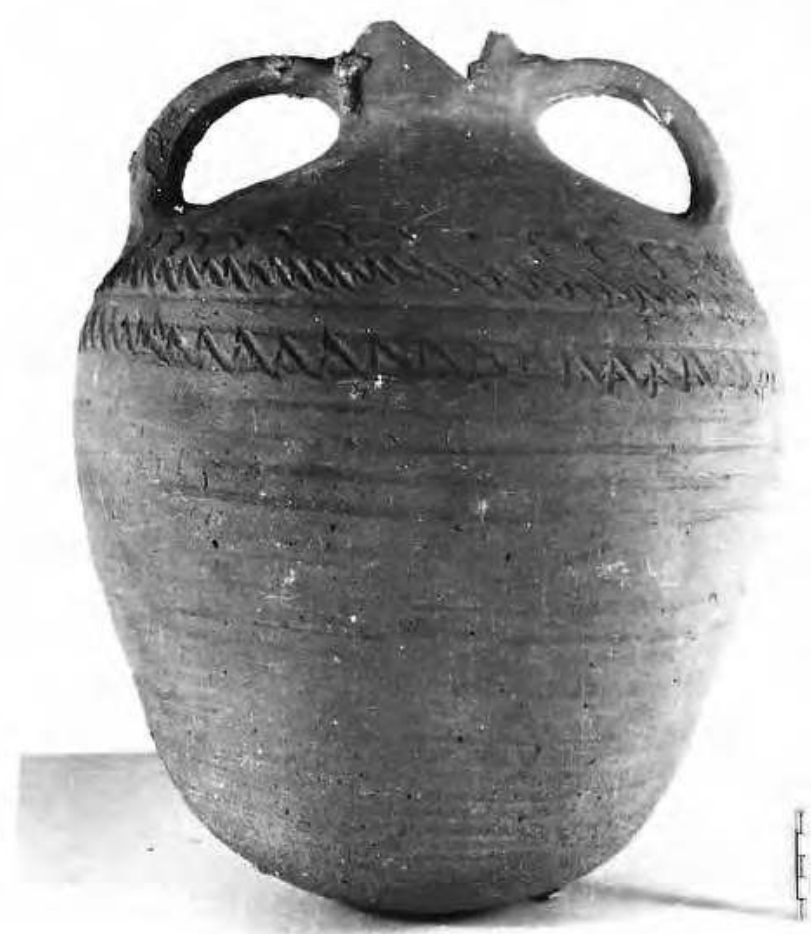

Fig. 37 : Amphore Günsenin XXVI : L'amphore de l'Agora d'Athènes $P$ 20359. Courtoisie $V$. Grace et H. Thompson (Günsenin 1990 : 318, pl. LXXXVIII/1a).

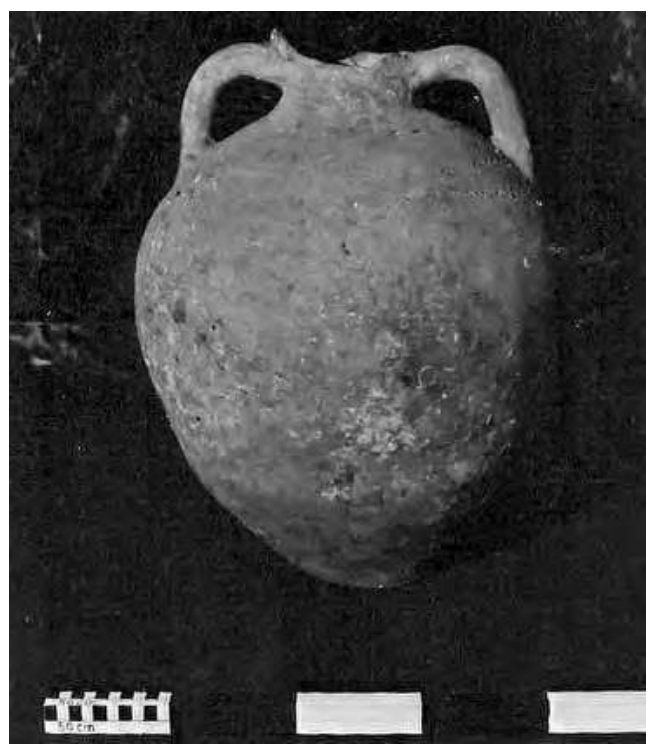

Fig. 38 : Amphore Günsenin XXVII : L'amphore de Sinop, exposée à l'Hôtel Melisa-Kasım, $\mathbf{n}^{\circ}$ inv. 13 (Günsenin 1990 : 250, pl. LXXIV/2a). 


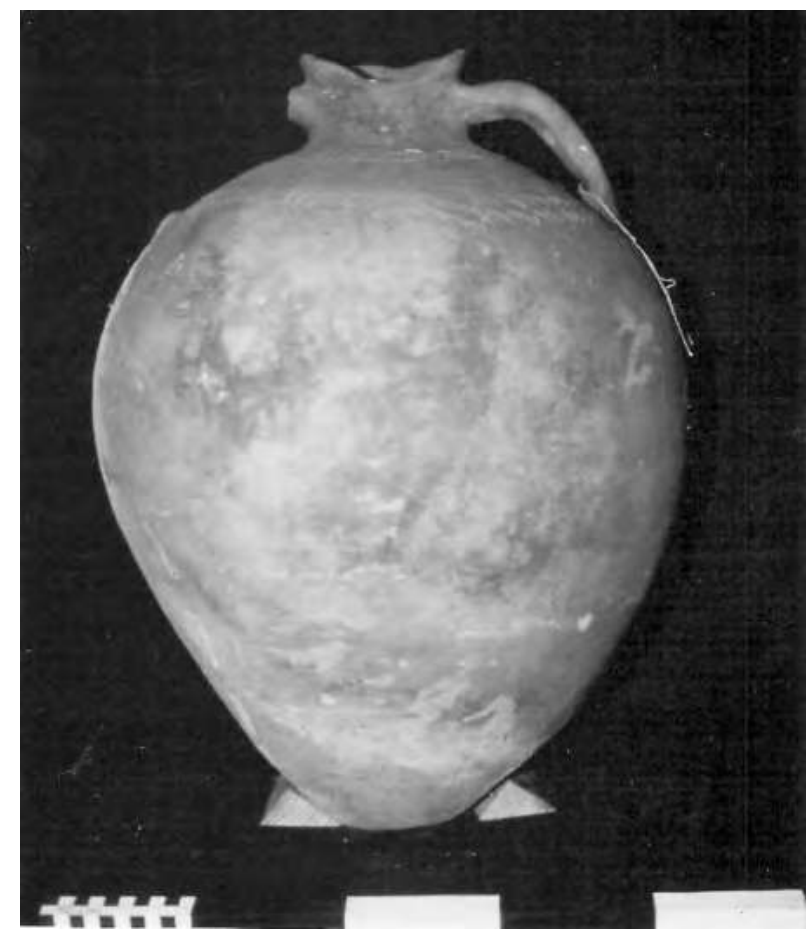

Fig. 39 : Amphore Günsenin XXVIII : Musée archéologique de Samsun, ${ }^{\circ}$ inv. 2.4.1978

(Günsenin 1990 : 269, pl. LXXV/1a).

\section{ADDENDUM}

Les types de la typologie Günsenin trouvés hors des collections turques : J'avais intitulé ma thèse Les amphores byzantines $\left(10^{e}-13^{e}\right.$ siècles $)$ : typologie, production, circulation d'après les collections turques. En rédigeant le présent article, je me suis bien rendue compte que certains types, comme les Günsenin VII, VIII, IX, X, XXIV et XXVI ne font pas partie de ces collections. Je préfère ne pas les exclure ni leur donner une autre désignation ce qui risque d'apporter une confusion à la typologie entière. On pourrait les nommer d'après les lieux de trouvaille ou les auteurs des publications.

Je voudrais attirer l'attention des lecteurs sur les actes du XI Congrès AIECM3 sur la Céramique Médiévale et Moderne en Méditerranée qui a eu lieu à Antalya le 19-23 Octobre 2015. Outre l'article de M. Daskalov et E. Todorova (mentionné en type XXI), cf. les articles de : Ö.E. Öncü et S. Çömlekçi, "Yenikapı Kazıları ve Bizans Dönemi Amphora Buluntuları" 176 ; G. Koutsouflakis et A. Tsompanidis, "The Kavalliani Shipwreck: A New Cargo of Byzantine Glazed Tableware from the South Euboean Gulf, Aegean”프 ; A. Ricci et R. Wohmann, "Byzantine Contexts from the Asian Suburbs of Constantinople: Preliminary Remarks on the Ceramics and Archaeology at the Küçükyalı ArkeoPark (Istanbul)"1178 ; M. Manolova-Voykova, "Import of Middle Byzantine Pottery to the Western Black Sea Coast: An Overview" $\underline{179}$; S. Bocharov, A. Maslovski et N. Iudin, "The Impact of Ceramic Imports on Ceramic Manufacturing in the Cities of the North-Eastern Black Sea Region in the Late XIII $^{\text {th }}$-XIV ${ }^{\text {th }}$ Centuries"180 $;$ E. Metalla, "Céramiques médiévales provenant des fouilles récentes de l'amphithéâtre de Durrës (Albanie)"181 pour le sujet que nous traitons.

Pour les recherches sous-marines pour l'ensemble des trouvailles d'épaves contenant les types Günsenin, en mer Egée cf. Paraskevi Micha ${ }^{182}$. Au congrès de AIECM3 G. Koutsouflakis m'a informé qu'il prépare un article destiné à mettre à jour les épaves trouvées dans la mer Egée ${ }^{183}$. Pour les épaves en mer Adriatique cf. Vesna Zmaic Kralj 184 . Dans la péninsule de Crimée cf. Sergiy Zelenko $\underline{\mathbf{1 8 5}}$.

Et bien évidemment, il faut surtout, consulter Serçe Limanı Vol. III!

Van Doorninck est toujours très généreux dans son utilisation de la typologie Günsenin. Outre "la classe" Günsenin I dans la cargaison de l'épave de Serçe Limanı, il y a d'autres types qu'il a bien étudiés et reclassifiés, à savoir, Günsenin XI, XII, XIII, XV et XXIII. Il distingue deux sous-types pour le type XIII et renomme le type XXIII comme "classe". Et les analyses d'argile en cours montrent peut-être que le type XII aussi va être renommé comme "classe".

Son immense connaissance sur les amphores byzantines à travers les fouilles de l'INA augmente de jour en jour grâce à sa patience et son énergie

176) In Yenişehirlioğlu (éd.) 2018, Vol. I : 15-29.

177) Ibid., Vol I : 39-48.

178) Ibid., Vol I : 453-458.

179) Ibid., Vol II : 103-115.

180) Ibid., Vol II : 117-125.

181) Ibid., Vol II : 151-155.

182) Micha $2007: 82-93$.

183) Koutsouflakis, G., "The Unharvested Sea": A Century of Underwater Exploration in the Hellenic Archipelagos. The evidence of shipwrecks, à paraître. Je le remercie de me faire confiance pour la lecture du texte avant la publication.

184) Kralj 2017 : 46-61.

185) Zelenko 2008. 
perpétuelle. Il retourne chaque année à Bodrum et poursuit son travail dans les dépôts du Musée d'Archéologie Sous-Marine tout comme dans les laboratoires de l'INA à Bodrum.

En ce qui me concerne, pendant mes années de recherches dans les dépôts de musées, le temps dont je disposais et mes possibilités ont été limités. J'ai dessiné les amphores, je les ai photographiées, pris les mesures et essayé de faire des analyses visuelles de l'argile dans l'obscurité.
J'ai beaucoup correspondu avec lui pendant la rédaction de cet article, et profité beaucoup de sa connaissance et sa générosité. Je suis bien évidemment seule responsable des fautes éventuelles. Comme toujours il me corrigera...!

N.G.

\section{ABREVIATIONS ET BIBLIOGRAPHIE}

AA Archäologischer Anzeiger

ADSV Anticnaja drevnost'i srednije veka (L'antiquité et le moyen âge Université de Sverdlovsk, URSS)

AIECM Association Internationale pour l'Etude des Céramiques Médiévales et Modernes en Méditerranée

AP Archeion Pontou

AST Araştırma Sonuçları Toplantısı

BiaBul Bulletin de l'Institut archéologique bulgare

BCH Bulletin de Correspondance Hellénique

CNRS Centre National de la Recherche Scientifique

DOP Dumbarton Oaks Papers

IJNA International Journal of Nautical Archaeology

INA Institute of Nautical Archaeology

ISBSA International Symposium on Boat and Ship Archaeology

KST Kazı Sonuçları Toplantısı

MIA Materialy i Issledovanija po Archeologii SSSR (Matériaux et recherches archéologiques de l'URSS)

SA Sovetskaja Archeologiya (Archéologie soviétique)

VEKAM Vehbi Koç Ankara Araştırmaları Uygulama ve Araştırma Merkezi

Adan-Bayewitz, D., 1986 : "The pottery from the Late Byzantine building (Stratum 4) and its implications" in L.I. Levine et E. Netzer (éds.), Excavations at Caesarea Maritima 1975, 1976, 1979. Final Report, Institute of Archaeology, Hebrew University of Jerusalem, Jérusalem : 91-100.

Amadouny, Z., 1973: Le site archéologique sub-aquatique d'el Mina, Tripoli-Liban, Trans-Press, Liban : pl. 3, T 11.

Antonova, I.A. , Danilenko, V.N. , Ivashuto, L.P., Kadeev, A.I. et Romancuk, A.I., 1971 : "Srednevekove amphor Chersonesa", ADSV 7 : 81-101.

Antonova, V. et Demjanov, S., 1969 : "Matériaux recueillis au cours des recherches et des sondages effectués à Pliska", Arh-Sofia 11.2 : 25-42.

Arnon, Y.D., 2007 : "Pottery, Oil Lamps and Carved Stone Vessels", in M. Artzy, ,S. Yanklevitz et G. Tsioni (éds.), Contract Archaeology Reports II. Excavation in Marcus Street, Ramla, University of Haifa : 38-99.

- 2008: Caesarea Maritima, the Late Periods (7001291 CE). BAR International Series.

Arthur 1989 : "Aspects of Byzantine Economy: An Evaluation of Amphora Evidence from Italy", in V. Deroche et J.M. Spieser (éds.), Recherches sur la céramique byzantine, Suppl. $B C H$ XVIII : 79-91.

Bakirtzis, C., 1984 : Buzantina Tsoukalaloghnoi, Thessalonique, (thèse publiée en 1989).

- 1989 : Byzantine Tsoukalolagena, Athènes.

Barnea, I., 1959 : "Découvertes archéologiques de l'époque féodale à Mangalia", Materiale si cercetari archeologice $6: 904-911$.

- 1967 : "Ceramica de import", Dinogetia I, Bucarest : 229-276.

- 1989 : "La céramique byzantine de Dobroudja, $\mathrm{X}^{\mathrm{e}}$-XII ${ }^{\mathrm{e}}$ siècles", in V. Deroche et J.M. Spieser (éds.), Recherches sur la céramique byzantine, Suppl. BCH XVIII : 131-142.

Barnea, I. et Barnea, A., 1984 : "Sâpâturile de salvare de la Noviodunum", Peuce 9: 97-105; 503-518.

Bass, G.F. et van Doorninck F.H. Jr., 1971 : "A FourthCentury Shipwreck at Yass1 Ada", American Journal of Archaeology 75 : 27-37.

- 1978 : "An $11^{\text {th}}$-century Shipwreck at Serçe Limanı, Turkey", IJNA 7 : 119-132.

- 1982 : Yassi Ada, Vol. 1. A Seventh-Century Byzantine Shipwreck, Texas A\&M University Press, College Station.

Bass, G.F., Matthews, S.D., Steffy, J.R. et van Doorninck, F.H. Jr., 2004 : Serçe Limanı, Vol. 1. An Eleventh-Century Shipwreck. The Ship and its Anchorage, Crew and Passengers, Texas A\&M University Press, College Station.

Bass, G.F., Brill, R.H., Lledó, B. et Matthews, S.D., 2009 : Serçe Limani, Vol. II, Glass from an Eleventh-Century Shipwreck, Texas A\&M University Press, College Station.

Bjelajac, L., 1989 : "Byzantine Amphorae in the Serbian Danubian Area in the $11^{\text {th }}-12^{\text {th }}$ Centuries", in V. Deroche et J.M. Spieser (éds.), Recherches sur la céramique byzantine, Suppl. BCH XVIII : 109-118. 
Bonifay M. et Villedieu, F., 1985 : Catalogue d'exposition d'archéologie sous-marine sur les côtes de France, Nantes.

- 1989 : "Importations d'amphores orientales en Gaule", in V. Deroche et J.M. Spieser (éds.), Recherches sur la céramique byzantine, Suppl. BCH XVIII : 17-46.

Borisov, B., 2002 ; Ceramics and Ceramic Production in $11^{\text {th }}-12^{\text {th }}$ Centuries on the Territory of Present-Day South East Bulgaria, Radnevo.

Brosh, N., 1986 : "Ceramic Remains: A. Pottery of the $8^{\text {th }}-13^{\text {th }}$ Centuries C.E. (Strata 1-3)", in L.I. Levine et E. Netzer (éds.), Excavations at Caesarea Maritima 1975, 1976, 1979. Final Report, Qedem 21, Hebrew University of Jerusalem, Institute of Archaeology, Jerusalem : 86-87, pl. 5.6.

Brusic, Z., 1976 : "Byzantine Amphorae (9 $9^{\text {th }}$ to $12^{\text {th }}$ century) from Eastern Adriatic Underwater Sites", Archeologica Jugoslavica 17 : 37-49.

Bulgakov, V.V., 2000 : "Vizantijskie amfory IXXIV vv.: osnovnye tipy", Vostochnoevropejskij arkheologicheskij zhurnal 4 (5) (iyul'-avgust).

http://archaeology.kiev.ua/journal/040700/bulgakov.htm

Cangova, J., 1959 : “Amphores du Moyen-Âge en Bulgarie", Bul InstArhcBulg 22 : 243-262.

Chadzidimitrova, C., 1960 : "Kulturdenkmäler in Silistra und Umgebung", in V. Beshevliev et J. Irmsches (éds.), Antike und mittelalter in Bulgarien, Berlin : 209-213.

Damian, O., Vasile, M., Stănică, A., Bănăseanu, A. et Samson, A., 2007 : "Cercetări arheologice preventive al Nufăru, jud. Tulcea”, Materiale si cercetări arheologice 3 : 107-151.

Daskalov, M. et Todorova, 2018 : “At the Threshold - Pottery Kilns for Sgraffito Ware and Günsenin IVLike Vessels (Late $14^{\text {th }}$-Early $15^{\text {th }} \mathrm{c}$. AD) from Urdoviza (Kiten) on The Western Black Sea Coast", in F. Yenişehirlioğlu (éd.) 2018, Vol. I : 217-226.

Demangel, R. et Mamboury, E., 1939 : Le Quartier des Manganes, Paris.

Diaconu, P., 1960 : "Şantierul arheologic de la Pâcuiul lui Soare", Materiale si cercetări arheologice 7 : 559-608.

- 1961 : "Krepost X-XV vv. v Pekuyl lui Soare v Svete Arheologicheskih issledovanii", Dacia 5 : 485501.

Florescu, Gr., 1959 : "Sâpâturile arheologice de la Capidava", Materiale si cercetari arheologice 6:617627.

Grozdanova, 2009 : "Amphorae Material from the Early Medieval Settlement at the Village of Kapitan Andreevo, Svilengrad Municipality", in V. Grigorov, M. Daskalov et E. Komatarova-Balinova (éds.), Eurika. In Honorem Ludmilae Donchevae-Petkovae, Sofia : 245-253.

Güner, G., 1988 : Anadoluda Yaşamakta olan Ilkel Çömlekçilik, Istanbul : 26.

Hayes, J.W., 1992 : Excavations at Saraçhane in Istanbul, Vol. 2, The Pottery, Princeton University Press.

Hocker, F., 2005 : "Sampling a Byzantine Vintage: Bozburun, Turkey", in Bass, G.F. (éd.), Beneath the Seven Seas, Thames \& Hudson : 100-105.
Holoda, R. et Yuriy Rassamakinb, Y., 2012 : "Imported and Native Remedies for a Wounded 'Prince': Grave Goods from the Chungul Kurgan in the Black Sea Steppe of the Thirteenth Century", Medieval Encounters 18, Koninklijke Brill NV, Leiden : 339-381.

Kralj, V.Z., 2017 : "Byzantine Maritime Trade, based on underwater archaeological finds of the eastern Adriatic", SKYLLIS, Zeitschrift für maritime und limnische Archäologie und Kulturgeschichte, 17. Jahrgang 2017 Heft 1 : 46-61.

Lazarov, M., 1975 : Potljanalata Flotilija, Varna.

Malevskaya, M.V., 1962: "L'Amphore avec une inscription provenant de Novogrudou" (IVa), SA 4 : 238241.

Megaw, A.H.S., 1972 : "Supplementary Excavations on a Castle Site at Paphos, Cyprus (1970-1971)", DOP $26: 322-343$

Micha, P., 2007 : "Amphora Shipwrecks in the Aegean, A Database of the Ephorate of Underwater Antiquities", SKYLLIS, Zeitschrift für Unterwasserarchäologie, 7. Jahrgang 2005/06, Heft 1-2: 82-93.

Öncü, Ö.E. et Çömlekçi, S., 2018 : "Yenikap1 Kazıları ve Bizans Dönemi Amphora Buluntuları,,", in F. Yenişehirlioğlu (éd.) 2018,Vol. I : 15-29.

Özügül, A., 2000 : "Appendix: The Amphorae", in R. Ousterhout, Z. Ahunbay, M. Ahunbay et A. Özügül (éds.), "Study and Restoration of the Zeyrek Camii in Istanbul: First Report, 1997-98”, DOP 54 : 265-270.

Panella, C., 1986 : “Oriente ed Occidente : Considerazioni su alcune anfore «Egee» di Età Imperiale a Ostia", in J.-Y. Empereur et Y. Garlan (éds.), Recherches sur les amphores grecques, Suppl. BCH XIII : 626, Fig. 25.

Papanikola-Bakirtzi, D., 2002 : Everyday Life in Byzantium, Kapon Editions, Hellenic Ministry of Culture, Athens.

Papanikola-Bakirtzi, D. et Skordali, G., 1999 : “Archaeological Store-Rooms in the Museum of Byzantine Culture", Museum of Byzantine Culture 6, Thessaloniki : 56-59.

Pierart, M. et Thalmann, J.-P., 1980 : “Céramique romaine et médiévale (Fouilles de l'agora)", Etudes Argiennes, Suppl. BCH VI : 459-492.

Pletneva, S.A., 1959 : "Keramika Sarkela-Beloi Vezhi”, MIA 75, Moscou : 214-295.

Popovic, M., 1989 : "Importation et production locale de céramique à Ras (fin $\mathrm{XI}^{\mathrm{e}}$ - début XIII ${ }^{\mathrm{e}}$ siècle)", in V. Deroche et J.-M. Spieser, (éds.), Recherches sur la céramique byzantine, Suppl. BCH XIII : 119-130.

Pulak, C., 1985 : "1984 Yılı Aydın, Muğla ve Antalya İlleri Sualtı Araştırmaları”, AST 3, Ankara : 47-62.

Ricci, A. et Wohmann, R., 2018 : "Byzantine Contexts from the Asian Suburbs of Constantinople: Preliminary Remarks on the Ceramics and Archaeology at the Küçükyalı ArkeoPark (Istanbul)", in Yenişehirlioğlu (éd.) 2018, Vol I : 453-458.

Rice, T., 1958 : The Great Palace of the Byzantine Emperors, second report, Edinbourg. 
Romanchuk, A., 1981 : "Torgovlia Chersonesa v VII-XII b. b”, BiaBul 7 : 319-331.

Roslund, M., 1997 : “Crumbs from the Rich Man's Table- Byzantine Finds in Lund and Sigtuna, ca. 9801250", in H. Andersson, P. Carelli et L. Ersgård (éds.), Visions of the Past. Trends and Traditions in Swedish Medieval Archaeology, Lund Studies in Medieval Archaeology 19 / Riksantikvarieämbeter Arkeologiska undersökningar Skrifter nr 24, Lund : 239-297.

Rosser, J., 1985 : "Excavations at Saranda Kolones, Paphos, Cyprus (1981-1983)", DOP 39 : 81-97.

Rudakov 1975 : "Materiel du $12^{\mathrm{e}}-13^{\mathrm{e}}$ siècles", ADSV 12

Shear, T.L. Jr., 1984 : “The Athenian Agora: Excavations of 1980-1982", Hesperia 53 : 1-57.

Stancev, S., 1960 : "Materiale ot dvorcovi centr, v Pliska", Izvestiya na archeolgicheski institut 23 : 23-62.

Tal, O. et Taxel, I., 2008 : "Chapter 6: The Late Umayyad, 'Abbasid and Fatimid Periods", in O. Tal et I. Taxel (éds.), Ramla (South): An Early Islamic Industrial and Remains of Previous Periods, Salvage Reports № 5, Emery and Claire Yass Publ. in Archaeology.

Tartari, F., 1982 : “Amforat e muzeut arkeologjik të Durrësit”, Iliria 2 : 239-279.

van Doorninck F.H. Jr., 1976 : "The $4^{\text {th }}$ Century Wreck at Yassi Ada: An Interim Report on the Hull”, IJNA 5 : 115- 131.

- 1988 : "The Amphoras: Old jars from the North", INA Newsletter $15.3: 22-23$.

- 1989 : "The Cargo Amphoras on the $7^{\text {th }}$ century Yassi Ada and $11^{\text {th }}$ Century Serçe Limanı Shipwrecks: Two examples of a Reuse of Byzantine Amphoras as Transport Jars", in V. Deroche et J.-M. Spieser (éds.), Recherches sur la céramique byzantine, Suppl. BCH XIII : 247-257.

- 1994 : "Byzantine Amphoras Made for War?", The INA Quarterly, Vol. 1, № $1: 21-27$.

Vasiliu, I., 1980: "Douâ Locuinte Feudale Timprui de la Aegyssus", Peuce 8 : 437-449.

Vasiliu, I. et Mănucu-Adameşteanu, G., 1984 : "Considerations finales sur l'habitat de haute époque feodale $\left(\mathrm{X}^{\mathrm{e}}-\mathrm{XI}^{\mathrm{e}}\right.$ siècles) d'Aegyssus-Tulcea (campagnes archéogiques de 1959 à 1980)," Peuce 9: 143-154.

Waage, F.O. (éd.), 1948 : Antioch on-the-Orontes, Vol. IV. 1 : Ceramics and Islamic Coins, Princeton.

Waksman, S.Y., Skartsis, S.S., Kontogiannis, N.D., Todorova, E.P. et Vaxevanis, G., 2018 : "Investigating the origins of two main types of Middle and Late Byzantine amphorae", Journal of Archaeological Science : Reports, Vol. 21, Octobre 2018 : 1111-1121.

Wohmann, R., 2016 : Tableware and Cargo Amphorae of the Late Antique to Late Byzantine Periods from Küçükyall (Istanbul): A Ceramic Assemblage from the Asian Hinterland of Constantinople ( $4^{\text {th }}-14^{\text {th }}$ centuries), Unpublished master's thesis, Koç University, Graduate School of Social Sciences and Humanities, Istanbul.

Yakobson, A.L., 1951 : "Srednevekovye amfory severnogo prichernomor'ya", SA XV : 325-344.

- 1964 : Srednevekovoj Krym, Leningrad.
- 1979 : Keramika, keramicheskoe proizvodsivo srednevekovoj Tavriki, Leningrad.

Yenişehirlioğlu, F. (éd.), 2018 : F. Yenişehirlioğlu (éd.), XI ${ }^{\text {th }}$ Congress AIECM3 on Medieval and Modern Period Mediterranean Ceramics Proceedings, Vols. I et II, 19-24 October 2015, Antalya, Ankara, VEKAM publication $\mathrm{n}^{\circ} 42$.

Zelenko, S., 2008 : Underwater Archaeology of Crimea, Kiev.

Zemer, A., 1977 : Storage Jars in Ancient Sea Trade, Haifa.

\section{BIBLIOGRAPHIE GÜNSENIN SELECTIONNEE PAR RAPPORT AU SUJET}

\section{Typologie des amphores}

Günsenin, N., 1989 : "Recherches sur les amphores byzantines dans les musées turcs", in V. Deroche et J.-M. Spieser (éds.), Recherches sur la céramique byzantine, Suppl. BCH XVIII : 267-276.

Günsenin, N., 1990 : Les amphores byzantines ( $X^{e}$ $X I I I^{e}$ siècles) : typologie, production, circulation d'après les collections turques, Université Paris I (Panthéon-Sorbonne), Paris, Atelier national de reproduction des thèses de Lille III.

\section{Recherches terrestres des ateliers et la fouille du four de Ganos (Günsenin I)}

Günsenin, N. 1992a: "1991 Yılı Tekirdağ İli, Hoşköy-Gaziköy Amphora Atölyeleri Yüzey Araştırması", AST 10, Ankara : 85-102.

Günsenin, N., 1992b : "Ganos : centre de production d'amphores à l'époque byzantine", Anatolia Antiqua II : 193-201.

Günsenin, N., 1992c : “Ganos : Bin Yıldır Şarap ve Amphora Üreten Kutsal Dağ”, Türk Arkeoloji Dergisi XXX, Ankara : 197-207.

Işın, A. et Günsenin, N., 1994: “Tekirdağ İli, Hoşköy-Gaziköy Amphora Fırınları Kurtarma Kazısı 1992", IV. Müze Kurtarma Kazılarl Semineri, Ankara : 497-512.

Günsenin, N., 1995a : "Ganos : résultats des campagnes de 1992 et 1993", Anatolia Antiqua III : 165-178.

Günsenin, N., 1995b : “1993 Yılı Tekirdağ ve Balıkesir İlleri Yüzey Araştırması (Hoşköy - Gaziköy Jeofizik (manyetik), Marmara Adaları Sualtı Araştırması", X. Arkeometri Sonuçları Toplantısı, Ankara : 201-220.

Armstrong, P. et Günsenin, N., 1995 : "Glazed pottery production at Ganos", Anatolia Antiqua III : 179-201

Günsenin, N. et Hatcher, H., 1997 : “Analyses chimiques comparatives des amphores de Ganos, de l'île de Marmara et de l'épave de Serçe Limanı (Glass Wreck)", Anatolia Antiqua V: 249-260.

Günsenin, N., 1999a : "Les ateliers amphoriques de Ganos à l'époque byzantine", in Y. Garlan (éd.), Production et commerce des amphores anciennes en mer Noire, Université de Provence : 125-128. 
Günsenin, N., 2003a : “Au Moyen Age, un centre de production en Propontide dominant aussi le bassin Méditerranéen : le cas de Ganos", in Bakirtzis, Ch. (éd.), VII $^{2}{ }^{2}$ Congrés international sur la céramique medieval en Méditerranée, Athènes : 67-70.

\section{Recherches sous-marines}

Günsenin, N., 1993 : "Marmara'daki Amphora Dağı", Atlas 9, Istanbul : 112 - 122.

Günsenin, N., 1995b : "1993 Yılı Tekirdağ ve Balıkesir İlleri Yüzey Araştırması (Hoşköy - Gaziköy Jeofizik (manyetik), Marmara Adaları Sualtı Araştırması", X. Arkeometri Sonuçları Toplantısı, Ankara : 201-220.

Günsenin, N., 1996 : “1994 Y1lı Marmara Adaları Sualtı Araştırması", AST 13, Ankara : 357-373.

Günsenin, N., 1997 : “1995 Yılı Marmara Adaları Sualtı Araştırması”, AST 14, Ankara : 97-105.

Günsenin, N., 1998a : "1996 Y1lı, Marmara Adaları Yan Taramalı Sonar Araştırması Ekinlik Adası Mermer Batığı", AST 15 : 295-305.

Günsenin, N., 1998b: "Récentes découvertes sur l'île de Marmara (Proconnèse) à l'époque byzantine : épaves et lieux de chargement", Archaeonautica 14, Paris : 309-316.

Günsenin, N., 1999b : "From Ganos to Serçe Limanı: Social and economic activities in the Propontis during Medieval Times, illuminated by recent archaeological and historical discoveries"', The INA Quarterly, 26.3, Texas : 18-23.

Günsenin, N., 2000 : "Up to date Discoveries at the Marmara Islands and a Log Boat", in J. Litwin (éd.), Down the River to the Sea, Proceedings of the Eighth International Symposium on Boat and Ship Archaeology (ISBSA), Gdansk : 241-243.

Günsenin, N., 2001a: "Byzantine Shipwrecks Discovered around the Marmara Islands (Prokonnessos): Points of Departure and Probable Destinations", in H. Tzalas (éd.), VI It International Symposium on Ship Construction in Antiquity, Tropis VI, Athens : 221-222.

Fouille sous-marine de l'épave de Çamalt Burnu I (Günsenin IV)

Günsenin, N. et Özaydın, N., 2000 : "Marmara Adası, Çamaltı Burnu I Batığı 1998”, KST 21, Ankara : 341-350.

Günsenin, N., 2001b : "L'épave de Çamaltı Burnu I (île de Marmara, Proconnèse) : résultats des années 1998-2000”, Anatolia Antiqua IX : 117-133.

Günsenin, N., 2001c : "Çamaltı Burnu I Wreck", in O. Belli (éd.), Istanbul University's Contributions to Archaeology in Turkey 1932-2000, Istanbul : 252-256.

Günsenin, N. et Özaydın, N., 2002 : "Marmara Adası, Çamaltı Burnu I Batığı-1999/2000”, KST 23, Ankara : 381-390.

Günsenin, N., 2002a : "Çamaltı Burnu I Wreck 98/99 Field Seasons", in H. Tzalas (éd.), VII ${ }^{\text {th }}$ International Symposium on Ship Construction in Antiquity, Tropis VII, Athens : 391-399.
Günsenin, N., 2003b : "L'épave de Çamaltı Burnu I (île de Marmara, Proconnèse) : résultats des années 2001-2002", Anatolia Antiqua XI : 361-376.

Günsenin, N., 2004 : "Underwater Archaeological Research in the Sea of Marmara", in T. Akal, R.D. Balard et G.F. Bass (éds.), The Application of Recent Advances in Underwater Detection and Survey Techniques to Underwater Archaeology, Istanbul : 31-38.

Günsenin, N., 2005a: "A 13 ${ }^{\text {th }}$-Century Wine Carrier: Çamaltı Burnu, Turkey", in G. Bass (éd.), Archaeology Beneath the Seven Seas, Thames and Hudson, England : 118-123.

Günsenin, N., 2010 : "The Construction of a Monastic Ship (?) in the Sea of Marmara: Çamaltı Burnu I Wreck", in P. Pomey (éd.), Transferts technologiques en architecture navale méditerranéenne de l'Antiquité aux temps modernes : identité technique et identité culturelle, Varia Anatolica XX, Paris : 151-153.

\section{Bibliographie Günsenin complémentaire}

Günsenin, N., 1998c : "Le vin de Ganos : les amphores et la mer", Eupsycia, Mélanges Offerts á Hélène Ahrweiler, Byzantina Sorbonensia, Paris : 281-291.

Günsenin, N., 2002b : "Medieval trade in the Sea of Marmara: the evidence of shipwrecks", in R. Macrides, (éd.), Travel in the Byzantine World, Ashgate, Great Britain : 125-135.

Günsenin, N., 2005b : "Epitaphes de marins de l'île de Marmara (Proconnèse)", Travaux et Mémoires 15, Mélanges Jean-Pierre Sodini, Association des Amis du Centre d'Histoire et Civilisation de Byzance, Paris : 371-380.

Günsenin, N., 2009a : "Ganos wine and its circulation in the $11^{\text {th }}$ century", in M.M. Mango (éd.), Byzantine Trade, $4^{\text {th }}-12^{\text {th }}$ centuries, Ashgate, Great Britain : 145-153.

Günsenin, N., 2009b : " Marmara Adası Çamaltı Burnu I Batığı'ndan, Sgraffito Desenli Bir Tabak”, Ebru Parman Anı Kitabı, Ankara : 237-242.

Günsenin, N. et Rieth, E., 2012 : "Un graffito de bateau à voile latine sur une amphore (IX ${ }^{\mathrm{e}} \mathrm{s}$. ap. J.-C.) du Portus Theodosiacus (Yenikap1)", Anatolia Antiqua XX : 157-164.

Günsenin, N., 2012: "City' Harbours from Antiquity through Medieval times", in N. Günsenin (éd.), Between Continents, Proceedings of the XII ${ }^{\text {th }}$ International Symposium on Boat and Ship Archaeology (ISBSA), Istanbul : 99-105.

Günsenin, N., 2016 : “Ganos Limanı'ndan Portus Theodosiacus'a", in P. Magdalino et N. Necipoğlu (éds.), 3. Uluslararası Sevgi Gönül Bizans Araştırmaları Sempozyuтu, Istanbul : 399-402.

Günsenin, N., 2017 : "Harbours and Shipbuilding in Byzantine Constantinople", in C. Buchet (gen. éd.), The Sea in History, Vol. 2 in M. Balard (éd.), The Medieval World, Rochester NY, Boydell\&Brewer : 412-424.

Günsenin, N. et Ricci, A., 2018 : "Les amphores Günsenin IV à Küçükyalı (Istanbul) : Un voyage entre monastères ?", dans ce volume pp. 125-139.

Günsenin, N. (sous presse) : "A Günsenin IV Amphora from Küçükyalı", Bizantinistica. Rivista di studi bizantini e slave. 


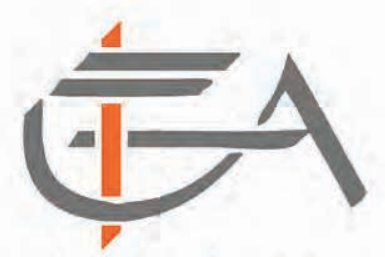

Institut Français d'Etudes Anatoliennes

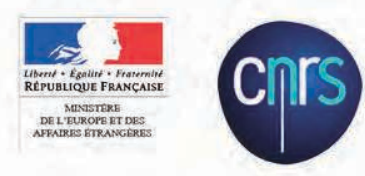

La citadelle de Tushpa (Van, Turquie).

ISBN: 978-2-36245-074-7

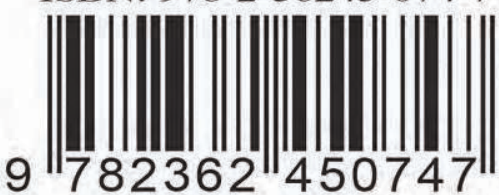

